\title{
Financial Literacy and Attitudes to Redistribution
}

\author{
Alberto Montagnoli, Mirko Moro, Georgios A. Panos ${ }^{\dagger}$, \\ and Robert E. Wright*
}

$28^{\text {th }}$ February 2017

\begin{abstract}
:
This study combines novel financial-literacy data with measures of attitudes to redistribution from the British Election Study. We find a significant negative relationship between financial literacy and attitudes in favour of government intervention for income redistribution. The effect is robust to several specifications, samples, longitudinal models and instrumental variable regressions. Falsification tests show that these results are independent of generic attitudes towards other types of inequality/discrimination, e.g. based on gender, race or sexual orientation. An inquiry into the mechanisms of the effect indicates that the homo oeconomicus effect does not exert an impact on attitudes to redistribution for the less financially literate.
\end{abstract}

JEL Classification: D14; D31; I24.

Keywords: Financial literacy, redistribution, inequality, attitudes, Great Britain

$\dagger$ Corresponding author: Georgios.Panos@glasgow.ac.uk

Panos gratefully acknowledges funding from the PROFIT project. Project PROFIT has received funding from the European Union's Horizon 2020 Framework Programme for Research and Innovation under grant agreement no. 687895 .

* Montagnoli: University of Sheffield. Moro: University of Stirling. Panos: Adam Smith Business School, University of Glasgow. Wright: University of Strathclyde Business School. We thank colleagues at the Universities of Glasgow, Strathclyde, Stirling and Sheffield and conference participants in the Financial Management Association, the DynIper and the IMAEF 2016 conferences for valuable comments. 
$[\mathrm{P}]$ eople train themselves to reduce and sometimes more than fully overcome any tendency towards undervaluation. The analysis in this ... allows people to maximize the discounted value of present and future utilities partly by spending time and other resources to produce "imagination" capital that helps them better appreciate future utilities.

Gary Becker (1996)

\section{Introduction}

Government intervention to redistribute and limit income inequality is at the heart of the policy dialogue in several countries around the world (Jones, 2015; Sturm and De Haan, 2015). Individual attitudes towards redistribution and government intervention are conducive to the formation of tax and transfer systems. Economic models have focused on the impact of current and expected income, future prospects and mobility in affecting the demand for redistribution at the individual level. The evidence suggests that the degree of redistribution desired by an individual is negatively correlated with income, wealth and future economic prospects. However, some variables employed in the literature, such as current and future income and education, are imperfect proxies for 'economic motives' in that they do not completely capture the full range of determinants of attitudes to redistribution.

The recent literature on financial literacy has shown that people's ability to process economic and financial information is linked with better financial planning, wealth accumulation, management of credit positions and pensions (Lusardi and Mitchell, 2014). Our study adheres to this literature by examining the impact of financial literacy on attributes towards income redistribution. The choice of the tax and transfer system have direct consequences on current and future individual financial positions. Hence, our hypothesis is that financial literacy is an important determinant of redistributive attitudes. The development of financial literacy may also change an individual's view on the social value of income equality, independently from own economic circumstances. This is in similar spirit to the conjecture that economics education may lead people to behave in a more selfinterested manner in the dictator game, hold more positive attitudes toward greed and agree more with normative statements in favour of self-interest (e.g., Wang et al., 2011).

We use two distinct representative samples for Great Britain and Scotland, respectively, from the British Election Study (hereafter BES). The BES is an online questionnaire survey, which is collected by Yougov and managed by a consortium of British Universities. The survey includes a number of questions on social attitudes and, following consultations with the authors of this study, a customized pilot module on financial literacy. The questions included in the survey are the three 
primary financial literacy questions employed by the literature in capturing the understanding of interest rates, inflation and risk diversification (e.g. Lusardi and Mitchell, 2014).

In 2014 and 2015, three waves of the BES were administered in Great Britain as a whole, while a fourth wave collected a boosted Scottish sample, with the motivation of tracking political and social perceptions following the referendum for Scottish independence of September 2014. Aiming for robustness, in our analysis we use the two samples of more than 5,000 individuals separately. The survey collectors have designed weights that render our samples representative of the whole population in Great Britain and Scotland, respectively. We employ answers to two distinct questions aiming to capture individual attitudes towards redistribution. The questions capture attitudes stated in two distinct ordinal scales, regarding the extend of agreement with the following two statements: "Should the government try to make incomes more equal?" and "The government should redistribute income from the better off to those who are less well off'. The survey also includes a very rich set of individual characteristics, such as personal and household income, education, age, gender, marital status, parental and family background, personality traits, risk attitudes, etc., which allow us to control for possible confounding factors.

Our analysis shows that individuals with a higher financial-literacy score are less supportive of redistributive policies and income equality in Great Britain and Scotland. The magnitude of the financial-literacy effect on the attitude towards redistribution is in the order of 25 percent, ceteris paribus. This magnitude stems from the marginal effects of financial literacy on the top and the bottom response categories of attitudes to redistribution in ordered probit models, controlling for a very rich set of other economic factors. This effect is economically important and it is robust to a number of functional forms, specifications and interactions between financial literacy and other socio-economic characteristics. In linear probability models, an additional correct answer to financially literacy questions leads to a negative effect of a magnitude between 9-13 percent on the probability to be supportive of "government intervention to make incomes more equal" and 3-8 percent on being in favour of "the government redistributing income from the better off to the less well off'.

Our identification assumption is that the financial-literacy variable is uncorrelated with omitted factors that are not controlled for, but are determinants for tax and transfer preferences. Our econometric models include a comprehensive set of socio-economic determinants discussed in the literature. In particular, we account for the effect of both education and income. These variables are 
defined using both very specific categories/classes and their continuous variable counterparts, along with their interactions with financial literacy. In order to validate our results, we perform a series of robustness exercises and a falsification test. The latter test confirms that financial literacy is not a determinant of generic attitudes towards other types of inequality, i.e. regarding equal opportunities for females, ethnic minorities, gay and lesbians. In an effort to address endogeneity more directly, we experiment with different instrumental variables. Moreover, we present estimates from longitudinal models, in which there is variation within individuals in attitudes to redistribution and time invariant financial literacy. The sign, statistical and economic significance of the parameter of interest are confirmed.

In the final part of the analysis, we investigate whether the effect of financial literacy on attitudes to redistribution is an independent channel or if it is part of the other main channels, which are already identified by the literature as pivotal to the formation of attitudes to income redistribution. More explicitly, following Corneo and Grüner (2002), we identify and utilize proxies for three other major explanatory factors. First, attitudes towards redistribution can be driven by pure economic self-interest (homo oeconomicus effect). Second, departing from same fundamental values of a 'veil-of-ignorance', individuals may entertain idiosyncratic beliefs about the contributions of, e.g., family background and individual effort to personal economic success. (public value effect). Third, individuals form such attitudes based the consideration that governmental redistribution affects the quality of their social environment (social rivalry effect). Our analysis presents supportive evidence of the idea that these effects are indeed primary drivers in explaining attitudes towards redistributive policies. However, our estimates in models with interaction terms between financial literacy and the three mechanisms, along with estimates from separate samples of individuals with high and low financial literacy, show that the homo oeconomicus effect exerts an insignificant impact on attitudes to redistribution for the less financially-literate individuals. In contrast, it remains statistically and economically significant for the more financially-literate individuals. We interpret this novel finding as preliminary evidence in favour of financial literacy being a major cognitive ability that is conducive to rational economic behaviour, via relevant attitude formation.

The remainder of this study is organized as follows. Section 2 presents the background of our study by reviewing the relevant literature. Section 3 presents the British Election Study, the variable definitions and relevant summary statistics. Then, Section 4 presents the empirical strategy and the main results. Section 5 presents and discusses the results of our robustness exercises, the falsification 
test and the estimates from instrumental variable regressions. Section 6 provides an inquiry into the possible mechanisms via which financial literacy can impact the demand for redistribution. Finally, Section 7 concludes.

\section{Background}

This section provides an overview of the literature on individual attitudes toward redistribution. Moreover, it provides a conceptual discussion on how financial literacy can play a key role in shaping individual's attitude towards government's redistribution policies.

\section{1 $\quad$ Attitudes for redistribution}

Economy theory on redistribution stems from the original works of Romer (1975), Roberts (1977) and Meltzer and Richard (1983), in which the focus is on the median voter's utility derived from income. The key idea is that, with rising inequality, the distance between median and mean income increases, since the distribution is skewed to the right and the median lies below the mean. Hence, the median voter extracts a higher level of utility from income redistribution as inequality rises. Overall, the net benefit derived from redistribution is inversely correlated to income. Alesina and Angeletos (2005) and Benabou and Tirole (2006), among others, expand the theoretical framework so that other factors, such as fairness and expected social mobility, are accounted for. They show that if a society believes that income is driven by effort, as opposed to luck, birth or social connections, then this society would have a lower propensity towards redistributive policies. In other words, fairness and social mobility can account for large differences between redistributive policies.

The empirical literature on redistribution can be divided in broadly two branches. The first and older branch examines attitudes towards redistribution across countries, using aggregate data. The measures typically employed to capture inequality and attitudes in favour of redistribution involve the Gini coefficient and the fraction of median to mean income (Persson and Tabellini, 1994; Perotti, 1996; and Shelton, 2007; inter alia $)^{1}$. Overall, the empirical evidence at the macroeconomic level does not favour the impact of economic inequality on redistribution. A possible explanation

1 More recently, using survey data from the International Social Security Programme across 38 countries, Kerr (2014) shows that a short-term increase in inequality is unlikely to prompt a vicious cycle, in which support for redistribution declines thereby promote a further increase in inequality. 
for this pattern is the fact that there are more than one possible mechanisms affecting the relationship between attitudes to redistribution and inequality. It is empirically challenging to capture all these mechanisms at once and at the macroeconomic level.

More recently, the second strand of the literature employs microeconomic data and identification strategies that aim to disentangle the impact of distinct determinants of attitudes towards redistribution. Alesina and Giuliano (2011), Alesina and La Ferrara (2005) and Fong (2001; 2006) emphasize on the role of current and expected income and social status. Then, Andreoni and Miller, (2002) and Fong and Oberholzer-Gee (2011) highlight the role of altruism, while Gruber and Hungerman, (2007) examine the role of religion in shaping attitudes to redistribution.

Corneo and Grüner (2002) propose a conceptual framework that aims to categorize the possible channels through which attitudes to redistribution can be explained. Specifically, they identify three primary competing mechanisms.

- First, individuals are driven by self-interest and their preferences are entirely shaped by their rank in the income scale (homo oeconomicus effect). Specifically, attitudes against redistribution are inversely related to the net gain that the individual obtains from governmental redistribution and/or to the individual's rank on the income scale (e.g. Meltzer and Richards, 1981; Benabou and Ok, 2001).

- Second, the public value effect states that attitudes towards redistribution are not correlated to the level of income. Instead, they are more likely to be formed based on endowments, such as ethics, that an individual is born with $^{2}$.

- Third, according to the social rivalry effect, redistributive attitudes are formed based on consideration of the living standards relative to one's peers, e.g. neighbours. In this framework, factors such as the social class composition of the population in the area in which an individual lives and/or marital status are pivotal to the formation of social attitudes.

The framework by Corneo and Grüner (2002) suggests empirical proxies for these three effects, along with a series of relevant hypotheses that can be tested empirically. However, the follow-up evidence is mixed. For instance, Fong (2001) attributes an insignificant effect to the proxy of self-interest on shaping attitudes towards redistribution. Luttmer (2001) finds that financial self-

2 This point is discussed in Piketty (1998) and Alesina and Angeletos (2005), inter alia. Alesina et al. (2001) propose a model, in which the individual's utility is dependent on the utility of members of other ethnic groups. They conclude that the individual's awareness of ethnic heterogeneity could be the driver of the difference in views on income redistribution across socio-economic groups. 
interest is not the only determinant of attitudes towards welfare spending, but other factors, such as loyalty to one's racial group, play an important role. In addition, using data from the General Social Survey for the period 1978-2000 to examine the role of identity markers, Keely and Tan (2008) find that only race, gender, age, and socioeconomic class are important determinants for income redistribution. More recently, Luttmer and Singhal (2011) suggest that culture could be a key determinant in explaining differences in such attitudes across Europe and the United States.

\subsection{The link between financial literacy and attitudes to income redistribution}

The potential link between financial literacy and the prevalence of social attitudes, such as those towards inequality and redistribution, is unexplored in the economics literature. In the related literature on cognitive ability and economic outcomes, Hanushek and Woessmann (2008) conclude that cognitive skills, both minimal and high-level, rather than mere school attainment are powerfully related to individual earnings, the distribution of income and economic growth. The authors find complementarity between the role of skills and the quality of economic institutions on economic growth. Heckman et al. (2006) find that a low-dimensional vector of cognitive and non-cognitive skills explains a variety of labour market and behavioural outcomes, e.g. a variety of risky behaviours. Non-cognitive skills strongly influence schooling decisions and also affect wages, ceteris paribus. Schooling, employment, work experience, and choice of occupation are affected by latent non-cognitive and cognitive skills.

In a meta-analysis of studies in social psychology, Schoon et al. (2010) find that that social background, cognitive ability, education, and own social status influence perceptions of society. However, the empirical evidence on the relationship between cognitive ability and social attitudes has been relatively mixed in social psychology. Using data from foreign students and applicants in colleges in the United States, Stankov (2009) shows that conservatism scores and cognitive ability are negatively correlated. However, Deary et al. (2008) find that people with higher childhood intelligence are more likely to take part in rallies and demonstrations, sign petitions, and express a greater interest in politics. Moreover, they are more likely to vote, particularly for the liberal parties. Onraet et al. (2015) conclude that cognitive ability is an important factor in the genesis of ideological attitudes and prejudice and thus should become more central in theorizing and model building. Their studies generally reveal lower cognitive ability to be associated with stronger endorsement of rightwing ideological attitudes and greater prejudice. However, this relationship has remained widely unrecognized in literature. 
This section tries to fill in the gap by laying out the conceptual channel though which financial literacy could affect individual attitude towards redistribution. As mentioned above, in the economic literature, such attitudes depend on economic factors (e.g. Romer, 1975; Meltzer and Richards, 1981). Our argument is that financial literacy is one of the most important, albeit overlooked, economic variables. The commonly accepted definition, based on the US President's Advisory Council on Financial Literacy (PACFL, 2008), introduces financial literacy as "the ability to use knowledge and skills to manage financial resources effectively for a lifetime of financial wellbeing" (Hung et al. 2009). In other words, financial literacy is about using cognitive ability for optimal financial planning, which results in greater private benefits. Thus, particularly in the environment of developed economies, entailing a rather sound welfare state, one should expect financial literacy to be associated with less favourable attitudes to redistribution.

In this context, Jappelli and Padula (2013) sketch a life-cycle model of consumption, in which the level of financial literacy is endogenously determined. Individuals are modelled as rational agents who choose how much to save and how much to invest in financial literacy. The prediction is that financial literacy is strongly positively correlated with future wealth. Moreover, in an illuminating recent study, Lusardi et al. (2016) suggest that differences in financial knowledge, formed endogenously early in life, can explain about 40 percent of retirement wealth inequality in the United States. The inference, supported by the evidence found in Jappelli (2010), is that there is a strong negative correlation between the average level of financial literacy within a country and how generous social security systems are. A more elaborate idea is that individuals with a higher level of financial literacy have higher expected income and may be driven by self-interest. In contrast, an individual with a low level of financial literacy might have lower expected income and therefore be in favour of more progressive tax systems (e.g. Meltzer and Richards, 1981; Banabou and Ok, 2001). Hence, financial literacy should matter for attributes towards redistribution, even when controlling for the levels of income and educational attainment.

Figure 1 presents an international comparison using weighted country-level averages on attitudes to redistribution and financial literacy. Expressions of attitudes to redistribution stem from two distinct questions in wave 6 of the World Values Survey, one question from the International Social Survey Programme (2014), and three distinct questions from the 2014 Eurobarometer survey. Financial literacy country averages stem from the S\&P financial literacy survey (2014). The figures are weighted by GDP per capita (PPP-current international \$) from the World Development Indicators. All 6 panels of Figure 1 show a negative relationship between average financial literacy 
and favourable attitudes to redistribution across countries. Thus, the inspection of the country-level data from three distinct sources seems to validate the expectation that financial literacy is negatively related to attitudes in favour of income redistribution.

\section{[INSERT FIGURE 1 ABOUT HERE]}

Linking the evidence above with the classification proposed by Corneo and Grüner (2002), one can classify the following interacting mechanisms, via which financial literacy could affect the expression of attitudes to redistribution. Firstly, financial literacy could interact with the homo oeconomicus channel, i.e. more financial literate individuals could emphasize more on self-interest and own rank in the income distribution. For instance, van Rooij et al., 2012 find a positive relationship between the level of financial literacy and the level of net worth. In a seminal work, Becker (1996) posits the concept of 'personal capital' and suggests that forward-looking individuals recognize that their current choices and experiences affect their personal capital in the future. Moreover, they are able to recognize that future utility depends on future personal capital. In that spirit, Becker and Mullighan (1997) suggest that higher wealth is related to higher patience. One can conceive financial literacy as mediating that cognitive 'recognition' process and, thus, be negatively related to the demand for redistributive policies.

In a normative setting, this emphasis is similar to attributing a higher importance on the role of effort, as an incentive to achieve a specific financial goal. The financially literate individual is more likely to attribute a personal economic success to both real and perceived level of effort. This level of effort would necessarily decrease the level of demand for redistribution. This idea is in line with the original model on redistribution, proposed by Meltzer and Richards (1981), in which individuals have various levels of productivity. Since own wage is related to productivity, individuals who are not in the position to earn a higher wage than the median income will choose not to work. This line of thought seems to find some support on the works of Alesina and La Ferrara (2005), Fong (2001) and Krawczyk (2011). They show that individual attitudes to redistribution are inversely correlated to the individual's belief that future success is determined by effort and talent. In contrast, those individuals who place more emphasis on the role of luck and social connections (e.g. help from others) generally do not oppose redistribution.

A recent strand of the redistribution literature assigns weights to the importance of beliefs, context and culture, as drivers that are independent from economic factors (Luttmer and Singhal, 2011). The interesting inference is that an individual with a high level of financial literacy should rely less on social beliefs derived from exogenously predetermined factors like family economic 
background, ethnicity, country's history and religiosity or on personal characteristics like gender and age. However, this is not to say that financial literacy should be independent of any public value effect. The prediction here is that the acquisition of financial literacy may induce beliefs and values regarding the benefits of equality in the same way that some theories conjecture that studying economics leads individuals to hold more positive views on self-interest (Wang et al., 2011).

A third possible channel though which financial literacy may come into play is via the interaction with the social rivalry effect. Financial literacy could improve the accuracy of a subjective evaluation of own position within the income distribution, thus reducing biases (Cruces et al., 2013). In that spirit, insights from Rayo and Becker's (2006) view of conspicuous consumption goods as potentially durable goods and Rayo and Becker's (2007a; 2007b) evolutionary theory of happiness, based on endogenous reference points, can explain why high levels of consumer debt can occur even among financially literate individuals.

Finally, it is important to highlight that the definition of financial literacy proposed here has a pure personal financial planning aspect and ignores any other potential effects or aggregate considerations. If, however, financial literacy embeds also strong elements of economic literacy then one can expect negative views on redistribution to arise from other reasons. Individuals with a high level of economic knowledge may believe that a high level of inequality can have positive spillover effects on growth. The rationale is that it can provide an incentive to both innovation and entrepreneurship (Lazear and Rosen, 1981), or it may increase saving and investment given that wealthier individuals have a higher propensity to save (Kaldor, 1957) 3 .

\section{Data and Summary Statistics}

We use waves 1, 2 and 4 of the British Election Study 2015 (hereafter BES). The BES is an internet panel study, collected by Yougov ${ }^{4}$. Wave 1 provides us with the basic socioeconomic information

3 An opposite view could suggest that a homo oeconomicus might also recognize that inequality may have long-term negative consequences on growth, because it may reduce the accumulation of human capital and could bring economic and political instability, which in turn reduces investment (e.g. Galor and Moav, 2004; Aghion, Caroli, and Garcia-Penalosa, 1999; Alesina and Perotti, 1996). Hence, we should expect that an individual who has been trained in economics (but is not necessarily more financially literate) is more averse to conservative policies. This would make the expected direction of the relation ambiguous.

4 The data is available at: http://www.britishelectionstudy.com/data-objects/panel-study-data/. The British Election Study 2015 is managed via a consortium of the University of Manchester, The University of Oxford, and The 
and was collected in February-March 2014 and Wave 2, which provides us with the financial literacy information, in May-June 2014. There were 30,219 respondents in Wave 2 and 26,870 respondents who also took Wave 1 (overall retention 88.9\%). Wave 4, which involve a boosted Scottish sample with financial-literacy information, was collected on March 2015. It stems from online interviews with 31,323 individuals and again a very high retention rate from wave 1 . The resulting dataset offers weights constructed at the regional level. Financial literacy questions were included in the survey of BES as a "playground item", following consultation between the authors of this study and the data collectors. The playground contains items that are only asked to subsets of respondents, primarily in England, but in the case of our questions these were also asked in Scotland and Wales in a subsample that does not oversample in the two regions. Hence, the three financial-literacy questions were asked in a representative sub-sample of 5,712 respondents in Wave 2 and a boosted sub-sample of 5,387 Scottish respondents in Wave 4. Although the BES includes more than 30,000 individuals in each wave, the financial literacy modules that we used in this paper was administered to two representative subsets of respondents ${ }^{5}$.

We conduct our analysis using items from two separate samples for robustness purposes: a standard sample of Great Britain (which includes England, Wales and Scotland) from wave 2 and a separate (boosted) sample of Scotland. The latter were interviewed at a different time (wave 4) for reasons related to the conduct of the referendum for Scottish independence of September 2014. The total amount of observations used depends on the outcome variable used and is around 5,000 observation for both the sample for Great Britain and the Scottish sample. In our robustness section, we also utilize a longitudinal version of the BES data, stemming from waves 1-9 (wave 9 was

University of Nottingham. The Scientific Leadership Team is comprised of Professors Ed Fieldhouse, Jane Green, Hermann Schmitt, Geoff Evans and Cees van der Eijk. The team is supported by researchers Dr Jon Mellon and Kathryn Simpson, and also by BES 2015 consultant Professor John Curtice (University of Strathclyde). The BES 2015 is working in close collaboration with colleagues within the Universities of Manchester, Oxford and Nottingham, and is partnering with a wide variety of affiliated datasets and projects (and proposed projects) to link BES voter data to other data on election candidates and campaigns. Neither the BES collectors nor managers bear any responsibility for the analysis and interpretations presented in our study.

5 The representativeness of the two sub-samples, to which financial literacy questions were administered, was ensured and confirmed by the data collectors. Moreover, the Appendix Table Al provides a comparison between the full sample and the used sub-samples in wave 2 and wave 4 . For the former, it also provides a comparison with wave 5 (2013-2014) of the Understanding Society survey, the major UK longitudinal representative household survey, funded primarily by the Economic and Social Research Council (ESRC) and by a consortium of UK government departments. The weighted summary statistics indicate that the two financial literacy sub-samples are representative and map well the full BES samples for Great Britain. Moreover, the weighted averages with respect to most representative characteristics are very close to those of wave 5 (2013-2014) of the Understanding Society survey. 
collected in September 2016), although the financial literacy questions were only asked in waves 2 (Great Britain sample) and 4 (Scottish sample).

For our dependent variables, we rely on two specific questions as indicators of the support that individuals give to redistribution. The first question (hereafter $R D_{1}$ ) asks: "Some people feel that government should make much greater efforts to make people's incomes more equal. Other people feel that government should be much less concerned about how equal people's incomes are. Where would you place yourself on this scale?" The respondent is provided with an ordinal response scale to choose from, ranging between zero and ten. We use the reversed version of the scale, in which zero explicitly represents the view that "Government should be less concerned about equal incomes" and ten explicitly represents the view that "Government should try to make incomes equal". The second question (hereafter $R D_{2}$ ) asks: "How much do you agree or disagree with the following statements? Government should redistribute income from the better off to those who are less well off". The respondents can choose among "Strongly disagree”, "Disagree”, "Neither agree nor disagree", "Agree", "Strongly agree", and "I don't know".

Table 1 presents the summary statistics for the distribution of the responses for attitudes to redistribution. Panel A presents the figures for the first redistribution question $\left(R D_{1}\right)$. In the first row, it is shown that for $10.4 \%$ of the British respondents, the government should not try to make incomes more equal. The figure amounts to $6.3 \%$ in the Scottish sample. At the other side of the spectrum, it is shown that $13.6 \%$ and $24.6 \%$, in Great Britain and Scotland, respectively, are strongly in favour of redistribution. If we consider the middle of the distribution of the British sample, we notice that about $28 \%$ of the interviewees report to be in favour or mildly in favour of redistribution (6-9 on the scale), while $30 \%$ think that the government should be less concern about equal incomes (1-4 on the scale). Some $17.5 \%$ state they are at point 5 of the $0-10$ scale or that they do not know where they stand in the scale. Similar percentages are recorded for the Scottish sample, with 13.6\% placing themselves in the middle of the scale. Panel B of Table 1 presents the figures for the second question identifying the attitude towards redistribution $\left(R D_{2}\right)$. It is shown that $5.1 \%$ of the British respondents strongly disagree with the proposition that the government should redistribute income from the better off to the less well off. $18.3 \%$ disagree, $24.6 \%$ neither agree nor disagree, $32.7 \%$ agree and $19.3 \%$ strongly agree with the proposition. This contrasts with the 52\% of the respondents, who are either in favour or strongly in favour of such redistribution. $20.8 \%$ state a value

6 For the purposes of our analysis, the few "Don't know" responses are considered equivalent to "Neither agree nor disagree". However, excluding these observations from the analysis, renders similar results and conclusions. 
of 3 or do not know where to place themselves in the 0-5 scale. The figures for the boosted Scottish sample of wave 4 show that $3.8 \%$ strongly disagree, $12.9 \%$ moderately disagree, $20.5 \%$ neither agree nor disagree, $33.6 \%$ moderately agree and $29.0 \%$ strongly agree that the government should redistribute income from the better off to those who are less well off.

\section{[INSERT TABLE 1 ABOUT HERE]}

\subsection{Financial literacy in Great Britain}

The financial literacy question, which were introduced at the BES, follow Lusardi and Mitchell (2014, p.10) and capture: (i) numeracy via capacity to do calculations related to interest rates, such as understanding basic interest compounding; (ii) understanding of inflation; and (iii) understanding of risk diversification. These three concepts have been robustly shown to be the essential basic skills required to make long-term decisions regarding the level of savings and investment. Hence, our resulting financial-literacy index is based on the three questions, which have become standard in the literature.

- The first question asks: "Suppose you have $£ 100$ in a savings account with an interest rate of $2 \%$ per year. If you never withdrew any money from this account, how much do you think there would be after 5 years?" The respondent has three possible answers: "More than £102”, "Exactly $£ 102 ”$, "Less than £102”, "Don’t know”, "Prefer not to say”.

- The second question is "Suppose inflation is $2 \%$ per year and you have put money into a savings account with an interest rate of $1 \%$ per year. Assuming that you buy the same things today and in one year's time, do you think you would be able to buy more with the money in this account in one year than today, less in one year than today, or do you think you would be able to buy exactly the same things in one year as today?" The five possible answers are: "More than today", "Exactly the same as today", "Less than today", "Don't know", "Prefer not to say".

- The final question is "Which one of the following do you think is the riskier asset to invest in?" Here the possible answers are "An individual share in a company", "A portfolio of different company shares", "The risk is the same", "Don't know", "Prefer not to say".

The responses to the three questions are combined to form an index, ranging from 0 (no correct answers) to 3 (all correct answers). Table 2 gives a snapshot of the level of financial literacy in Great Britain and Scotland in 2014. In Panel B, about 40.2\% of the people surveyed answered correctly to all three questions while about $10.8 \%$ responded incorrectly to all questions. Some $30 \%$ and $20 \%$ answered correctly to two questions and to one out of three questions, respectively. The figures are 
very similar for the boosted Scottish sample of Wave 4, with $37.3 \%$ of the respondents answering correctly to all three questions, $31.1 \%$ and $19.1 \%$ answering correctly to two and to one of the questions, respectively. $12.5 \%$ of the Scottish interviewees answered incorrectly to all three questions. Similar to other financial-literacy surveys around the world (Panel D), about a third of individuals in both samples responded that they do not know the answer in at least one out of the three questions.

\section{[INSERT TABLE 2 ABOUT HERE]}

Panel $C$ shows that the question with the highest number of correct responses was regarding compound interest, with $80 \%$ of the interviewees responding correctly in both samples, while the question assessing the understanding of risk was answered correctly by $48.7 \%$ of individuals in Great Britain and $46.6 \%$ of individuals in Scotland. 69\% of the sample in Great Britain and 65.8\% of the sample in Scotland responded correctly to the inflation question. Panel $D$ of Table 2 presents an international comparison of financial literacy between Great Britain, Scotland and counties for which there exist representative surveys utilizing the same three questions. The figures in the table for countries other than Great Britain are from the references in the literature review by Lusardi and Mitchell (2014). Financial literacy in Great Britain and Scotland is shown to be comparable to countries such as Australia and the Netherlands, higher than the USA, Japan and New Zealand and lower than Germany. Strikingly, the figures for correct responses in the three questions are very similar between the United Kingdom, the Netherlands and Australia.

\subsection{Socioeconomic characteristics at the British Election Study}

The British Election Study comprises of a rich set of questions related to individual and household characteristics. Table 3 gives an overview of the data for the sample from Great Britain in wave 2 (column 1) and for the Scottish sample (column 4). The table also provides the averages of the main variables for two subsets of individuals. Columns 2 and 5 present means for individuals with a high level of financial literacy, i.e. two or three correct responses in the three questions (hereafter $F L H$ ). Then, columns 3 and 6 present the means for the individuals with a low level of financial literacy, i.e. zero or one correct responses in the three questions (hereafter $F L L$ ). The asterisks next to the highest average denote the level of significance in mean difference between FLH and FLL.

[INSERT TABLE 3 ABOUT HERE] 
$49.4 \%$ of the GB sample and $47.7 \%$ of the Scottish sample are males. The average age is 47 years with 12.7 years of education in both samples. $60.2 \%$ of the respondents in the GB sample and $35.4 \%$ of the Scottish respondents live in urban regions ${ }^{7}$. Fractions close to $60 \%$ are married in both samples. The vast majority of the sample is of a white ethnic group, i.e. $91 \%$ of the GB sample and $96.5 \%$ of the Scottish sample. The average individual has a personal income of about $£ 21,000$ (about $£ 16,500$ in the Scottish sample) and a household income of $£ 32,350$ ( $£ 29,603$ in the Scottish sample). $30.7 \%$ of the individual interviewed are home owners (27.6\% in Scotland) while $28.5 \%$ have a mortgage (29.4\% in Scotland). $14.8 \%$ of the GB sample have experienced a negative income shock in the last year, while that figure for the Scottish sample is $9.9 \%$.

Regarding family background, $5.8 \%$ of the sample in Great Britain and 4.7\% in Scotland come from an entrepreneurial family. $18.4 \%$ have attended a private school at some point in their past (11.6\% in Scotland). With respect to labour market status, $7 \%$ of the sample (4.8\% in Scotland) are self-employed, $37.8 \%$ (35.6\%) are full-time employees, $11.5 \%$ (13.8\%) are part-time employees, $3.5 \%$ (4.3\% in Scotland) are unemployed, 5.9\% (7.9\%) are students, $22.8 \%$ (20.9\%) are retired and 11.5\% (14.8\%) are inactive. 15.4\% in Great Britain and 2.9\% in Scotland are trade union members.

The weighted t-tests for mean differences in columns 4 and 8 reveal that FLH individuals are less likely to be in favour of income redistribution, compared to FLL individuals, as they provide lower scores in both measures $R D_{1}$ and $R D_{2}$ and in both the sample for Great Britain and Scotland. The more financially literate are more likely to be males, of older age, married, less likely to have young children and of white ethic group. The FLH have more than one additional year of education, compared to the FLL. The FLH have higher personal and household income, compared to the FLL. They are more likely to be home owners and to have a mortgage. They are less likely to have experienced a negative income shock during the last year. They are more likely to stem from an entrepreneurial family in Scotland and less likely to have attended a private school in Great Britain. With respect to personality traits, the FLH are more likely to score higher on agreeableness, conscientiousness, openness, and score lower with respect to extraversion and neuroticism, compared to the FLL.

7 The definition of an urban region stems from a geocoding matching process of the 376 local authority regions in the GB sample [54 local authority regions in the Scottish sample] with urban audit core city data, available from the Office for National Statistics at: https:/geoportal.statistics.gov.uk/datasets/57285cffe42344ad95a98d9ab9298da5_0 


\section{Empirical strategy and results}

The summary statistics of Table 3 have already indicated that more financially-literate individuals tend to report less favourable attitudes towards income redistribution. In this section, we formalize the examination of this relationship, by estimating models of attitudes to redistribution for our two primary measures. We estimate specifications of the following form for attitudes towards redistribution:

$$
R D_{i n}=\beta_{1}\left(F L_{i}\right)+\beta_{2} X_{i}+\theta_{r}+\varepsilon_{i}
$$

where: $R D_{i}$ denotes attitudes towards redistribution for individual $i, F L_{i}$ is a variable capturing financial literacy, $X_{i}$ is a vector of individual characteristics, $\theta_{r}$ is a fixed effect for region of residence and $\varepsilon_{i}$ is the usual error term. As previously described, the measures of attitudes towards redistribution $\left(R D_{i n}\right)$ stem from two distinct questions, which render two separate ordinal outcomes $(n)$. The first one $\left(R D_{i l}\right)$ captures individual demand for direct government intervention to make incomes more equal, while the second one $\left(R D_{i 2}\right)$ asks whether the participant believes that the government should redistribute income from the better off to the less well off. The vector $X_{i}$ includes a rich set of individual characteristics such as personal and household income, education, age, gender, marital status, household size, number of children at preschool and school age, occupation status (whether self-employed, full or part-time employed, unemployed, inactive, student or retired), trade union membership, ethnic group, country of birth (Scotland, Wales, Northern Ireland, Republic of Ireland, Commonwealth, European Union, Rest of the World), home ownership, mortgage, whether the respondent has experienced an income shock last year, attitudes to risk, i.e., a risk-taking index from 1 (very unwilling to take risks) to 4 (very willing to take risks), a political-orientation index, i.e. an ordinal variable ranging from 0 (indicating the far left) to 10 (indicating the far right), a social-desirability index, i.e. a count variable ranging from 0 (low) to 4 (high) ${ }^{8}$, a dummy variable indicating religiosity, the big 5 personality traits and whether the individual lives in an urban area. Finally, it includes two variables capturing family background, i.e. whether the individual had a father who was an entrepreneur and whether the individual attended a private school at some point in the past. In an attempt to isolate the effect of financial literacy from potential confounding factors,

8 The social desirability measurement is provided by the survey as a count outcome, which stems from the aggregation of agreement or disagreement with four statements: "I always smile at people every time I meet them", "I always practice what I preach", "If I say to people that I will do something, I always keep my promise no matter how inconvenient it might be", and "I would never lie to people". The individual is asked to agree or disagree with the ones that apply to him/her. 
we take advantage of the richness of the survey and experiment with different functional forms, specifications and interactions of financial literacy with income, education and age ${ }^{9}$.

For robustness purposes, equation (1) is estimated using both OLS and ordered probit to account for the ordinal nature of the two dependent variables. All estimates presented are weighted using representative sampling weights and entail robust standard errors. These two estimation methods yield very similar results. For exposition purposes, all our main tables presented estimates using weighted least squares. The Appendix Table A3 presents two sets of ordered probit estimates for Great Britain and Scotland, respectively, to establish robustness and present the full specification. All remaining estimates using ordered probit are available upon request. Table 4 and $\underline{\text { Table } 5}$ present in short the weighted least squares estimates for Great Britain and Scotland, respectively. Panels A and B of both tables present the estimates of the effect of financial literacy on the two outcome variables, $R D_{1}$ and $R D_{2}$, respectively. Specifically, in Panel A, the dependent variable is an index ranging from 0 to 10 on whether the 'Government should make incomes more equal'. In Panel B, the dependent variable is an index ranging from 1 to 5 on whether the 'Government should redistribute to the less well off'. Each column presents a different specification of equation (1). The bottom of the table indicates the set of control variables used in each specification.

In columns 1 and 7 of Table 4, we present the simplest variant of the model, in which the specification only includes our financial-literacy measure, i.e. the number of correct responses in the three questions. This specification does not entail any other control variables. Then, in the remaining columns, we incorporate control variables for confounding factors such as education, income, age and other individual characteristics. This exercise facilitates the inspection of the robustness of our main finding, i.e. taking into account of the impact of confounding factors, and also helps establish the magnitude of the financial-literacy effect on attitudes to redistribution. The relationship between financial literacy and the attitude towards redistribution is negative and statistically significant at the $1 \%$ level, suggesting that financial literacy is associated with attitudes against redistribution. Specifically, an additional correct response to a financial literacy question is associated with -0.537 (more than half a point) on the 10-point scale for the first measure, $R D_{1}$. The magnitude of the relationship is also economically significant, when compared to the linear prediction of the model of 5.147. The magnitude of the effect is -10.4 percent, when dividing the

9 The Appendix Table A3 provides the weighted pairwise correlation matrix for some of the key variables in our analysis. 
coefficient with the liner prediction of the model. In the estimate shown for $R D_{2}$ (column 7 of Panel B), the effect is highly statistically significant but smaller, i.e. equivalent to -4.4 percent.

\section{[INSERT TABLE 4 ABOUT HERE]}

As shown in the literature, financial literacy is highly likely to be correlated with variables such as income, age and education, inter alia (e.g. Lusardi and Mitchell, 2014). The remaining columns of the two panels include the full set of control variables, shown in Appendix Table A3. Moreover, they present exercises with different specifications on income, education and age, so as to emphasize that the main effects are not the outcome of an interaction effect between financial literacy and these variables. Columns $2\left(R D_{l}\right)$ and $8\left(R D_{2}\right)$ include individual characteristics, along with personal income, education and age groups as dummy variables. Specifically, these groups involve 15 categories for personal income, 9 categories for education and 7 age groups. The significant negative effect of financial literacy remains, at a magnitude of -8.7 percent for $R D_{1}$ and -3.4 percent for $R D_{2}$. The magnitudes of the two effects remain almost identical when including the continuous versions of the three variables in columns 3 and 9, namely the years of education and the logarithms of age and personal income ${ }^{10}$.

One may argue that the effect of financial literacy on attitudes to redistribution stems from unobserved household income or is some combination of household and personal income. For instance, some individuals with high financial literacy might decide for a vocational job that earns less if their partner/spouse's occupation can compensate for the lower earnings. Columns 4 and 10 include a third order polynomial in the logarithm of personal income, a second order polynomial in household income, in order to account for potential nonlinearity in their effect. Moreover, they include an interaction term between the logarithms of personal and household income, in order to account for their possible combinations within households. The effect of financial literacy in columns 4 and 10 becomes slightly smaller, but is still statistically significant at the $1 \%$ level. In

10 The categorical variable for personal income has been transformed to a continuous variable by assigning to respondents the midpoint value of their selected income class, with the maximum value being $£ 125,000$ for individuals stating "More than $£ 100,000$ ". The missing values of personal income for about $20 \%$ of both samples have been imputed using Mincerian-type regressions of the logarithm of personal income. The list of independent variables includes the logarithms of age, years of education, gender, marital and family status, occupation, ethnicity, migrant status, home ownership, urban region, region of residence and self-declared social class (4 dummy variables capturing: none, working, middle and other social class). Educational attainment has been converted into years of schooling on the basis of how many years are required to attain a certain qualification on average in the United Kingdom. 
column 4 it is in the magnitude of -7.8 percent and in column 10 , it is an effect of -3.1 percent magnitude.

Furthermore, in order to show that financial literacy is not picking up any education effects, we interact financial literacy with years of education in the specification of columns 5 and 11 . The coefficient reported is the main effect of financial literacy, so - despite its effect having more than twice the magnitude of the effects of the previous columns - its size cannot be directly compared with the other coefficients. However, its significance at the $1 \%$ level is notable, because it suggests that financial literacy impacts attitudes to redistribution, in a manner that is completely disentangled from the effect of education. It is worth noting that the effect of the interaction term between financial literacy and years of education is positive, significant and of a small magnitude (not shown). Finally, in order to isolate the effect of financial literacy from all potential confounding factors, in columns 6 and 12 we present a fully saturated model, in which financial literacy is interacted with years of education, the logarithm of personal income and the logarithm of age. The coefficient reported shows the main effect of financial literacy and is negative, significant and of a magnitude of -12.0 percent for $R D_{1}$ and -5.7 percent for $R D_{2}$. The effect of the multiple interaction term is positive, significant and of a small magnitude (not shown).

All the specifications for the two measures provide strong support to the idea that a higher level of financial literacy is related to weaker attitudes towards redistribution. An additional correct response to the three financial literacy questions decreases the likelihood to agree with the statements that the "Government should try to make incomes more equal" and that the "Government should redistribute income from the better off to those who are less well off' by about 0.5 points on the 10-point scale, and 0.1 points on the 5-point scale, respectively. Based on the linear predictions of the models, these effects are equivalent to about -10 percent and -5 percent, respectively.

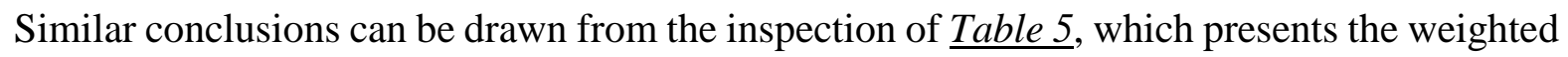
least squares estimates for the boosted Scottish sample of Wave 4, for both outcome variables. For parsimony, we present three specifications only, i.e. those of column 2, 4 and 6 of Table 4 . The coefficients are all negative and statistically significant at the $1 \%$ level. Their effect is in magnitudes between -3.9 and -5.9 percent for $R D_{1}$, and between -1.9 and -4.2 percent for $R D_{2}$, respectively. We 
interpret these results for the Scottish sample as a further confirmation of the robustness of our main finding ${ }^{11}$.

\section{[INSERT TABLE 5 ABOUT HERE]}

In the remainder of our analysis, we use the specification of column 2 of Table 4 as our main specification, i.e. the specification that includes income, education and age dummy variables, along with the full set of individual characteristics and region fixed effects. A reasonable line of analysis involves the utilization of a model that takes into account the ordinal nature of the response categories of our two measures of attitudes to redistribution. Hence, we estimate a weighted ordered

probit regression to account for the ordinal nature of the response variables ${ }^{12}$. Table 6 reports average marginal effects (AME), the predicted probability and the financial literacy effect (i.e. the ratio between the average marginal effect of financial literacy and the predicted probability of each response category in the model, expressed in percentage terms). We do this for both outcome variables, i.e. for $R D_{1}$ and $R D_{2}$, and on both the GB sample (in Panel A) and the Scottish sample (in Panel B). In addition, Figure 2 plots the average marginal effects and their $95 \%$ confidence intervals, in order to facilitate the inspection of the effects. These estimates reinforce our previous findings, but also adhere an important insight regarding the heterogeneity in the magnitude of the effects. In particular, financial literacy exerts a sizeable negative impact on the probability of strongly agreeing with redistributive policies. For the GB sample, the probability of answering 'Yes' to the first statement declines by -0.032 , while the probability of answering 'No' increases by 0.027 . Given the predicted probabilities of 0.135 and 0.106 , for the top and the bottom category, the magnitude of the marginal effect of financial literacy is in the order of -24 percent for the top category and -25.8 percent for the bottom category. The magnitude of these effects for the Scottish sample is in the order of -12.6 percent for the top category and 19 percent for the bottom category.

\section{[INSERT TABLE 6 ABOUT HERE]}

11 Appendix Figure A1, A2, A3 and $\underline{A 4}$ show how the impact of financial literacy on attitudes to redistribution varies across education, income, age, and political orientation/party voting respectively. In all four figures, the evident message is that the negative effect exerted by financial literacy is quite homogenous over income, education, age and by political orientation. Interestingly, opposition to government intervention to redistribute or make incomes equal is stronger for individuals with high financial literacy but low education. Similar homogeneity can be found when looking at income groups, whereby financial literacy makes someone less in favour of government intervention to make incomes more equal no matter what level of income for $R D_{1}$. For individuals with higher financial literacy and higher income, the opposition to redistribution is stronger for $R D_{2}$ in both the GB and the Scottish sample. There is also a negative interaction effect of financial literacy with age and with "right" political orientation. The latter effect is less evident when interacting financial literacy with actual party voting. The political parties have been ordered from left to right in the 4 plots at the bottom of the figure.

12 The Appendix Table A3 presents all coefficients and robust standard errors from weighted ordered probit models of the specifications of columns 2 and 8 in Table 4 and columns 1 and 4 in Table 5. 
A similar pattern emerges in Panel $\mathrm{B}$ for $R D_{2}$, i.e. financial literacy decreases the probability to strongly agree that the government should redistribute income from the better off to those who are less well off by -14.2 percent and raises the probability to strongly disagree with that statement by 21 percent. An identical pattern prevails when looking at the marginal effects of financial literacy on $R D_{2}$ in the Scottish sample, with magnitudes in the order of -9.4 percent and 17.2 percent for the top and the bottom category, respectively. The impact of financial literacy on attitudes to redistribution is of a smaller magnitude in the Scottish sample.

Figure 2 visualizes the probability changes across each outcome category. The average marginal effects are all statistically significant, with the exception of category 5 for $R D_{1}$ in the GB sample. There is a robust negative trend emerging when considering both samples and measures. The negative effect is non-linear and much higher for the bottom and the top category of $R D_{l}$. This is also the case for $R D_{2}$, with the negative effect being the highest for the top response category. The figure confirms that the higher the individual's level of financial literacy the lower is the probability that the individual will have a negative attitude towards the role of government in redistributing income. This plot makes more evident the larger impact that financial literacy exerts on the extreme responses ('Yes', 'No' and 'Strongly Agree' or 'Strongly Disagree'). However, the marginal effects for financial literacy are all significant and of sizeable magnitudes for the all the remaining categories. In order to mitigate the concern that nearby larger values in the ordered probit do not necessarily correspond to a lower preference for redistribution, we have also estimated generalized ordered probit regressions. The Appendix Figure A5 plots the marginal effects from these regressions, with the non-parallel line assumption imposed for the effect of financial-literacy. The robustness of our findings is confirmed. The plot indicates that the negative effect of financial literacy on attitudes to redistribution is stronger and significant for those in the categories 3, 5, 9 and 10 for $R D_{1}$ and categories 2 and $5 R D_{2}{ }^{13}$.

\section{[INSERT FIGURE 2 ABOUT HERE]}

13 The results are very similar when relaxing the non-parallel line assumption for all independent variables in the context of a generalized ordered probit model (results available upon request). 


\section{Falsification, instrumental variables and longitudinal models}

A potential concern in the analysis so far is that financial literacy may be correlated with the error term in Eq. (1) via omitted factors measuring generic preferences against equality or attitudes towards equal opportunity. As a falsification exercise, we test whether financial literacy is independent of generic attitudes towards other types of inequality/discrimination. We do so by estimating models of attitudes against equal opportunities to the following groups (a) gay and lesbian, (b) females and (c) ethnic minorities. Specifically, we use the following question from the BES: "Please say whether you think these things have gone too far or have not gone far enough in Britain”.

- Attempts to give equal opportunities to ethnic minorities.

- Attempts to give equal opportunities to women.

- Attempts to give equal opportunities to gays and lesbians

The response categories are five: "Not gone nearly far enough", "Not gone far enough", "About right", "Gone too far", "Gone much too far". If our financial-literacy variable is well defined - and the model well specified - we should not expect it to be systematically related to any of the generic attitudes to inequality. Panel A of Table 7 reports estimated coefficients of financial literacy from separate weighted least squares regressions on the GB sample and on the boosted Scottish sample. All the coefficients are small in size and statistically insignificant, confirming that financial literacy is not capturing feelings of general aversion to equality. We interpret the outcome of this falsification exercise as a validation of our strategy.

\section{[INSERT TABLE 7 ABOUT HERE]}

The second falsification exercise consists of running our main specification, i.e. that of column 2 of Table 4, using the number of incorrect responses to the financial literacy question and the number of "Don't knows" and "Prefer not to say" (instead of number of correct responses). These estimates are presented in Panel B of Table 7 using our two redistribution variables as outcomes $\left(R D_{1}\right.$ and $\left.R D_{2}\right)$. Interestingly, the estimates confirm the validity of our financial literacy measure. As the number of incorrect answers increases, the likelihood of being in favour of redistribution and income equality also increases. The effects are of similar sign and magnitude when the number of "Don't know/Don't answer" is used as a proxy of financial illiteracy. We interpret the estimates of Panel B as a validation of our primary financial literacy measure used. 
Finally, in Panel C of Table 7, we distinguish between the three financial literacy components, by jointly incorporating dummy variables for a correct response to the interest question, the inflation question and the risk question. Then, we incorporate dummy variables for a wrong response to each of the three questions, along with a "don't know" response to each of the questions. The estimates of Panel $\mathrm{C}$ confirm that all three financial literacy components exert a negative and statistically significant impact on attitudes to redistribution. The magnitudes of the effects are similar in column 15. It is worth noting that the interest question does not exert a significant impact on attitudes to redistribution in the Scottish sample. Overall, it appears that the components of financial literacy exert a predictive role on attitudes to redistribution.

Another concern in our estimates so far is related to the potential endogeneity of financial literacy. In order to mitigate such a concern, we experiment with instrumental variable regressions in Table 8. The choice of valid instruments for financial literacy is tedious, stemming from the limited availability of suitable exclusion restrictions as instruments at the BES. For this reason, the first estimates reported are based on the method proposed by Lewbel (2012). In his approach, the method is applied without traditional instruments. In particular, the first-stage exclusion restriction is generated by the control variables, which we know are heteroskedastic. The greater the degree of heteroskedasticity in the error process, the higher will be the correlation of the generated instruments with the included endogenous variable.

Aiming for robustness, these estimates are accompanied by three more sets of instrumental variable regressions, using traditional instruments as exclusion restrictions. The first instrument used stems from answers regarding daily newspaper readership, and the choice of a newspaper that an individual most often reads on a daily basis. Among the sixteen options offered ${ }^{14}$, only five newspapers entailed a dedicated personal finance section in the year 2014, namely The Daily Telegraph, The Financial Times, The Guardian, The Independent, and The Times. We define a dummy variable, named P.F. section, taking the value 1 if the respondent frequently reads one of the five newspapers with dedicated personal finance sections. Our second instrumental variable, named FinEdu, stems from the studying "Engineering, Mathematics or Natural sciences" or "Economics or business" at the most recent degree/diploma ${ }^{15}$. This is a broad definition of financial

14 The Express, The Daily Mail / The Scottish Daily Mail, The Mirror / Daily Record, The Daily Star / The Daily Star of Scotland, The Sun, The Daily Telegraph, The Financial Times, The Guardian, The Independent, The Times, The Scotsman, The Herald (Glasgow), The Western Mail, Other local daily morning newspaper, Other Newspaper, None.

15 The original question is: "What subject area did you study in your most recent degree/diploma (at university etc.) or what subject area are you studying now (if you are still studying)?" 
education on subject that are likely to involve stronger numeracy skills and mathematical ability. Intuitively, this can be thought to be highly correlated with financial literacy and less likely to be correlated with the unobserved determinants of attitudes to redistribution. Finally, in a fourth specification we use both our instrumental variables, jointly, as exclusion restrictions.

The instrumental-variable regression estimates are presented in Table 8 . The battery of tests confirms that the instruments are strong, i.e. the F-test of the excluded instruments is well above the rule-of-thumb of 10 and the Kleibergen-Paap rk Wald statistic is large. The results confirm our previous findings, in that the estimated coefficients are negative and statistically significant. It is worth noting that Lewbel's (2012) method provides estimates in which the size is comparable with our previous estimates, while the other specifications with exclusion restrictions produce larger negative coefficients. However, it is worth noting that even these estimates are not unreasonably large. Hence, even in the moderate estimates, stemming from the method of Lewbel (2012), the instrumental variables approach used confirms the validity of our finding of a strong negative relationship between financial literacy and attitudes to income redistribution.

\section{[INSERT TABLE 8 ABOUT HERE]}

Our final line of inquiry in this section involves the utilization of longitudinal models for attitudes to redistribution. The BES survey has conducted nine waves so far in different quarters of the period 2014-2016. The longitudinal information on $R D_{1}$ is for waves $1,2,3,4,6$ and 7 . The time-varying information on $R D_{2}$ stems from waves 1, 6 and 7. One difficulty in employing fixed effects models stems from the fact that the majority of the information on our independent variables is time-invariant. Most importantly, financial literacy was only asked in wave 2 for the GB sample and in wave 4 for the boosted Scottish sample. The only variables with time-varying information are age, labour market status, political orientation, risk taking, union membership, social desirability, having children at pre-school age and experiencing a negative income shock during the last year. Hence, we are able to generate two panel datasets of six waves for $R D_{1}$ and three waves for $R D_{2}$. In $\underline{\text { Table 9, }}$, we estimate random effects GLS regressions for our two attitudinal measures. Moreover, we also estimate pooled weighted least squares regressions, with standard errors clustered at the individual level. Finally, we estimate attitudinal change models via weighted least squares, in which the dependent variable is the difference in $R D_{1}$ between wave 2 and wave 7 , and, then, the respective difference in $R D_{2}$.

[INSERT TABLE 9 ABOUT HERE] 
The estimates in Table 9 confirm our finding, by further establishing a significant negative relationship between financial literacy in wave 2 (wave 4 for the Scottish sample) and attitudes to redistribution across six waves for $R D_{1}$ and three waves for $R D_{2}$. The magnitude of the effects is similar to that of our cross-sectional models. Moreover, the models of column 5 and 6 (11 and 12 for the Scottish sample) find very large negative relationships between financial literacy and attitudinal change against redistribution between waves 2 and 7 , greater than -25 percent for $R D_{1}$ and between -11.9 and -32.4 percent for $R D_{2}$. The longitudinal analysis confirms that the negative relationship established is not due to omitted time-invariant factors that are uncorrelated with the independent variables in the context of the random effects model. Moreover, the findings are reinforced by the large negative association between financial literacy and attitudinal change against redistribution across waves.

\section{Mechanisms}

In the previous sections, we established that the link between attitude towards redistribution and financial literacy is robust to the choice of economic controls and to different samples, functional forms, specifications and models. Although this result has important implications per se, it is of primary importance to dissect the potential mechanisms through which financial literacy may impact attitudes for income equality and redistribution. In particular, our interest lies on whether the previous link between financial literacy and redistributive policies can be captured by any of the traditional channels proposed in the literature or if financial literacy mitigates or amplifies any of these mechanisms.

To this end, we utilize the categorization proposed by Corneo and Grüner (2002), introduced in Section 2. This involves a set of three specific mechanisms by which the agents form their views on public policies, as below:

a) The homo oeconomicus effect (hereafter $H O E$ ): This essentially involves the generation of a proxy of the individual's net pecuniary gain from governmental redistribution. The idea is that the support in favour of e.g. the more redistributive policies can be inversely related to an individual's position in the income scale. We generate a proxy by merging the full version of the British Election Study, i.e. entailing more than 30,000 individuals with data on median personal income for each of 
the 650 parliamentary constituencies in the United Kingdom ${ }^{16}$. We impute the 8,185 missing values on personal income by obtaining predicted values from Mincerian regressions on the remaining 25,785 observations. ${ }^{17}$ Then, the $H O E$ is obtained as the difference of the logarithm of personal income minus the logarithm of median income in the parliamentary constituency.

b) The public value effect (hereafter $P V E$ ): The generation of a proxy $P V E$ requires data on individual beliefs about success factors or data on the mobility experience of individuals. We take the former approach by generating the summation over two questions regarding success factors. Specifically, both questions ask individuals to express the extent with which they agree or disagree, on a scale from 1 (completely disagree) to 5 (completely agree) with the following two statements: (i) When someone is unemployed, it's usually through no fault of their own; and (ii) In business, bonuses are a fair way to reward hard work. Departing from Arrow's (1963) view that individuals may be endowed with a social welfare function that expresses their preferences over resource allocations to all individuals in society, one can infer that an individual's political orientation may reflect such a social welfare function. Corneo and Grüner (2002) explain that, departing from the same fundamental values of a 'veil-of-ignorance', individuals may entertain idiosyncratic beliefs about the contributions of, e.g., family background and individual effort to personal economic success ${ }^{18}$.

c) The social rivalry effect (hereafter $S R E$ ): In our setting, the $S R E$ could arise when individuals form political attitudes based the consideration that governmental redistribution affects the quality of their social environment. Cole et al. (1992) show that social competition for some goods can endogenously generate a concern for relative consumption. We assume that, within each local authority of Great Britain, it is possible to identify the social value people associate with different status level. The social value of a given social class can be thought of as the average contribution to their social environment made by people with that status, e.g. determined by education and/or income. Following Corneo and Grüner (2002), using such a definition of social classes, we assume

16 Data on median personal income by parliamentary constituency stem from the Office for National Statistics: http://www.ons.gov.uk/ons/datasets-and-tables/index.html?pageSize=50\&sortBy=none\&sortDirection= none \&newquery=income+by+constituency \&content-type $=$ Reference+table \&content-type=Dataset

17 The list of explanatory variables involves: the logarithm of age, the years of education, gender, marital status, the logarithm of household size, occupational status, ethnicity, immigrant status, home ownership, urban region, government office region of residence and social class (4 categories).

18 Piketty (1995) argues that experiential learning about the role of family background and the role of individual effort to personal economic success, generates a link between own experience of upward income mobility and the individual's degree of political conservatism. 
that "a marginal increase in the government's reduction of economic inequality increases the amount of social contact between neighbouring classes without affecting the contact with more distant classes"19.

The $S R E$ is then computed in the following four steps:

1) We generate a social rivalry proxy by aggregating over variables capturing the extent to which an individual disagrees (i.e. the reversed scale, measured from 1 to 5, where 5 indicates complete disagreement) with the following five statements: "Big business takes advantage of ordinary people", "Ordinary working people do not get their fair share of the nation's wealth", "There is one law for the rich and one for the poor", "Management will always try to get the better of employees if it gets the chance", and "Politicians only care about people with money".

2) We generate personal income deciles, at the local authority level ${ }^{20}$, using the full BES sample, with the $10^{\text {th }}$ category representing higher income. Then, we use the 8 educational categories, as in the Appendix Table A1. Based on the categories of the two variables we generate 18 status classes, i.e. using an aggregation of the ordered income and educational categories. The assumption is that higher income and higher education amount to higher social status. The two can substitute each other, but individuals with both higher education and higher income will be at the top of the social status ladder. If the income classes are monotonically ordered, so that class $\mathrm{k}+1$ is richer than class $\mathrm{k}$, then each class $\mathrm{k} \in[2,17]$ has two neighbouring classes, $\mathrm{k}-1$ and $\mathrm{k}+1$.

3) Then, we generate the average social rivalry score $\left(\mathrm{V}_{\mathrm{k}}\right)$ by local authority and status class at the full BES sample. So, if there are 18 status classes denoted by $\mathrm{k}=1, \ldots, 18$, people inside class $\mathrm{k}$ are associated with a social value $\mathrm{V}_{\mathrm{k}}$. There are 637 distinct values for $\mathrm{V}_{\mathrm{k}}$.

4) Finally, by collapsing the dataset at the 637 data points for $V_{k}$ and sorting at local authority and status class (i.e. $V_{k}$, capturing neighbouring classes at the local level), our SRE variable is computed as: $\mathrm{SRE}_{\mathrm{k}}=\mathrm{DVD}_{\mathrm{k}}-\mathrm{UVD}_{\mathrm{k}}$, where $D V D_{k}=V_{k}-V_{k-1}$ is the downward value

19 "Increasing the degree of political redistribution therefore changes the average quality of social contacts of class $k$ individuals in two ways. First, their milieu will consist of an increased fraction of class $k-1$ individuals, which tends to decrease the expected utility from social interactions proportionally to $D V D_{k}=V_{k}-V_{k-1}$, which is termed the downward value differential for individuals of class $k$. Second, their social environment will be made up by an increased portion of individuals from class $k+1$, which improves the quality of social life of class $k$ individuals in proportion to $U V D_{k}=V_{k+1}-V_{k}$, the upward value differential of class $k$ " (Corneo and Grüner, 2002: p. 88). Then, the social rivalry effect can be defined as: $\mathrm{SRE}_{\mathrm{k}}=\mathrm{DVD}_{\mathrm{k}}-\mathrm{UVD}_{\mathrm{k}}$.

20 There are some 380 local authorities at the BES. 
differential for individuals of class $k$ and $U V D_{k}=V_{k+1}-V_{k}$ is the upward value differential of class $k$. Hence: $\mathrm{SRE}=2 * \mathrm{~V}_{\mathrm{k}}-\left(\mathrm{V}_{\mathrm{k}-1}+\mathrm{V}_{\mathrm{k}+1}\right)$.

It is worth noting that for the purposes of our analysis we normalize the three proxies using a Z-score for purposes of comparability of the effects produced. Our empirical strategy in this section involves examining the impact of the three mechanisms, along with financial literacy. We further aim to disentangle these channels for individuals with high and low financial literacy (FLH and FLL, respectively) as defined in the data section, by introducing relevant interaction terms and producing estimates for the two sub-samples of FLH and FLL.

$\underline{\text { Table } 10}$ presents our estimates regarding the mechanisms of formation of attitudes towards redistribution for our $R D_{1}$ measure. In column 1, all three mechanisms, namely the HOE, the PVE and the SRE, exert a negative effect on attitudes to redistribution. The magnitude of the effects is comparable to that in Corneo and Grüner (2002). The PVE effect appears to exert the largest negative impact among the three effects, with a coefficient twice as large as that of the other two mechanisms. Its magnitude is similar in size to our previous estimates of the financial literacy effect. In column 2, we introduce our financial literacy measure. The results show that accounting for the three mechanisms only slightly reduces the financial-literacy effect from -0.449 in Table 4 to -0.427 . However, the relationship is still strongly statistically significant at the $1 \%$ level, indicating that financial literacy is capturing aspects that are orthogonal to these standard proxies. The magnitude of the coefficients of the three mechanisms remains virtually unaffected when controlling for financial literacy. In Column 3, we further distinguish between the DVD and the UVD components of the $S R E$. Expectedly, the $D V D$ exerts a significant negative impact on $R D_{1}$ and the $U V D$ a symmetrical positive impact.

\section{[INSERT TABLE 10 ABOUT HERE]}

Column 4 introduces interaction terms between financial literacy and the three mechanisms proposed in the literature, in the following fashion (omitting the subscript $i$ ):

$$
\begin{gathered}
R D_{n}=\beta_{1} F L H+\beta_{2} X_{i}+\beta_{3}\left(H O E^{*} F L H\right)+\beta_{4} H O E^{*}(1-F L H)+ \\
+\beta_{5}\left(P V E^{*} F L H\right)+\beta_{6} P V E^{*}(1-F L H)+\beta_{7}\left(S R E^{*} F L H\right)+S R E^{*}(1-F L H)+\theta_{r}+\varepsilon
\end{gathered}
$$

The estimates in column 4 (and 10 for the Scottish sample) indicate significant terms for the interactions between FLH, FLL and SRE and PVE. Moreover, the interaction term between $H O E$ and FLH is negative and significant. However, the interaction term between HOE and 1-FLH (i.e. $F L L)$ is statistically insignificant in both column 4 and 10. So is the interaction term between SRE 
and FLL. Columns 5 and 6 (11 and 12 for Scotland) present estimates for the two sub-samples of FLH and FLL. Interestingly, the estimation for the two sub-samples indicates that the effect of the $H O E$ is significantly large and negative for the $F L H$. However, it becomes statistically insignificant for the FLL. This is the case in both the GB and the Scottish sample estimations. The SRE effect also diminishes to insignificance for GB, although it is significant at the $10 \%$ level in the Scottish sample.

\section{[INSERT TABLE 11 ABOUT HERE]}

In Table 11, we repeat this exercise using $R D_{2}$ as the dependent variable. The same specifications as in Table 10 are estimated. In Table 11, the HOE becomes insignificant. However, the analysis using interaction terms and disaggregated samples suggests it is negative and significant for the FLH and insignificant for the FLL. The SRE is significantly negative for both groups in Table 11.

Overall, the results in this section indicate that both the PVE and largely the SRE exert a negative impact on attitudes to redistribution for both the high and the low financial literacy group. However, the HOE effect vanishes for the low-financial literacy individuals, while it is negative and significant among the high financial-literacy group. We interpret this evidence with caution, as a potential indication of a mediating role of financial literacy in the perception of the individual's net pecuniary gain from governmental redistribution. Individuals with high financial literacy are more likely to emphasize on self-interest and own rank in the income distribution. In the spirit of Becker (1996) forward-looking individuals may recognize that their current choices and experiences affect their personal capital in the future and that future utility depends on future personal capital. In that spirit, Becker and Mullighan (1997) suggest that higher wealth is related to higher patience. Thus, higher financial literacy may exert a mediating role in that cognitive 'recognition' process and, thus, reinforce attitudes against redistributive policies.

\section{Concluding remarks and implications}

This study examines the mediating role of financial literacy in the formation of attitudes against redistribution in Great Britain. We show that financial literacy exerts a statitically significant negative impact on attitudes in favour of the view that the governemnt should actively intervene to make incomes more equal or redistribute from those better off to the worse off. Our analysis also 
shows that the size of these effects is economically important and that financial literacy exerts an even stronger influence for individuals with polarized views on the matter of income redistribution. The effects are robust under various specifications, including a rich set of control variables and interactions with income, education and age. We show our results are robust when using instrumental variable regressions and longitudinal models. Financial literacy is shown to be unrelated to generic attitudes against inequality, with respect to gender, sexual orientation or ethnic group.

The importance of financial literacy in modern economies cannot be overemphasized. Financial literacy has a clear public good element to it, as it has been conceptually linked with macroeconomic financial stability. Lusardi et al. (2016) show that differences in financial knowledge formed early in life can explain some $40 \%$ of retirement wealth inequality in the United States. We find our findings are complementary to this recent insight, by suggesting that in addition to affecting current and future financial choices, financial literacy can affect views on 'personal capital' which can induce attitudes towards income redistribution, inequality and government intervention. Our analysis suggests that efforts to improve financial literacy in this realm can lead to lower demand for redistribution.

We contribute to the economics literature by presenting some preliminary evidence that the homo oeconomicus effect is more likely to prevail for the more financial literate individuals, while it vanishes for their financially-illiterate counterparts. With most economic models relying on the premise of rational agents, any cognitive skills that are likely to induce such behaviour, such as financial literacy in our setting, are likely to be conducive to the validity and predictive power of these economic models. We contribute to the literature on public economics, by presenting one additional main channel to those proposed in the literature on the formation of public attitudes, namely financial literacy. We contribute to the literature on education economics. Our findings may potentially be taken into account when designing policy interventions, by including elements on economics of inequality with the objective to provide a broader view on the subject. Finally, from a socioeconomics perspective, efforts to improve financial literacy can be seen as conducive to the processes of social constructivism and open democracy. 


\section{References}

Aghion, Philippe, Eve Caroli, and Cecilia Garcia-Penalosa, 1999. "Inequality and economic growth: the perspective of the new growth theories". Journal of Economic literature. Vol. 37, No. 4, pp. 1615-1660.

Alesina Alberto, Edward Glaeser and Bruce Sacerdote, 2001. "Why doesn't the United States have a European-style welfare state?" Brookings Paper on Economics Activity. Fall, pp. 187-278.

Alesina, Alberto, and George-Marios Angeletos, 2005. "Fairness and redistribution: US vs. Europe". American Economic Review. Vol 95, pp. 913-935.

Alesina, Alberto, and Paola Giuliano. 2011. "Preferences for redistribution". In: A. Bisin and J. Benhabib (Eds.). Handbook of Social Economics. North Holland. pp. 93-132.

Alesina, Alberto, and Eliana La Ferrara, 2005. "Preferences for redistribution in the land of opportunities". Journal of Public Economics. Vol. 89, pp. 897-931.

Alesina, Alberto, and Roberto Perotti. "Income distribution, political instability, and investment". European Economic Review”. Vol. 40, No. 6, pp. 1203-1228.

Andreoni, James, and John Miller, 2002. "Giving according to GARP: An experimental test of the consistency of preferences for altruism”. Econometrica. Vol. 70, No. 2, pp. 737-753.

Arrow, K., 1963. Social Choice and Individual Values. New York, NY: Wiley, and Sons.

Becker, Gary S., 1996. Accounting for tastes. Cambridge: MA, Harvard University Press.

Becker, Gary S. and Casey B. Mulligan, 1997. "The endogenous determination of time preference". Quarterly Journal of Economics. Vol. 112, No. 3, pp. 729-758

Benabou, Roland, and Efe A. Ok, 2001. "Mobility as progressivity: ranking income processes according to equality of opportunity”. NBER Working Paper No. 8431.

Benabou, Roland, and Jean Tirole, 2006. "Identity, dignity and taboos: Beliefs as assets." Quarterly Journal of Economics. Vol. 126, No. 2, pp. 805-855.

Boarini, Romina, and Christine Le Clainche, 2009. "Social preferences for public intervention: An empirical investigation based on French data". Journal of Socioeconomics. Vol. 38, pp. 115128.

Cole, H., Mailath, G., and A. Postlewaite, 1992. "Social norms, savings behavior and growth". Journal of Political Economy.100, pp. 1092-1125.

Corneo, Giacomo, and Hans Peter Grüner, 2002. "Individual preferences for political redistribution". Journal of Public Economics. Vol. 83, pp. 83-107.

Cruces Guillermo, Ricardo Perez-Truglia, and Martin Tetaz, 2013. "Biased perceptions of income distribution and preferences for redistribution: Evidence from a survey experiment". Journal of Public Economics. Vol. 98, pp. 100-112.

Deary Ian J., Batty G. David, and Catharine R. Gale, 2008. "Childhood intelligence predicts voter turnout, voting preferences, and political involvement in adulthood: The 1970 British Cohort Study”. Intelligence. Vol. 36. pp. 548-555.

Fong, Christina M., Samuel Bowles, and Herbert Gintis, 2006. "Strong reciprocity and the welfare state". In: S.-C. Kolm and J. M. Ythier (Eds). Handbook on the Economics of Giving, Altruism and Reciprocity. Volume 2. Amsterdam: Elsevier. pp.1440-1464.

Fong, Christina M., and Felix Oberholzer-Gee, 2011. "Truth in giving: Experimental evidence on the welfare effects of informed giving to the poor". Journal of Public Economics. Vol. 95, No. 5, pp. 436-444.

Fong, Christina M., 2001. "Social preferences, self-interest and the demand for redistribution". Journal of Public Economics. Vol. 82, pp. 225-246. 
Galor, Oded, and Omer Moav, 2004. "From physical to human capital accumulation: Inequality and the process of development". Review of Economic Studies. Vol. 71, No. 4, pp. 1001-1026.

Jappelli, Tullio, and Mario Padula, 2013. "Investment in financial literacy and saving decisions". Journal of Banking and Finance. Vol. 37, No.8, pp. 2779-2792.

Jappelli, Tullio, 2010. "Economic literacy: An international comparison”. Economic Journal. Vol. 120, pp. F429-F451.

Jones, Charles I., 2015. "Pareto and Piketty: The macroeconomics of top income and wealth inequality". Journal of Economic Perspectives. Vol. 29, No. 1, pp. 29-46(18).

Hanushek Eric A. and Ludger Woessmann, 2008. "The role of cognitive skills in economic development". Journal of Economic Literature. Vol. 43, No. 6, pp. 607-668.

Heckman James J., Stixrud Jora, and Sergio Urzua, 2006. "The effects of cognitive and noncognitive abilities on labor market outcomes and social behavior". Journal of Labor Economics. Vol. 24, No. 3, pp. 411-482.

Hung, Angela, Andrew M. Parker, and Joanne Yoong, 2009. "Defining and measuring financial literacy". RAND Working Paper Series WR-708.

Kaldor, Nicholas, 1957. “A model of economic growth”. Economic Journal. Vol. 67, pp. 591-624.

Keely, Louise C., and Chih Ming Tan, 2008. "Understanding preferences for income redistribution". Journal of Public Economics. Vol. 92, pp. 944-961.

Kerr, William R., 2014. "Income inequality and social preferences for redistribution and compensation differentials". Journal of Monetary Economics. Vol. 66, pp. 62-78.

Klor, Esteban F., and Moses Shayo, 2010. "Social identity and preferences over redistribution". Journal of Public Economics. Vol. 94, pp. 269-278.

Krawczyk, Michal, 2010. "A glimpse through the veil of ignorance: Equality of opportunity and support for redistribution”. Journal of Public Economics. Vol. 94, pp. 131-141.

Kuziemko, Ilyana, Emmanuel Saez, Michael I. Norton, and Stefanie Stancheva, 2015. "How elastic are preferences for redistribution? Evidence from randomized survey experiments". American Economic Review. Forthcoming.

Lazear, Edward P., and Sherwin Rosen, 1981 "Rank-order tournaments as optimum labor contracts". Journal of Political Economy. Vol. 89, No. 5, pp. 841-864.

Lusardi, Annamaria, and Olivia S. Mitchell, 2014. "The economic importance of financial literacy: Theory and evidence". Journal of Economic Literature. Vol. 52, No. 1, pp. 5-44.

Lusardi, Annamaria, Michaud Pierre-Carl and Olivia S. Mitchell, 2016. "Optimal financial knowledge and wealth inequality". Journal of Political Economy. Forthcoming.

Luttmer, Erzo F. P., and Monica Singhal, 2011. "Culture, context, and the taste for redistribution". American Economic Journal: Economic Policy. Vol. 3, pp. 157-179.

Luttmer, Erzo F. P., 2001. "Group loyalty and the taste for redistribution". Journal of Public Economics. Vol. 109, No. 3, pp. 500-528.

Meltzer, Allan H., and Scott F. Richard, 1983. "Tests of a rational theory of the size of government". Public Choice. Vol. 41, No. 3, pp.403-418.

Onraet Emma, Van Hiel Alan, Dhont Kristof, Hodson Gordon, Schittekatte Mark and Sarah de Pauw. 2015. "The association of cognitive ability with right-wing ideological attitudes and prejudice: A meta-analytic review”. European Journal of Personality. Vol. 29, pp. 599-621.

Persson, Torsten, and Guido Tabellini, 1994. "Does centralization increase the size of government?" European Economic Review. Vol. 38, No. 3, pp. 765-773. 
Piketty, T., 1995. "Social mobility and redistributive politics". Quarterly Journal of Economics. 110(3), pp. 551-585.

Piketty, Thomas, 1998. "Self-fulfilling beliefs about social status". Journal of Public Economics. Vol. 70, No. 1, pp. 115-132.

President's Advisory Council on Financial Literacy (PACFL), 2008. Annual Report to the President.

Rayo, Luis, and Gary S. Becker, 2006. "Peer comparisons and consumer debt". Harvard Law Review. Vol. 73, pp. 231-248.

Rayo, Luis, and Gary S. Becker, 2007a. "Evolutionary Efficiency and Happiness". Journal of Political Economy. Vol. 115, No. 2, pp. 302-337.

Rayo, Luis, and Gary S. Becker, 2007b. "Habits, Peers, and Happiness: An Evolutionary Perspective". American Economic Review Papers and Proceedings. Vol. 97, No. 2 (May), pp. 487-491.

Ravallion, Martin and Michael Lokshin, 2000. "Who wants to redistribute? The tunnel effect in 1990s Russia”. Journal of Public Economics. Vol. 76, pp. 87-104.

Roberts, Kevin W. S., 1977. "Voting over income tax schedules". Journal of Public Economics, Vol. 8, No. 3, pp.329-340.

Romer, Thomas, 1975. "Individual welfare, majority voting, and the properties of a linear income tax". Journal of Public Economics. Vol. 4, No. 2, pp.163-185.

Schoon Ingrid, Cheng Helen, Gale Catharine R., Batty G. David, and Ian J. Deary, 2010. "Social status, cognitive ability, and educational attainment as predictors of liberal social attitudes and political trust”. Intelligence. Vol. 38, pp. 144-150.

Shelton, Cameron A., 2007 "The size and composition of government expenditure". Journal of Public Economics. Vol. 91, No. 11, pp. 2230-2260.

Stankov Lazar, 2009. “Conservatism and cognitive ability”. Intelligence. Vol. 37, pp. 294-304.

Strum, Jan-Egbert, and Jakob De Haan, 2015. "Income inequality, capitalism and ethno-linguistic fractionalization". American Economic Review. Vol. 105, No. 5, pp. 593-597(5).

Wang, Long, Deepak Malhotra, and J. Keith Murnighan, 2011. "Economics education and greed". Academy of Management Learning \& Education. Vol. 10, No 4, pp. 643-660. 
Figure 1

International comparisons of attitudes to redistribution and financial literacy World Values Survey (Wave 6), International Social Survey Programme (2014), Eurobarometer (2014), and S\&P Financial Literacy Survey (2014)

(a) World Values Survey: Wave 6 ( RD1)

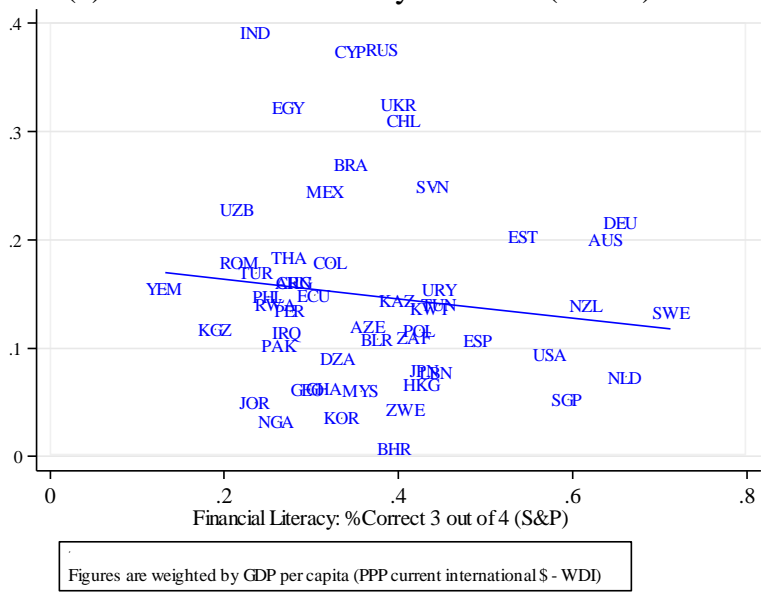

(c) ISSP 2014

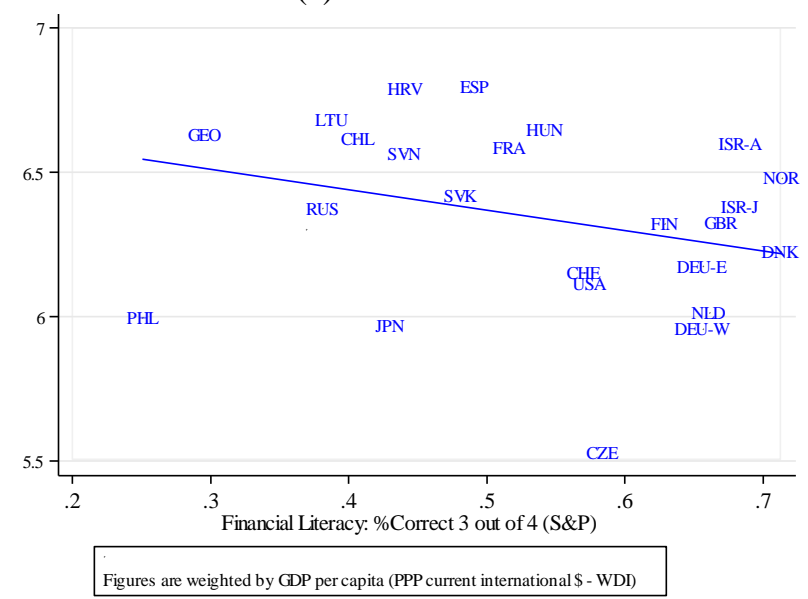

(e) Eurobarometer 2014

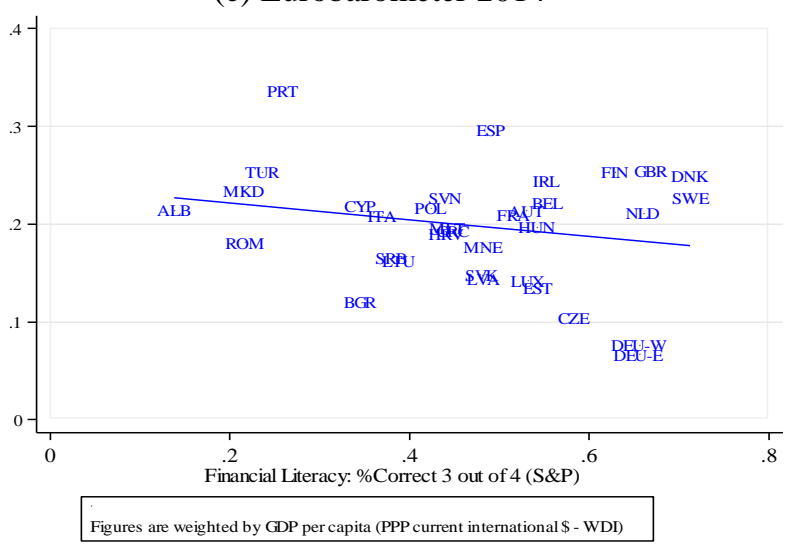

(b) World Values Survey: Wave $6(\sim \mathrm{RD} 2)$

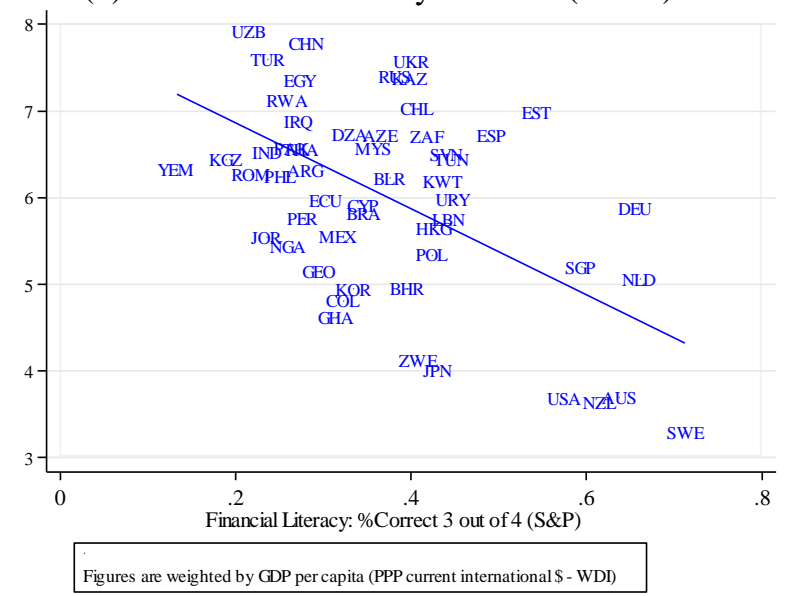

(d) Eurobarometer 2014

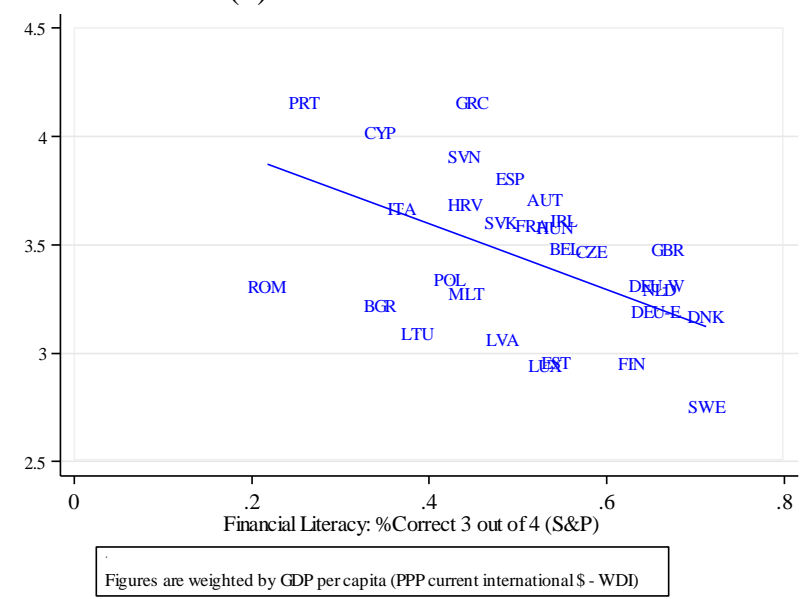

(f) Eurobarometer 2014

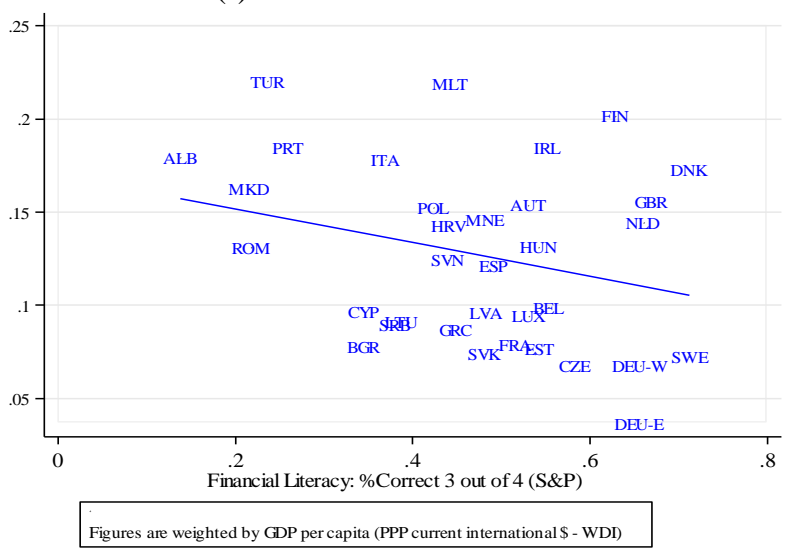

Notes: Figures are weighted by GDP per capita for 2014 (PPP-adjusted current \$international), from the World Development Indicators. 


\section{Figure 2}

Average marginal effects of financial literacy on attitudes towards redistribution from ordered probit regressions

(a)

Government should try to make incomes more equal (RD1)

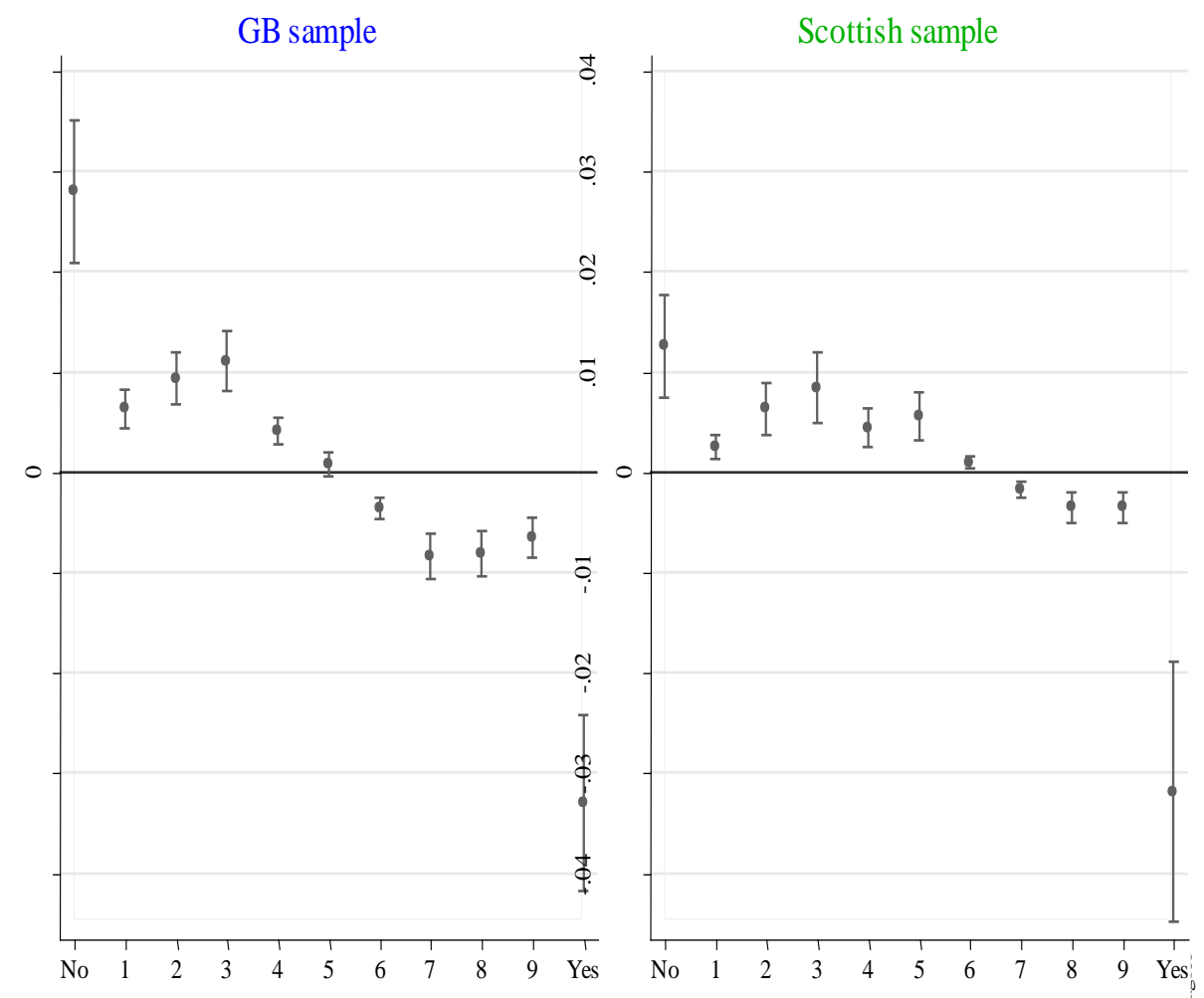

(b)

Government should redistribute income (RD2)

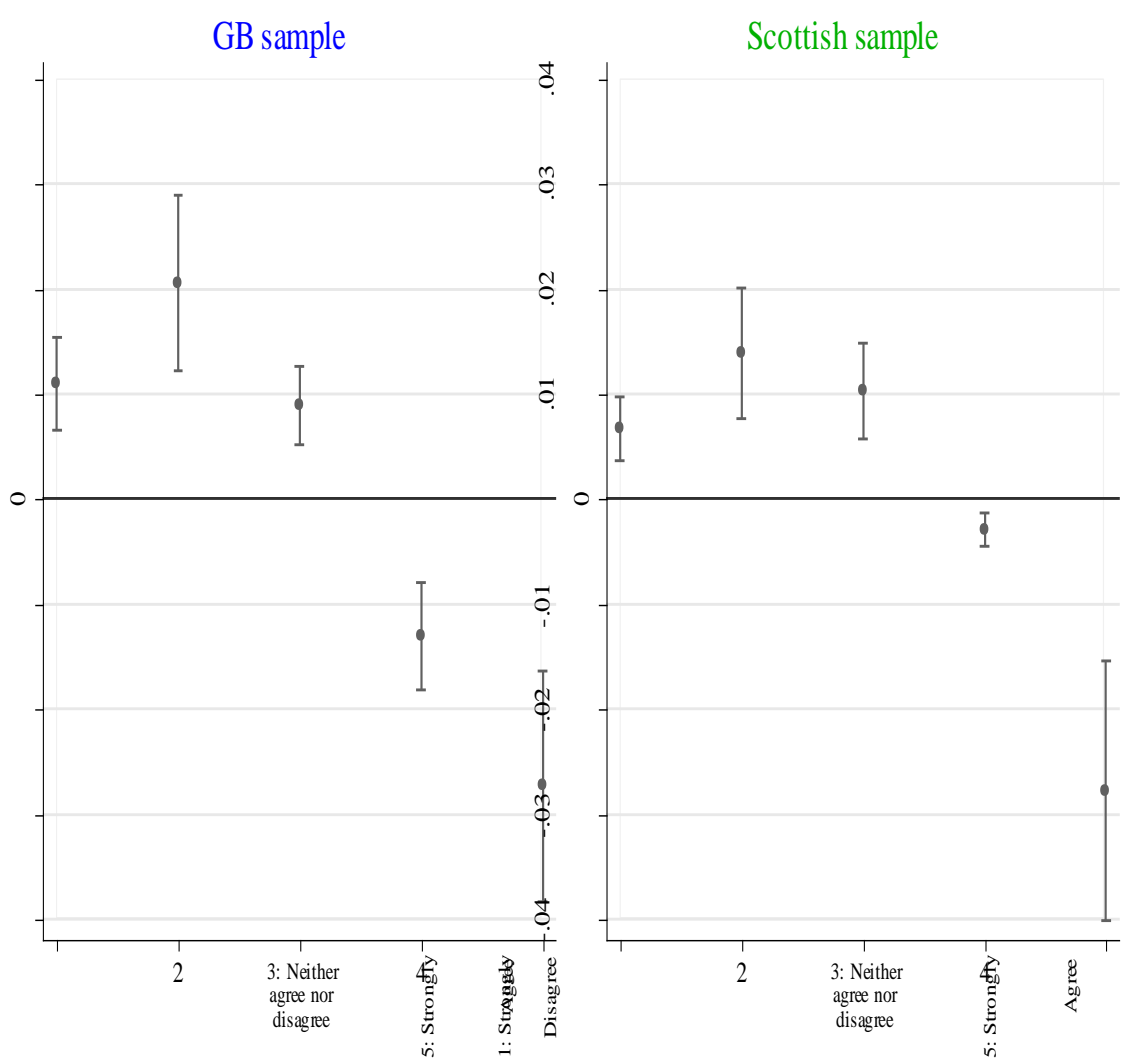

Notes: Each graph plots average marginal effects of financial literacy on attitudes to redistribution along with $95 \%$ confidence intervals. The estimates are from separate ordered probit regressions of the redistribution variables, i.e. $R D_{1}$ and $R D_{2}$ respectively, on financial literacy and a rich set of control variables. The estimates are presented in the Appendix Table A3. They are weighted using population level weights and utilise robust standard errors. 
Table 1

Frequencies for attitudes towards redistribution, by financial literacy level

\begin{tabular}{|c|c|c|c|c|c|c|c|c|c|c|c|c|}
\hline \multicolumn{13}{|c|}{ Panel A: $R D_{l}$ - "Government should try to make incomes more equal" (\%) } \\
\hline & & No: $0-$ & $-1-$ & $-2-$ & $-3-$ & $-4-$ & $-5-$ & $-6-$ & $-7-$ & $-8-$ & $-9-$ & - 10: Yes \\
\hline \multicolumn{2}{|c|}{ GB sample [BES: Wave 2] } & 10.39 & 3.73 & 6.66 & 11.7 & 7.59 & 17.49 & 8.07 & 9.94 & 6.7 & 4.17 & 13.56 \\
\hline \multirow{4}{*}{ Fin. literacy: \#Correct responses } & $-0-$ & 6.59 & 1.86 & 5.07 & 7.42 & 5.97 & 22.18 & 7.38 & 8.16 & 5.25 & 5.76 & 24.37 \\
\hline & $-1-$ & 7.31 & 3.50 & 4.61 & 9.20 & 6.50 & 20.31 & 5.60 & 8.37 & 8.03 & 4.89 & 21.69 \\
\hline & $-2-$ & 10.11 & 3.24 & 6.92 & 11.83 & 7.83 & 17.58 & 7.56 & 9.84 & 6.82 & 4.53 & 13.73 \\
\hline & $-3-$ & 12.65 & 4.53 & 7.68 & 13.52 & 8.21 & 15.3 & 9.61 & 11.03 & 6.33 & 3.31 & 7.82 \\
\hline \multirow{5}{*}{$\begin{array}{l}\text { Scottish sample [BES: Wave } \\
\text { Fin. literacy: \#Correct responses }\end{array}$} & 4] & 6.34 & 1.66 & 5.10 & 8.83 & 6.31 & 13.60 & 8.55 & 11.06 & 8.32 & 5.68 & 24.55 \\
\hline & $-0-$ & 4.37 & 1.04 & 5.41 & 3.30 & 6.41 & 18.94 & 5.28 & 7.89 & 5.48 & 7.13 & 34.75 \\
\hline & $-1-$ & 5.25 & 1.54 & 4.01 & 6.99 & 5.99 & 13.42 & 5.68 & 7.08 & 8.22 & 6.19 & 35.63 \\
\hline & $-2-$ & 5.35 & 1.03 & 4.61 & 8.97 & 5.43 & 13.34 & 9.09 & 11.51 & 8.76 & 5.79 & 26.12 \\
\hline & $-3-$ & 8.24 & 2.40 & 5.94 & 11.15 & 7.17 & 12.41 & 10.4 & 13.50 & 8.80 & 4.95 & 15.04 \\
\hline \\
\hline & & & \multirow{2}{*}{\multicolumn{2}{|c|}{$\begin{array}{c}\text { 2come from the bett } \\
\text { Strongly Disagree } \\
-1-\end{array}$}} & \multicolumn{6}{|c|}{ Neither agree nor disagree } & \multirow{2}{*}{\multicolumn{2}{|c|}{$\begin{array}{c}\text { Strongly Agree } \\
-5-\end{array}$}} \\
\hline & & & & & & & \multicolumn{2}{|c|}{$-3-$} & \multicolumn{2}{|c|}{$-4-$} & & \\
\hline \multirow{5}{*}{$\begin{array}{l}\text { GB sample [BES: Wave 2] } \\
\text { Fin. literacy: \#Correct responses }\end{array}$} & & & \multicolumn{2}{|c|}{5.10} & \multicolumn{2}{|c|}{18.32} & \multicolumn{2}{|c|}{24.60} & \multicolumn{2}{|c|}{32.68} & \\
\hline & $-0-$ & & \multicolumn{2}{|c|}{3.12} & \multicolumn{2}{|c|}{8.12} & \multicolumn{2}{|c|}{26.88} & \multicolumn{2}{|c|}{36.77} & \multicolumn{2}{|c|}{25.11} \\
\hline & $-1-$ & & \multicolumn{2}{|c|}{4.78} & \multicolumn{2}{|c|}{13.55} & & & \multicolumn{2}{|c|}{33.70} & \multicolumn{2}{|c|}{23.80} \\
\hline & $-2-$ & & \multicolumn{2}{|c|}{3.91} & \multicolumn{2}{|c|}{18.24} & \multicolumn{2}{|c|}{25.59} & & & \multicolumn{2}{|c|}{18.30} \\
\hline & $-3-$ & & \multicolumn{2}{|c|}{6.52} & & & & & & & & .64 \\
\hline Scottish sample [BES: Wave & 4] & & & & & & & & & & & .03 \\
\hline Fin. literacy: \#Correct responses & $-0-$ & & & & & & & & & & & .72 \\
\hline & $-1-$ & & & & & & & & & & & .83 \\
\hline & $-2-$ & & & & & & & & & & & .44 \\
\hline & $-3-$ & & & & & & & & & & & .48 \\
\hline
\end{tabular}

Notes: This table shows the distribution of responses to different questions about attitudes towards redistribution in the British Election Study 2014/2015 and their frequencies by the number of correct responses in the financial-literacy questions. All statistics are weighted using population level weights. 
Table 2

Financial literacy in Great Britain and Scotland (British Election Study)

\begin{tabular}{|c|c|c|c|c|c|c|}
\hline \multicolumn{7}{|c|}{ Panel A: Financial literacy measures } \\
\hline & & $\begin{array}{l}\text { \#Correct } \\
\text { responses }\end{array}$ & \multicolumn{2}{|c|}{ \#Wrong } & $\begin{array}{l}\text { \#DK/DA } \\
\text { responses }\end{array}$ & $\begin{array}{l}\text { At least one } \\
\text { "Don't know" }\end{array}$ \\
\hline GB sample & & 1.99 & $\frac{0.4}{0.4}$ & & 0.52 & $31.25 \%$ \\
\hline Scottish sample & & 1.93 & 0.5 & & 0.56 & $33.91 \%$ \\
\hline \multicolumn{7}{|c|}{ Panel B: Financial literacy: \#Correct responses } \\
\hline & & $\begin{array}{c}\text { All } 3 \\
\text { correct }\end{array}$ & \multicolumn{2}{|c|}{$\stackrel{2}{\text { correct }}$} & $\stackrel{1}{\text { correct }}$ & $\stackrel{\underline{O}}{\text { correct }}$ \\
\hline GB sample & & $40.22 \%$ & \multicolumn{2}{|c|}{$\frac{\text { correct }}{29.45 \%}$} & $19.55 \%$ & $10.78 \%$ \\
\hline Scottish sample & & $37.28 \%$ & \multicolumn{2}{|c|}{$31.15 \%$} & $19.12 \%$ & $12.45 \%$ \\
\hline \multicolumn{7}{|c|}{ Panel C: Distribution of financial-literacy responses } \\
\hline & & Correct & \multicolumn{2}{|c|}{ Incorrect } & Don't know & Refuse \\
\hline GB: Compound interest & & $81.32 \%$ & \multicolumn{2}{|c|}{$8.88 \%$} & $9.80 \%$ & $3.10 \%$ \\
\hline GB: Inflation & & $69.09 \%$ & \multicolumn{2}{|c|}{$12.48 \%$} & $18.43 \%$ & $3.18 \%$ \\
\hline GB: Stock risk & & $48.68 \%$ & \multicolumn{2}{|c|}{$27.93 \%$} & $23.38 \%$ & $2.41 \%$ \\
\hline Scotland: Compound interest & & $80.87 \%$ & \multicolumn{2}{|c|}{$7.96 \%$} & $11.17 \%$ & $2.68 \%$ \\
\hline Scotland: Inflation & & $65.81 \%$ & \multicolumn{2}{|c|}{$14.33 \%$} & $19.85 \%$ & $2.81 \%$ \\
\hline Scotland: Stock risk & & $46.57 \%$ & \multicolumn{2}{|c|}{$28.57 \%$} & $24.86 \%$ & $2.43 \%$ \\
\hline \multicolumn{7}{|c|}{ Panel D: International comparison (Lusardi and Mitchell, 2014) } \\
\hline Country & $\underline{\text { Survey year }}$ & $\begin{array}{l}\text { Interest } \\
\text { rate }\end{array}$ & $\underline{\text { Inflation }}$ & $\underline{\text { Risk }}$ & $\begin{array}{c}\text { All } 3 \\
\text { correct }\end{array}$ & $\begin{array}{c}\text { At least } 1 \\
\text { "Don't know" }\end{array}$ \\
\hline USA & 2009 & $64.9 \%$ & $64.3 \%$ & $51.8 \%$ & $30.2 \%$ & $42.4 \%$ \\
\hline Netherlands & 2010 & $84.8 \%$ & $76.9 \%$ & $51.9 \%$ & $44.8 \%$ & $37.6 \%$ \\
\hline Germany & 2009 & $82.4 \%$ & $78.4 \%$ & $61.8 \%$ & $53.2 \%$ & $37.0 \%$ \\
\hline Japan & 2010 & $70.5 \%$ & $58.8 \%$ & $39.5 \%$ & $27.0 \%$ & $61.5 \%$ \\
\hline Australia & 2012 & $83.1 \%$ & $69.3 \%$ & $54.7 \%$ & $42.7 \%$ & $41.3 \%$ \\
\hline
\end{tabular}

Notes: Weighted averages from the British Election Study (2014-2015) 
Table 3

Sample averages and mean differences

\begin{tabular}{|c|c|c|c|c|c|c|c|c|}
\hline & \multicolumn{4}{|c|}{$\begin{array}{c}\text { Great Britain } \\
\text { [BES Wave 2:5,732 obs.] }\end{array}$} & \multicolumn{4}{|c|}{$\begin{array}{c}\text { Scotland } \\
\text { [BES Wave 4: } 5,387 \text { obs.] }\end{array}$} \\
\hline & All & $F L H$ & $F L L$ & (p-value) & All & $F L H$ & FLL & (p-value) \\
\hline & (1) & $(\underline{2})$ & (ㅁ) & $(\underline{4})$ & $(\underline{5})$ & $(\underline{6})$ & $(\underline{7})$ & $(\underline{8})$ \\
\hline $\mathrm{RD}_{1}$ & 5.15 & 4.86 & 5.92 & $(0.000)$ & 6.23 & 5.98 & 6.84 & $(0.000)$ \\
\hline $\mathrm{RD}_{2}$ & 3.43 & 3.35 & 3.63 & $(0.000)$ & 3.71 & 3.67 & 3.82 & $(0.002)$ \\
\hline Male & $49.4 \%$ & $53.4 \%$ & $40.1 \%$ & $(0.000)$ & $47.7 \%$ & $53.0 \%$ & $36.1 \%$ & $(0.000)$ \\
\hline Age & 47.45 & 49.42 & 42.93 & $(0.000)$ & 46.61 & 47.68 & 44.28 & $(0.000)$ \\
\hline Years of education & 12.66 & 13.06 & 11.74 & $(0.000)$ & 12.66 & 13.23 & 11.42 & $(0.000)$ \\
\hline Married & $58.5 \%$ & $62.2 \%$ & $50.0 \%$ & $(0.000)$ & $60.8 \%$ & $62.3 \%$ & $57.5 \%$ & $(0.021)$ \\
\hline Single & $22.6 \%$ & $19.7 \%$ & $29.3 \%$ & $(0.000)$ & $27.8 \%$ & $26.8 \%$ & $29.9 \%$ & $(0.113)$ \\
\hline Widowed/divorced/separated & $10.5 \%$ & $10.3 \%$ & $11.1 \%$ & $(0.442)$ & $11.4 \%$ & $10.9 \%$ & $12.6 \%$ & $(0.216)$ \\
\hline Household size & 2.56 & 2.51 & 2.66 & $(0.005)$ & 2.48 & 2.47 & 2.51 & $(0.359)$ \\
\hline Has young children & $21.4 \%$ & $20.5 \%$ & $23.5 \%$ & $(0.096)$ & $20.5 \%$ & $19.7 \%$ & $22.3 \%$ & $(0.162)$ \\
\hline Urban region & $60.2 \%$ & $58.6 \%$ & $64.1 \%$ & $(0.005)$ & $35.4 \%$ & $35.5 \%$ & $35.1 \%$ & $(0.873)$ \\
\hline Race: White & $91.0 \%$ & $92.9 \%$ & $86.7 \%$ & $(0.000)$ & $96.5 \%$ & $96.9 \%$ & $95.7 \%$ & $(0.132)$ \\
\hline -"-: Black & $2.0 \%$ & $2.0 \%$ & $1.9 \%$ & $(0.904)$ & $0.1 \%$ & $0.1 \%$ & $0.2 \%$ & $(0.467)$ \\
\hline -"'-: Mixed & $1.2 \%$ & $1.1 \%$ & $1.6 \%$ & $(0.258)$ & $0.6 \%$ & $0.8 \%$ & $0.2 \%$ & $(0.019)$ \\
\hline -”-: Asian & $3.8 \%$ & $2.3 \%$ & $7.2 \%$ & $(0.000)$ & $0.8 \%$ & $0.7 \%$ & $1.0 \%$ & $(0.479)$ \\
\hline -"'-: Other & $2.0 \%$ & $1.8 \%$ & $2.6 \%$ & $(0.189)$ & $2.0 \%$ & $1.6 \%$ & $2.9 \%$ & $(0.034)$ \\
\hline Personal income & $21,042.0$ & $22,984.1$ & $16,582.2$ & $(0.000)$ & $16,710.6$ & $18,690.9$ & $12,407.7$ & $7(0.000)$ \\
\hline Household income & $32,350.2$ & $35,385.6$ & $25,379.7$ & $(0.000)$ & $29,603.1$ & $32,657.3$ & $22,966.9$ & $9(0.000)$ \\
\hline House owner & $30.7 \%$ & $34.4 \%$ & $22.3 \%$ & $(0.000)$ & $27.6 \%$ & $30.7 \%$ & $20.8 \%$ & $(0.000)$ \\
\hline Has mortgage & $28.5 \%$ & $31.0 \%$ & $22.8 \%$ & $(0.000)$ & $29.4 \%$ & $32.2 \%$ & $23.1 \%$ & $(0.000)$ \\
\hline Income shock & $14.8 \%$ & $13.5 \%$ & $17.9 \%$ & $(0.002)$ & $9.9 \%$ & $8.8 \%$ & $12.3 \%$ & $(0.012)$ \\
\hline Father entrepreneur & $5.8 \%$ & $6.2 \%$ & $4.8 \%$ & $(0.130)$ & $4.7 \%$ & $5.2 \%$ & $3.6 \%$ & $(0.058)$ \\
\hline Attended private school & $18.4 \%$ & $16.6 \%$ & $22.5 \%$ & $(0.001)$ & $11.6 \%$ & $11.6 \%$ & $11.7 \%$ & $(0.954)$ \\
\hline Risk-taking & 2.54 & 2.54 & 2.54 & $(0.990)$ & 2.60 & 2.63 & 2.53 & $(0.003)$ \\
\hline Left-right orientation & 5.14 & 5.19 & 5.03 & $(0.049)$ & 4.65 & 4.62 & 4.73 & $(0.116)$ \\
\hline Social desirability & 1.94 & 1.98 & 1.82 & $(0.001)$ & 1.89 & 1.91 & 1.83 & $(0.106)$ \\
\hline Religious & $55.2 \%$ & $55.0 \%$ & $55.6 \%$ & $(0.788)$ & $51.4 \%$ & $50.3 \%$ & $53.9 \%$ & $(0.089)$ \\
\hline Occ. status: Self-employed & $7.0 \%$ & $8.2 \%$ & $4.3 \%$ & $(0.000)$ & $4.8 \%$ & $5.4 \%$ & $3.3 \%$ & $(0.001)$ \\
\hline -"-: Full-time employed & $37.8 \%$ & $38.9 \%$ & $35.2 \%$ & $(0.073)$ & $35.6 \%$ & $38.0 \%$ & $30.2 \%$ & $(0.000)$ \\
\hline -"-: Part-time employed & $11.5 \%$ & $10.5 \%$ & $13.8 \%$ & $(0.021)$ & $11.3 \%$ & $10.8 \%$ & $12.4 \%$ & $(0.220)$ \\
\hline -"-: Unemployed & $3.5 \%$ & $2.7 \%$ & $5.2 \%$ & $(0.006)$ & $4.3 \%$ & $3.9 \%$ & $5.2 \%$ & $(0.161)$ \\
\hline -"-: Student & $5.9 \%$ & $5.0 \%$ & $7.8 \%$ & $(0.024)$ & $7.9 \%$ & $7.8 \%$ & $8.1 \%$ & $(0.832)$ \\
\hline -"-: Retired & $22.8 \%$ & $24.9 \%$ & $17.9 \%$ & $(0.000)$ & $20.9 \%$ & $22.3 \%$ & $17.7 \%$ & $(0.003)$ \\
\hline -"-: Inactive & $11.5 \%$ & $9.7 \%$ & $15.6 \%$ & $(0.000)$ & $14.8 \%$ & $11.4 \%$ & $22.1 \%$ & $(0.000)$ \\
\hline Trade union member & $15.4 \%$ & $17.3 \%$ & $11.0 \%$ & $(0.000)$ & $2.9 \%$ & $2.8 \%$ & $2.9 \%$ & $(0.915)$ \\
\hline Agreeableness & 6.06 & 6.06 & 6.06 & $(0.989)$ & 6.03 & 5.98 & 6.14 & $(0.024)$ \\
\hline Conscientiousness & 6.75 & 6.87 & 6.49 & $(0.000)$ & 6.49 & 6.60 & 6.27 & $(0.000)$ \\
\hline Extraversion & 4.16 & 4.07 & 4.36 & $(0.000)$ & 4.14 & 4.06 & 4.31 & $(0.002)$ \\
\hline Neuroticism & 3.76 & 3.61 & 4.10 & $(0.000)$ & 3.83 & 3.68 & 4.16 & $(0.000)$ \\
\hline Openness & 5.50 & 5.53 & 5.42 & $(0.078)$ & 5.53 & 5.59 & 5.41 & $(0.009)$ \\
\hline Home oeconomicus effect [HOE] & 0.00 & 0.11 & -0.27 & $(0.000)$ & -0.02 & 0.10 & -0.29 & $(0.000)$ \\
\hline Public value effect [PVE] & 0.00 & 0.04 & -0.08 & $(0.007)$ & 0.06 & 0.06 & 0.05 & $(0.748)$ \\
\hline Social rivalry effect [SRE] & 0.00 & 0.01 & -0.03 & $(0.216)$ & 0.02 & 0.00 & 0.07 & $(0.123)$ \\
\hline Downward-value differential [DVD] & 0.00 & 0.03 & -0.06 & $(0.024)$ & 0.02 & 0.01 & 0.02 & $(0.871)$ \\
\hline Upward-value differential [UVD] & 0.00 & 0.00 & 0.00 & $(0.898)$ & -0.02 & 0.01 & -0.09 & $(0.009)$ \\
\hline
\end{tabular}

Notes: Weighted averages from the British Election Study. HOE, PVE, SRE, DVD and UVD are in normalized values. The p-values in parentheses stem from weighted t-tests of mean differences between individuals with high financial literacy $(F L H)$ and low financial literacy $(F L L)$. 
Table 4

Regressions: Attitudes towards redistribution and financial literacy in Great Britain (BES, 2014, Wave 2)

\begin{tabular}{|c|c|c|c|c|c|c|}
\hline \multicolumn{7}{|c|}{ Panel A: Dependent variable - RD $D_{l}$ "Government should try to make incomes more equal" } \\
\hline \multirow{3}{*}{ Financial literacy: \#Correct responses } & $(\underline{1})$ & $(\underline{2})$ & $(\underline{3})$ & $(\underline{4})$ & $(\underline{5})$ & $(\underline{6})$ \\
\hline & $-0.537 * * *$ & $-0.449 * * *$ & $-0.440 * * *$ & $-0.402 * * *$ & $-0.661 * * *$ & $-0.617 * * *$ \\
\hline & {$[0.058]$} & [0.059] & {$[0.059]$} & {$[0.060]$} & {$[0.154]$} & [0.137] \\
\hline$\%$ Financial-literacy effect & $-10.4 \%$ & $-8.7 \%$ & $-8.6 \%$ & $-7.8 \%$ & $-12.9 \%$ & $-12.0 \%$ \\
\hline Linear prediction & 5.147 & 5.134 & 5.134 & 5.134 & 5.134 & 5.134 \\
\hline \#Observations & 5,066 & 4,895 & 4,895 & 4,895 & 4,895 & 4,895 \\
\hline$R^{2}$ & 0.029 & 0.231 & 0.220 & 0.224 & 0.225 & 0.225 \\
\hline \multicolumn{7}{|c|}{ Panel B: Dependent variable $-R D_{2}$ : "Government should redistribute income from the better off to those who are less well off" } \\
\hline \multirow{3}{*}{ Financial literacy: \#Correct responses } & (7) & $(\underline{8})$ & $(\underline{9})$ & $(\underline{10})$ & $(\underline{11})$ & $(\underline{12})$ \\
\hline & $-0.151 * * *$ & $-0.116 * * *$ & $-0.117 * * *$ & $-0.105 * * *$ & $-0.274 * * *$ & $-0.194 * * *$ \\
\hline & {$[0.020]$} & {$[0.022]$} & {$[0.022]$} & {$[0.022]$} & {$[0.057]$} & {$[0.054]$} \\
\hline$\%$ Financial-literacy effect & $-4.4 \%$ & $-3.4 \%$ & $-3.4 \%$ & $-3.1 \%$ & $-8.0 \%$ & $-5.7 \%$ \\
\hline Linear prediction & 3.428 & 3.425 & 3.425 & 3.425 & 3.425 & 3.425 \\
\hline \#Observations & 5,297 & 5,101 & 5,101 & 5,101 & 5,101 & 5,101 \\
\hline$R^{2}$ & 0.017 & 0.244 & 0.233 & 0.236 & 0.239 & 0.237 \\
\hline \multicolumn{7}{|l|}{ Control variables for both Panels A and B: } \\
\hline Individual characteristics & - & + & + & + & + & + \\
\hline Education (dummy variables) & - & + & - & - & - & - \\
\hline Age (dummy variables) & - & + & - & - & - & - \\
\hline Personal income (dummy variables) & - & + & - & - & - & - \\
\hline Years of education & - & - & + & + & + & + \\
\hline $\log ($ Age $)$ & - & - & + & + & + & + \\
\hline $\log ($ Personal income $)$ & - & - & + & + & + & + \\
\hline $\log (\text { Personal income })^{\wedge} 2$ and ${ }^{\wedge} 3$ & - & - & - & + & + & + \\
\hline Log(Household income $)$ & - & - & - & + & + & + \\
\hline $\log (\text { Household income })^{\wedge} 2$ & - & - & - & + & + & + \\
\hline $\log ($ Personal income $) * \log ($ Household income $)$ & - & - & - & + & + & + \\
\hline Financial literacy*Years of education & - & - & - & - & + & - \\
\hline $\begin{array}{l}\text { Fin. literacy* } \log (\text { Personal income }) * \text { Years of } \\
\text { education* } \log (\text { Age })\end{array}$ & - & - & - & - & - & + \\
\hline
\end{tabular}

Notes: Individual characteristics are shown in detail in Appendix Table A3 and discussed in Section 3. All estimates are weighted using population level weights. Robust standard errors in brackets. Asterisks denote the following levels of significance: $* * * \mathrm{p}<0.01, * * \mathrm{p}<0.05, * \mathrm{p}<0.1$. 
Table 5

Attitudes to redistribution and financial literacy in Scotland (BES, 2014, Wave 4)

\begin{tabular}{cccc}
\hline \hline Panel A: Dependent variable $-R D_{1}:$ "Government should try to make incomes more equal" & \\
\hline & $(\underline{1})$ & $(\underline{2})$ & $(\underline{3})$ \\
Financial literacy: \#Correct responses & $-0.283^{* * *}$ & $-0.246^{* * *}$ & $-0.369^{* *}$ \\
& {$[0.061]$} & {$[0.062]$} & {$[0.157]$} \\
\% Financial-literacy effect & $-4.5 \%$ & $-3.9 \%$ & $-5.9 \%$ \\
Linear prediction & 6.239 & 6.239 & 6.239 \\
\#Observations & 4,989 & 4,989 & 4,989 \\
$R^{2}$ & 0.251 & 0.249 & 0.249 \\
\hline
\end{tabular}

Panel B:

Dep. variable $-R D_{2}$ : "Government should redistribute income from the better off to those who are less well off"

Financial literacy: \#Correct responses

$(\underline{4}) \quad(\underline{5}) \quad(\underline{6})$

$-0.088 * * * \quad-0.069 * * * \quad-0.155 * * *$
\% Financial-literacy effect
Linear prediction
\#Observations
$R^{2}$

[0.021] [0.021]

[0.058]

\begin{tabular}{|c|c|c|c|}
\hline $\begin{array}{c}\text { \% Financial-literacy effect } \\
\text { Linear prediction } \\
\text { \#Observations } \\
R^{2}\end{array}$ & $\begin{array}{l}-2.4 \% \\
3.719 \\
4,986 \\
0.236\end{array}$ & $\begin{array}{r}-1.9 \% \\
3.719 \\
4,986 \\
0.237\end{array}$ & $\begin{array}{l}-4.2 \% \\
3.709 \\
4,986 \\
0.236\end{array}$ \\
\hline Individual characteristics & + & + & + \\
\hline Education (dummy variables) & + & - & - \\
\hline Age (dummy variables) & + & - & - \\
\hline Personal income (dummy variables) & + & - & - \\
\hline Years of education & - & + & + \\
\hline $\log ($ Age $)$ & - & + & + \\
\hline Log(Personal income) & - & + & + \\
\hline $\log (\text { Personal income })^{\wedge} 2$ and ${ }^{\wedge} 3$ & - & + & + \\
\hline Log(Household income $)$ & - & + & + \\
\hline $\log (\text { Household income })^{\wedge} 2$ & - & + & + \\
\hline $\log ($ Personal income $) * \log ($ Household income $)$ & - & + & + \\
\hline $\begin{array}{l}\text { Financial literacy*Log(Personal income }) * \text { Years of } \\
\text { education*Log }(\text { Age })\end{array}$ & - & - & + \\
\hline
\end{tabular}

Notes: Individual characteristics include the set of controls, which is shown in detail in Appendix Table A3 and discussed in Section 3. All estimates are weighted using population level weights. Robust standard errors in brackets. Asterisks denote the following levels of significance: *** $\mathrm{p}<0.01, * * \mathrm{p}<0.05, * \mathrm{p}<0.1$. 
Table 6

Predicted probabilities and financial literacy effects

\begin{tabular}{|c|c|c|c|c|c|c|c|c|c|c|c|}
\hline \multicolumn{12}{|c|}{ Panel A: Dependent variable - RD $D_{1}$ " Government should try to make incomes more equal" } \\
\hline & No -0 & $-1-$ & $-2-$ & $-3-$ & $-4-$ & $-5-$ & $-6-$ & $-7-$ & $-8-$ & $-9-$ & Yes -10 \\
\hline \multicolumn{12}{|l|}{ GB sample [Wave 2] } \\
\hline \multirow[t]{2}{*}{ Fin. literacy AME } & $0.027 * * *$ & * $0.006 * * *$ & $0.009 * * *$ & $0.011 * * *$ & $0.004 * * *$ & 0.001 & $-0.003 * * *$ & $-0.008 * * *$ & \multirow{2}{*}{$\begin{array}{c}-0.008 * * * \\
{[0.001]}\end{array}$} & \multirow{2}{*}{$\begin{array}{c}-0.006 * * * \\
{[0.001]}\end{array}$} & \multirow{2}{*}{$\begin{array}{c}-0.032 * * * \\
{[0.004]}\end{array}$} \\
\hline & {$[0.004]$} & [0.001] & {$[0.001]$} & {$[0.002]$} & {$[0.001]$} & {$[0.001]$} & {$[0.001]$} & {$[0.001]$} & & & \\
\hline$\%$ Fin. literacy effect & $25.8 \%$ & $17.2 \%$ & $13.9 \%$ & $9.3 \%$ & $5.2 \%$ & $0.4 \%$ & $-4.4 \%$ & $-8.1 \%$ & $-12.0 \%$ & $-15.1 \%$ & $-24.0 \%$ \\
\hline Predicted probability & 0.106 & 0.036 & 0.066 & 0.116 & 0.076 & 0.176 & 0.079 & 0.101 & 0.066 & 0.042 & 0.135 \\
\hline \#Observations & 4,895 & 4,895 & 4,895 & 4,895 & 4,895 & 4,895 & 4,895 & 4,895 & 4,895 & 4,895 & 4,895 \\
\hline \multicolumn{12}{|l|}{ Scottish sample [Wave 4] } \\
\hline \multirow[t]{2}{*}{ Fin. literacy AME } & $0.013 * * *$ & $0.002 * * *$ & $0.006 * * *$ & $0.008 * * *$ & $0.004 * * *$ & $0.005 * * *$ & $* 0.001 * * *$ & $-0.002 * * *$ & \multirow{2}{*}{$\begin{array}{c}*-0.003 * * * \\
{[0.001]}\end{array}$} & \multirow{2}{*}{$\begin{array}{c}-0.003 * * * \\
{[0.001]}\end{array}$} & \multirow{2}{*}{$\begin{array}{c}-0.031 * * * \\
{[0.005]}\end{array}$} \\
\hline & {$[0.002]$} & {$[0.000]$} & {$[0.001]$} & {$[0.001]$} & {$[0.001]$} & {$[0.001]$} & {$[0.000]$} & {$[0.000]$} & & & \\
\hline \% Fin. literacy effect & $19.0 \%$ & $14.0 \%$ & $12.0 \%$ & $9.0 \%$ & $6.5 \%$ & $3.7 \%$ & $0.8 \%$ & $-1.6 \%$ & $-4.1 \%$ & $-6.1 \%$ & $-12.6 \%$ \\
\hline Predicted probability & 0.068 & 0.018 & 0.051 & 0.088 & 0.063 & 0.136 & 0.084 & 0.111 & 0.083 & 0.055 & 0.244 \\
\hline \#Observations & 4,989 & 4,989 & 4,989 & 4,989 & 4,989 & 4,989 & 4,989 & 4,989 & 4,989 & 4,989 & 4,989 \\
\hline \multicolumn{12}{|c|}{ Panel B: Dependent variable $-R D_{2}:$ "Government should redistribute income from the better off to those who are less well off" } \\
\hline & \multicolumn{3}{|c|}{1 - Strongly Disagree } & $-2-\quad 3$ & \multicolumn{3}{|c|}{3 - Neither agree nor disagree } & \multicolumn{2}{|c|}{$-4-$} & \multicolumn{2}{|c|}{5 - Strongly Agree } \\
\hline \multicolumn{12}{|l|}{ GB sample [Wave 2] } \\
\hline \multirow[t]{2}{*}{ Fin. literacy AME } & \multirow{2}{*}{\multicolumn{2}{|c|}{$\begin{array}{l}0.011 * * * \\
{[0.002]}\end{array}$}} & \multirow{2}{*}{\multicolumn{2}{|c|}{$\begin{array}{l}0.020 * * * \\
{[0.004]}\end{array}$}} & \multicolumn{3}{|c|}{$0.009 * * *$} & \multirow{2}{*}{\multicolumn{2}{|c|}{$-0.013 * * *$}} & \multicolumn{2}{|c|}{$-0.027 * * *$} \\
\hline & & & & & \multirow{2}{*}{\multicolumn{2}{|c|}{$\begin{array}{l}{[0.002]} \\
3.6 \%\end{array}$}} & & & & {$[0.0$} & 06] \\
\hline$\%$ Fin. literacy effect & \multicolumn{2}{|c|}{$21.0 \%$} & \multicolumn{2}{|r|}{$11.0 \%$} & & & \multicolumn{3}{|c|}{$-3.9 \%$} & -14.2 & \\
\hline Predicted probability & & 0.052 & & 0.184 & & 0.244 & & 0.329 & & 0.15 & \\
\hline \#Observations & & 5,101 & & 5,101 & & 5,101 & & 5,101 & & 5,10 & \\
\hline Scottish sample [Wave 4] & & & & & & & & & & & \\
\hline Fin. literacy AME & & $.007 * * *$ & & $0.014 * * *$ & & $0.010 * * *$ & & $-0.003 * *$ & & -0.02 & $7 * * *$ \\
\hline & & {$[0.002]$} & & {$[0.003]$} & & {$[0.002]$} & & {$[0.001]$} & & {$[0.0$} & 06] \\
\hline \% Fin. literacy effect & & $17.2 \%$ & & $10.3 \%$ & & $5.0 \%$ & & $-0.9 \%$ & & -9.4 & \\
\hline Predicted probability & & 0.038 & & 0.133 & & 0.203 & & 0.336 & & 0.25 & \\
\hline \#Observations & & 4,986 & & 4,986 & & 4,986 & & 4,986 & & 4,98 & \\
\hline
\end{tabular}

Notes: Each panel shows the predicted probability of each response category of $R D_{1}$ and $R D_{2}$, from ordered probit regressions reported in the Appendix Table A3. The response categories are 0-10 for $R D_{1}$, and 1-5 for $R D_{2}$, respectively. Probability changes due to an additional correct financialliteracy response (i.e. the average marginal effect) are reported, along with the percentage effect of financial literacy (i.e. the ratio between the average marginal effect and the predicted probability for each category). The estimates are weighted and robust standard errors of the AME are reported in brackets. Asterisks denote the following levels of significance: $* * * \mathrm{p}<0.01, * * \mathrm{p}<0.05, * \mathrm{p}<0.1$. 
Table 7

Falsification tests and counterfactual hypotheses

Panel A: Financial literacy and attitudes to equality rights - Please say whether you think these have gone too far [5] or have not gone nearly far enough in Britain [1]

\begin{tabular}{|c|c|c|c|c|c|c|}
\hline \multirow[b]{2}{*}{$\begin{array}{l}\text { Dep. Variable: } \\
\text { Attempts to give equal } \\
\text { opportunities to: }\end{array}$} & \multicolumn{3}{|c|}{ GB sample } & \multicolumn{3}{|c|}{$\underline{\text { Scottish sample }}$} \\
\hline & $\begin{array}{c}\text { Gays and } \\
\text { lesbians }\end{array}$ & Women & $\begin{array}{c}\text { Ethnic } \\
\text { minorities }\end{array}$ & $\begin{array}{c}\text { Gays and } \\
\text { lesbians }\end{array}$ & Women & $\begin{array}{c}\text { Ethnic } \\
\text { minorities }\end{array}$ \\
\hline Financial literacy: & $(\underline{1})$ & $(\underline{2})$ & $(\underline{3})$ & $(\underline{4})$ & $(\underline{5})$ & $(\underline{6})$ \\
\hline \#Correct responses & $\begin{array}{c}0.001 \\
{[0.022]}\end{array}$ & $\begin{array}{l}-0.023 \\
{[0.018]}\end{array}$ & $\begin{array}{l}-0.027 \\
{[0.021]}\end{array}$ & $\begin{array}{l}-0.010 \\
{[0.022]}\end{array}$ & $\begin{array}{c}0.025 \\
{[0.019]}\end{array}$ & $\begin{array}{l}-0.031 \\
{[0.021]}\end{array}$ \\
\hline Linear prediction & 3.142 & 2.735 & 3.392 & 2.992 & 2.561 & 3.207 \\
\hline \#Observations & 5,007 & 5,104 & 4,988 & 4,872 & 4,974 & 4,857 \\
\hline$R^{2}$ & 0.216 & 0.140 & 0.213 & 0.245 & 0.143 & 0.208 \\
\hline
\end{tabular}

Panel B: Financial illiteracy and attitudes to redistribution: \# Incorrect and \#DK/DA responses

\begin{tabular}{|c|c|c|c|c|c|c|c|c|}
\hline \multirow[b]{2}{*}{ Dependent. Variable: } & \multicolumn{4}{|c|}{ GB sample } & \multicolumn{4}{|c|}{ Scottish sample } \\
\hline & \multicolumn{2}{|c|}{$R D_{1}$} & \multicolumn{2}{|c|}{$R D_{2}$} & \multicolumn{2}{|c|}{$R D_{1}$} & \multicolumn{2}{|c|}{$R D_{2}$} \\
\hline Financial illiteracy: & (7) & () & $(\underline{9})$ & $(\underline{10})$ & (11) & (12) & $(\underline{13})$ & $(14)$ \\
\hline \#Wrong responses & $\begin{array}{c}0.241 * * * \\
{[0.084]}\end{array}$ & - & $\begin{array}{c}0.101 * * * \\
{[0.029]}\end{array}$ & - & $\begin{array}{c}0.214 * * * \\
{[0.082]}\end{array}$ & - & $\begin{array}{c}0.109 * * * \\
{[0.029]}\end{array}$ & - \\
\hline \#DK/DA responses & - & $\begin{array}{r}0.440 * * * \\
{[0.071]}\end{array}$ & - & $\begin{array}{c}0.075 * * * \\
{[0.026]}\end{array}$ & - & $\begin{array}{c}0.208 * * * \\
{[0.077]}\end{array}$ & - & $\begin{array}{c}0.036 \\
{[0.024]}\end{array}$ \\
\hline \% Fin.-illiteracy effect & $4.7 \%$ & $8.6 \%$ & $2.9 \%$ & $2.2 \%$ & $3.4 \%$ & $3.3 \%$ & $2.9 \%$ & $1.0 \%$ \\
\hline Linear prediction & 5.134 & 5.134 & 3.425 & 3.425 & 6.239 & 6.239 & 3.719 & 3.719 \\
\hline \#Observations & 4,895 & 4,895 & 5,101 & 5,101 & 4,989 & 4,989 & 4,986 & 4,986 \\
\hline$R^{2}$ & 0.218 & 0.225 & 0.239 & 0.238 & 0.246 & 0.247 & 0.235 & 0.232 \\
\hline \multicolumn{9}{|c|}{ Panel C: Financial literacy components and attitudes to redistribution } \\
\hline Financial literacy: & $(\underline{15})$ & $(\underline{16})$ & $(\underline{17})$ & $(\underline{18})$ & $(\underline{19})$ & $(\underline{20})$ & $(\underline{21})$ & (22) \\
\hline Interest: Correct & $\begin{array}{c}-0.363 * * \\
{[0.169]}\end{array}$ & - & $\begin{array}{c}-0.196 * * * \\
{[0.056]}\end{array}$ & - & $\begin{array}{l}-0.076 \\
{[0.171]}\end{array}$ & - & $\begin{array}{l}-0.023 \\
{[0.060]}\end{array}$ & - \\
\hline Inflation: Correct & $\begin{array}{c}-0.529 * * * \\
{[0.137]}\end{array}$ & - & $\begin{array}{c}-0.03 \\
{[0.048]}\end{array}$ & - & $\begin{array}{l}-0.225^{*} \\
{[0.134]}\end{array}$ & - & $\begin{array}{c}-0.118^{* *} \\
{[0.049]}\end{array}$ & - \\
\hline Risk: Correct & $\begin{array}{c}-0.435 * * * \\
{[0.114]}\end{array}$ & - & $\begin{array}{c}-0.112 * * * \\
{[0.041]}\end{array}$ & - & $\begin{array}{c}-0.478 * * * \\
{[0.113]}\end{array}$ & - & $\begin{array}{c}-0.105^{* *} \\
{[0.041]}\end{array}$ & - \\
\hline Interest: Wrong & - & $\begin{array}{c}0.317 \\
{[0.213]}\end{array}$ & - & $\begin{array}{l}0.176 * * \\
{[0.071]}\end{array}$ & - & $\begin{array}{c}0.005 \\
{[0.222]}\end{array}$ & - & $\begin{array}{c}0.019 \\
{[0.083]}\end{array}$ \\
\hline Inflation: Wrong & - & $\begin{array}{c}0.342 \\
{[0.250]}\end{array}$ & - & $\begin{array}{c}0.265 * * * \\
{[0.080]}\end{array}$ & - & $\begin{array}{c}0.212 \\
{[0.249]}\end{array}$ & - & $\begin{array}{c}0.088 \\
{[0.082]}\end{array}$ \\
\hline Risk: Wrong & - & $\begin{array}{l}0.462 * * \\
{[0.182]}\end{array}$ & - & $\begin{array}{c}0.064 \\
{[0.064]}\end{array}$ & - & $\begin{array}{c}0.322 * \\
{[0.166]}\end{array}$ & - & $\begin{array}{c}0.191 * * * \\
{[0.060]}\end{array}$ \\
\hline Interest: DK/DA & - & $\begin{array}{c}0.541 * * * \\
{[0.185]}\end{array}$ & - & $\begin{array}{l}-0.012 \\
{[0.063]}\end{array}$ & - & $\begin{array}{c}0.062 \\
{[0.184]}\end{array}$ & - & $\begin{array}{c}0.023 \\
{[0.063]}\end{array}$ \\
\hline Inflation: DK/DA & - & $\begin{array}{c}0.343 * * * \\
{[0.131]}\end{array}$ & - & $\begin{array}{c}0.131 * * * \\
{[0.047]}\end{array}$ & - & $\begin{array}{c}0.440 * * * \\
{[0.130]}\end{array}$ & - & $\begin{array}{r}0.103 * * \\
{[0.048]}\end{array}$ \\
\hline Risk: DK/DA & - & $\begin{array}{c}0.608 * * * \\
{[0.148]}\end{array}$ & - & $\begin{array}{c}0.080 \\
{[0.053]}\end{array}$ & - & $\begin{array}{c}0.555^{* * *} * \\
{[0.147]}\end{array}$ & - & $\begin{array}{r}0.118^{* * *} \\
{[0.050]} \\
\end{array}$ \\
\hline Linear prediction & 5.134 & 5.134 & 3.413 & 3.413 & 6.239 & 6.239 & 3.718 & 3.718 \\
\hline No. of Observations & 4,895 & 4,895 & 5,292 & 5,292 & 4,989 & 4,989 & 4,986 & 4,986 \\
\hline$R^{2}$ & 0.231 & 0.232 & 0.242 & 0.243 & 0.252 & 0.253 & 0.234 & 0.235 \\
\hline
\end{tabular}

Notes: The remaining specification is identical to Column 2 of Table 4 and the comments there apply. Asterisks denote the following levels of significance: *** $\mathrm{p}<0.01,{ }^{*} \mathrm{p}<0.05, * \mathrm{p}<0.1$. 
Table 8

Instrumental-variable regressions

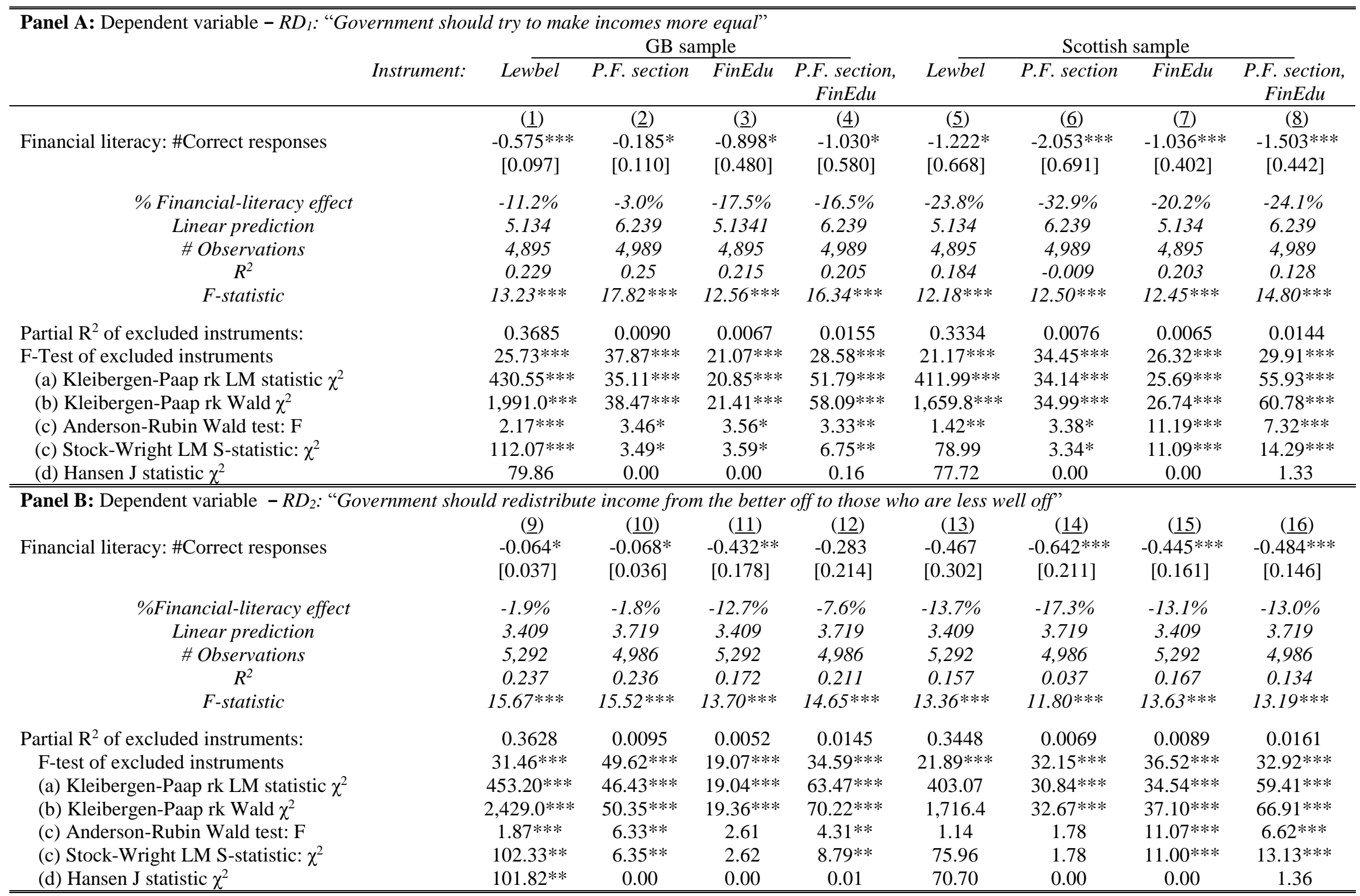

Notes: Individual characteristics include the set of controls, which is shown in detail in Appendix Table A3 and discussed in Section 3 . Estimates are weighted using population level weights. Robust standard errors in brackets. Asterisks denote the following levels of significance: $* * * \mathrm{p}<0.01$, $* * \mathrm{p}<0.05, * \mathrm{p}<0.1$. 
Table 9

Longitudinal models of attitudes to redistribution

\begin{tabular}{|c|c|c|c|c|c|c|}
\hline & \multicolumn{2}{|c|}{$\begin{array}{l}\text { Random effects } \\
\text { GLS }_{[\text {Waves 1-7] }}\end{array}$} & \multicolumn{2}{|c|}{$\begin{array}{l}\text { Weighted Least } \\
\text { Squares }_{\text {[Waves 1-7] }}\end{array}$} & \multicolumn{2}{|c|}{$\underline{\text { WLS }}_{\Delta[\text { wave 2-wave7] }}$} \\
\hline & $R D_{1}$ & $R D_{2}$ & $R D_{1}$ & $R D_{2}$ & $R D_{l}$ & $R D_{2}$ \\
\hline$\underline{\text { GB sample }}$ & $(\underline{1})$ & $(\underline{2})$ & $(\underline{3})$ & $(\underline{4})$ & $(\underline{5})$ & $(\underline{6})$ \\
\hline Financial literacy: \# correct responses & $\begin{array}{c}-0.422 * * * \\
{[0.034]}\end{array}$ & $\begin{array}{c}-0.391 * * * \\
{[0.043]}\end{array}$ & $\begin{array}{c}-0.099 * * * \\
{[0.012]}\end{array}$ & $\begin{array}{c}-0.090 * * * \\
{[0.015]}\end{array}$ & $\begin{array}{c}-0.373 * * * \\
{[0.063]}\end{array}$ & $\begin{array}{l}-0.048 * \\
{[0.025]}\end{array}$ \\
\hline$\%$ Financial-literacy effect & $-8.0 \%$ & $-7.3 \%$ & $-3.0 \%$ & $-2.7 \%$ & $-979.0 \%$ & $-32.4 \%$ \\
\hline Linear prediction & 5.288 & 5.350 & 3.343 & 3.335 & -0.038 & 0.148 \\
\hline \#Observations & 23,042 & 23,042 & 14,073 & 14,073 & 4,895 & 5,101 \\
\hline [Overall] $R^{2}$ & 0.294 & 0.283 & 0.275 & 0.244 & 0.086 & 0.057 \\
\hline Scottish sample & $(\underline{7})$ & $(\underline{8})$ & $(\underline{9})$ & $(\underline{10})$ & $(\underline{11})$ & $(\underline{12})$ \\
\hline Financial literacy: \# correct responses & $\begin{array}{c}-0.336 * * * \\
{[0.034]}\end{array}$ & $\begin{array}{c}-0.322 * * * \\
{[0.045]}\end{array}$ & $\begin{array}{c}-0.063 * * * \\
{[0.012]}\end{array}$ & $\begin{array}{c}-0.070 * * * \\
{[0.016]}\end{array}$ & $\begin{array}{c}-0.188 * * * \\
{[0.061]}\end{array}$ & $\begin{array}{l}-0.034 \\
{[0.021]}\end{array}$ \\
\hline \% Financial-literacy effect & $-5.6 \%$ & $-5.2 \%$ & $-1.7 \%$ & $-1.9 \%$ & $-25.9 \%$ & $-11.8 \%$ \\
\hline Linear prediction & 5.984 & 6.167 & 3.601 & 3.611 & 0.727 & 0.288 \\
\hline \#Observations & 23,852 & 23,852 & 14,055 & 14,055 & 4,989 & 4,986 \\
\hline [Overall] $R^{2}$ & 0.276 & 0.265 & 0.256 & 0.232 & 0.098 & 0.063 \\
\hline
\end{tabular}

Notes: The longitudinal information on $R D_{1}$ is for waves $1,2,3,4,6$ and 7 . The information on $R D_{2}$ stems from waves 1,6 and 7 . The remaining specification is identical to column 2 of Table 4 and the comments there apply. Robust standard errors in brackets. The models in columns 2 and 4 also have the standard errors clustered at the individual level. Asterisks denote the following levels of significance: $* * * p<0.01, * * p<0.05, * p<0.1$. 
Table 10

Mechanisms $\left(R D_{1}\right)$

\begin{tabular}{|c|c|c|c|c|c|c|c|c|c|c|c|c|}
\hline & \multicolumn{6}{|c|}{ Great Britain } & \multicolumn{6}{|c|}{$\underline{\text { Scotland }}$} \\
\hline & All & All & $A l l$ & $\bar{A} l l$ & $F L H$ & $F L L$ & All & All & $A \overline{l l}$ & $\overline{F L H}$ & $F L H$ & $F L L$ \\
\hline & $(\underline{1})$ & $(\underline{2})$ & $(\underline{3})$ & $(\underline{4})$ & $(\underline{5})$ & $(\underline{6})$ & $(\underline{7})$ & $(\underline{8})$ & $(\underline{9})$ & $(\underline{10})$ & $(11)$ & $(\underline{12})$ \\
\hline Homo oeconomicus effect [HOE] & $\begin{array}{c}-0.275 * * * \\
{[0.069]}\end{array}$ & $\begin{array}{c}-0.248 * * * \\
{[0.068]}\end{array}$ & $\begin{array}{c}-0.248 * * * \\
{[0.068]}\end{array}$ & - & $\begin{array}{c}-0.307 * * * \\
{[0.072]}\end{array}$ & $\begin{array}{l}-0.147 \\
{[0.152]}\end{array}$ & $\begin{array}{c}-0.152 * * \\
{[0.061]}\end{array}$ & $\begin{array}{c}-0.130 * * \\
{[0.062]}\end{array}$ & $\begin{array}{c}-0.130 * * \\
{[0.062]}\end{array}$ & - & $\begin{array}{c}-0.135 * * \\
{[0.066]}\end{array}$ & $\begin{array}{l}-0.120 \\
{[0.129]}\end{array}$ \\
\hline Public value effect [PVE] & $\begin{array}{c}-0.518 * * * \\
{[0.064]}\end{array}$ & $\begin{array}{c}-0.505 * * * \\
{[0.063]}\end{array}$ & $\begin{array}{c}-0.506 * * * \\
{[0.063]}\end{array}$ & - & $\begin{array}{c}-0.473 * * * \\
{[0.070]}\end{array}$ & $\begin{array}{c}-0.608 * * * \\
{[0.134]}\end{array}$ & $\begin{array}{c}-0.682 * * * \\
{[0.060]}\end{array}$ & $\begin{array}{c}-0.679 * * * \\
{[0.060]}\end{array}$ & $\begin{array}{c}-0.679 * * * \\
{[0.060]}\end{array}$ & - & $\begin{array}{c}-0.844 * * * \\
{[0.066]}\end{array}$ & $\begin{array}{c}-0.329 * * * \\
{[0.117]}\end{array}$ \\
\hline Social rivalry effect [SRE] & $\begin{array}{c}-0.222 * * * \\
{[0.052]}\end{array}$ & $\begin{array}{c}-0.216^{* * *} \\
{[0.051]}\end{array}$ & & - & $\begin{array}{c}-0.265 * * * \\
{[0.055]}\end{array}$ & $\begin{array}{l}=-0.078 \\
{[0.121]}\end{array}$ & $\begin{array}{c}-0.187 * * * \\
{[0.051]}\end{array}$ & $\begin{array}{c}-0.190 * * * \\
{[0.051]}\end{array}$ & & - & $\begin{array}{c}-0.177 * * * \\
{[0.050]}\end{array}$ & $\begin{array}{l}-0.222 * \\
{[0.121]}\end{array}$ \\
\hline Downward value diff. [SRE $\left.{ }^{\mathrm{DVD}}\right]$ & - & - & $\begin{array}{l}-0.131 * * \\
{[0.054]}\end{array}$ & - & - & - & - & - & $\begin{array}{c}-0.133 * * \\
{[0.064]}\end{array}$ & - & - & - \\
\hline Upward value diff. [SRE $\left.{ }^{\mathrm{UVD}}\right]$ & - & - & $\begin{array}{l}0.127 * * \\
{[0.058]}\end{array}$ & - & - & - & - & - & $\begin{array}{c}0.095^{*} \\
{[0.052]}\end{array}$ & - & - & - \\
\hline Fin. literacy: \# correct responses & - & $\begin{array}{c}-0.420 * * * \\
{[0.059]}\end{array}$ & $\begin{array}{c}-0.420 * * * \\
{[0.059]}\end{array}$ & - & - & - & - & $\begin{array}{c}-0.289 * * * \\
{[0.061]}\end{array}$ & $\begin{array}{c}-0.289 * * * \\
{[0.061]}\end{array}$ & - & - & - \\
\hline FLH & - & - & - & $\begin{array}{c}-0.807 * * * \\
{[0.133]}\end{array}$ & - & - & - & - & - & $\begin{array}{c}-0.476 * * * \\
{[0.130]}\end{array}$ & - & - \\
\hline $\mathrm{HOE}^{*} \mathrm{FLH}$ & - & - & - & $\begin{array}{c}-0.269 * * * \\
{[0.070]}\end{array}$ & - & - & - & - & - & $\begin{array}{l}-0.142 * * \\
{[0.066]}\end{array}$ & - & - \\
\hline $\mathrm{HOE}^{*}(1-\mathrm{FLH})$ & - & - & - & $\begin{array}{l}-0.205 \\
{[0.127]}\end{array}$ & - & - & - & - & - & $\begin{array}{l}-0.101 \\
{[0.117]}\end{array}$ & - & - \\
\hline PVE*FLH & - & - & - & $\begin{array}{c}-0.476 * * * \\
{[0.069]}\end{array}$ & - & - & - & - & - & $\begin{array}{c}-0.833 * * * \\
{[0.065]}\end{array}$ & - & - \\
\hline $\mathrm{PVE}^{*}(1-\mathrm{FLH})$ & - & - & - & $\begin{array}{c}-0.601 * * * \\
{[0.129]}\end{array}$ & - & - & - & - & - & $\begin{array}{c}-0.326^{* * * *} \\
{[0.112]}\end{array}$ & - & - \\
\hline SRE*FLH & - & - & - & $\begin{array}{c}-0.265 * * * \\
{[0.055]}\end{array}$ & - & - & - & - & - & $\begin{array}{c}-0.181 * * * \\
{[0.051]}\end{array}$ & - & - \\
\hline $\mathrm{SRE}^{*}(1-\mathrm{FLH})$ & - & - & - & $\begin{array}{l}-0.061 \\
{[0.128]}\end{array}$ & - & - & - & - & - & $\begin{array}{l}-0.197 \\
{[0.124]}\end{array}$ & - & - \\
\hline $\begin{array}{l}\text { Linear prediction } \\
\text { \# Observations }\end{array}$ & $\begin{array}{l}5.128 \\
4,826\end{array}$ & $\begin{array}{l}5.128 \\
4,826\end{array}$ & $\begin{array}{l}5.128 \\
4,826\end{array}$ & $\begin{array}{l}5.128 \\
4,826\end{array}$ & $\begin{array}{l}4.850 \\
3,817\end{array}$ & $\begin{array}{l}5.910 \\
1,009\end{array}$ & $\begin{array}{l}6.234 \\
4,861\end{array}$ & $\begin{array}{l}6.234 \\
4,861\end{array}$ & $\begin{array}{l}6.234 \\
4,861\end{array}$ & $\begin{array}{l}6.234 \\
4,861\end{array}$ & $\begin{array}{l}5.979 \\
3,810\end{array}$ & $\begin{array}{l}6.861 \\
1,051\end{array}$ \\
\hline
\end{tabular}

Notes: HOE, PVE, SRE, (SRE ${ }^{\mathrm{DVD}}$ and SRE ${ }^{\mathrm{UVD}}$ ) are normalized measures of the homo-oeconomicus, public value and social rivalry effects (downward-value differential and upward-value differential), respectively. These are described at Section 6. The specification is identical to Column 2 of Table 4, excluding the personal income dummies, which can not be used simultaneously with HOE. All estimates are weighted. Robust standard errors are shown in brackets. 
Table 11

Mechanisms $\left(R D_{2}\right)$

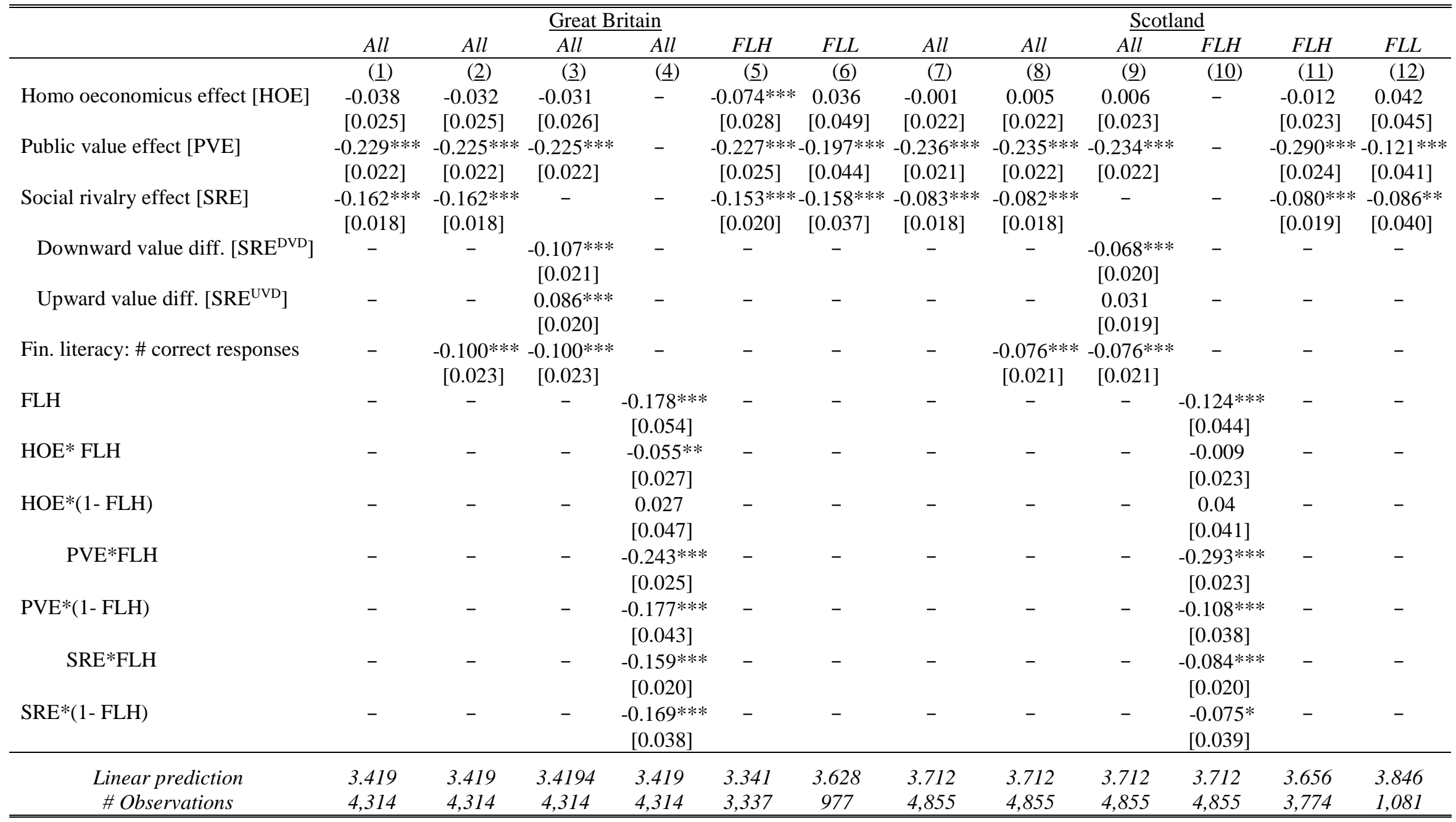

Notes: HOE, PVE, SRE, (SRE ${ }^{\mathrm{DVD}}$ and $\mathrm{SRE} \mathrm{UVD}^{\mathrm{U}}$ ) are normalized measures of the homo-oeconomicus, public value and social rivalry effects (downward-value differential and upward-value differential), respectively. These are described at Section 6. The specification is identical to Column 2 of Table 4, excluding the personal income dummies, which can not be used simultaneously with HOE. All estimates are weighted. Robust standard errors are shown in brackets. 
Figure A1

Average marginal effects of financial literacy on attitudes towards redistribution, by education
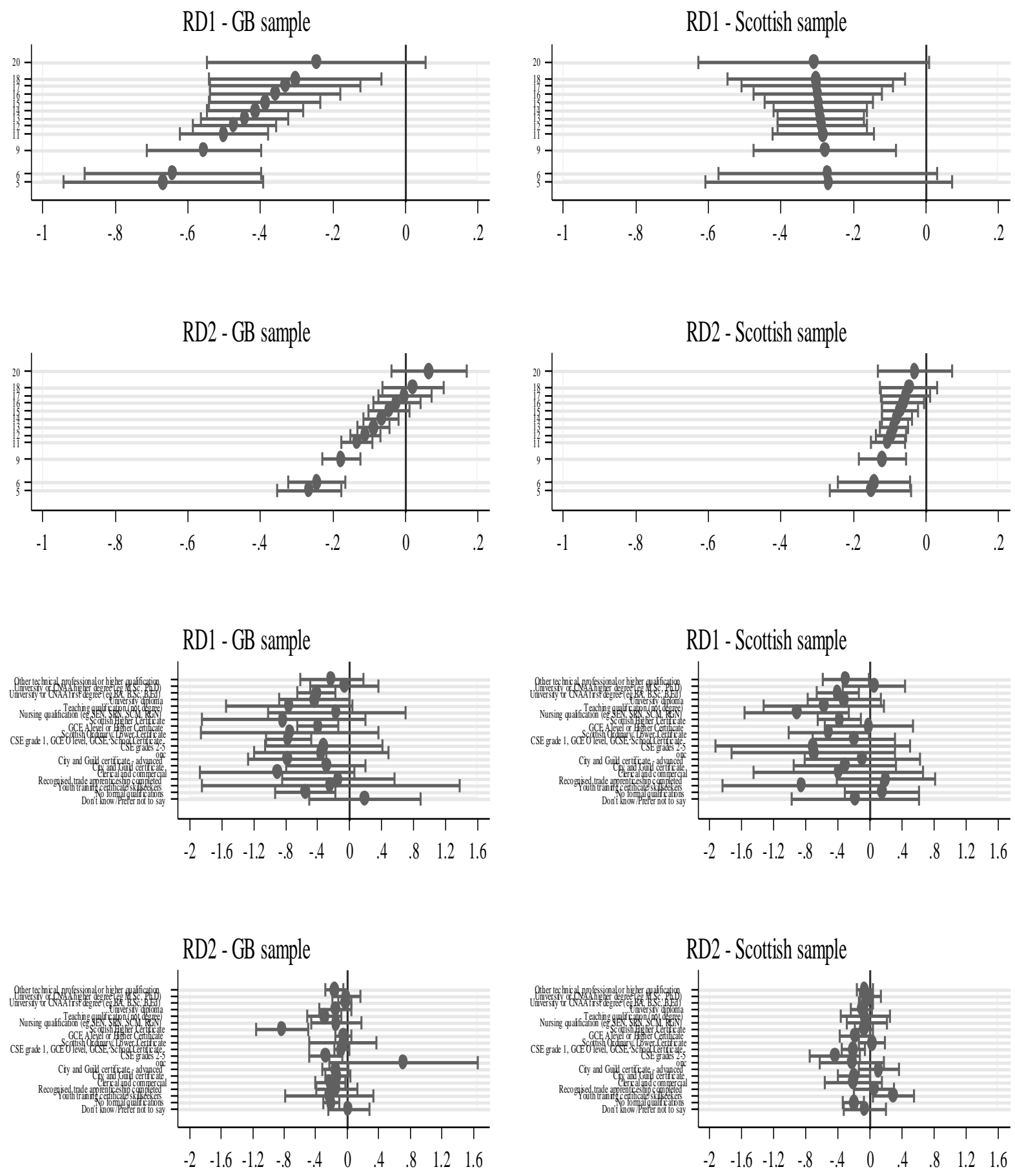

Notes: Each graph plots the impact of financial literacy on attitudes to redistribution, as education varies. The effects presented are from linear regressions that incorporate interaction terms between financial literacy and education variables. The specifications used are those of columns 2 and 3 of Table 4 . The first set of 4 plots uses a continuous variable for years of education, while the bottom set of 4 plots uses educational qualification dummy variables. 


\section{Figure A2}

Average marginal effects of financial literacy on attitudes towards redistribution, by income
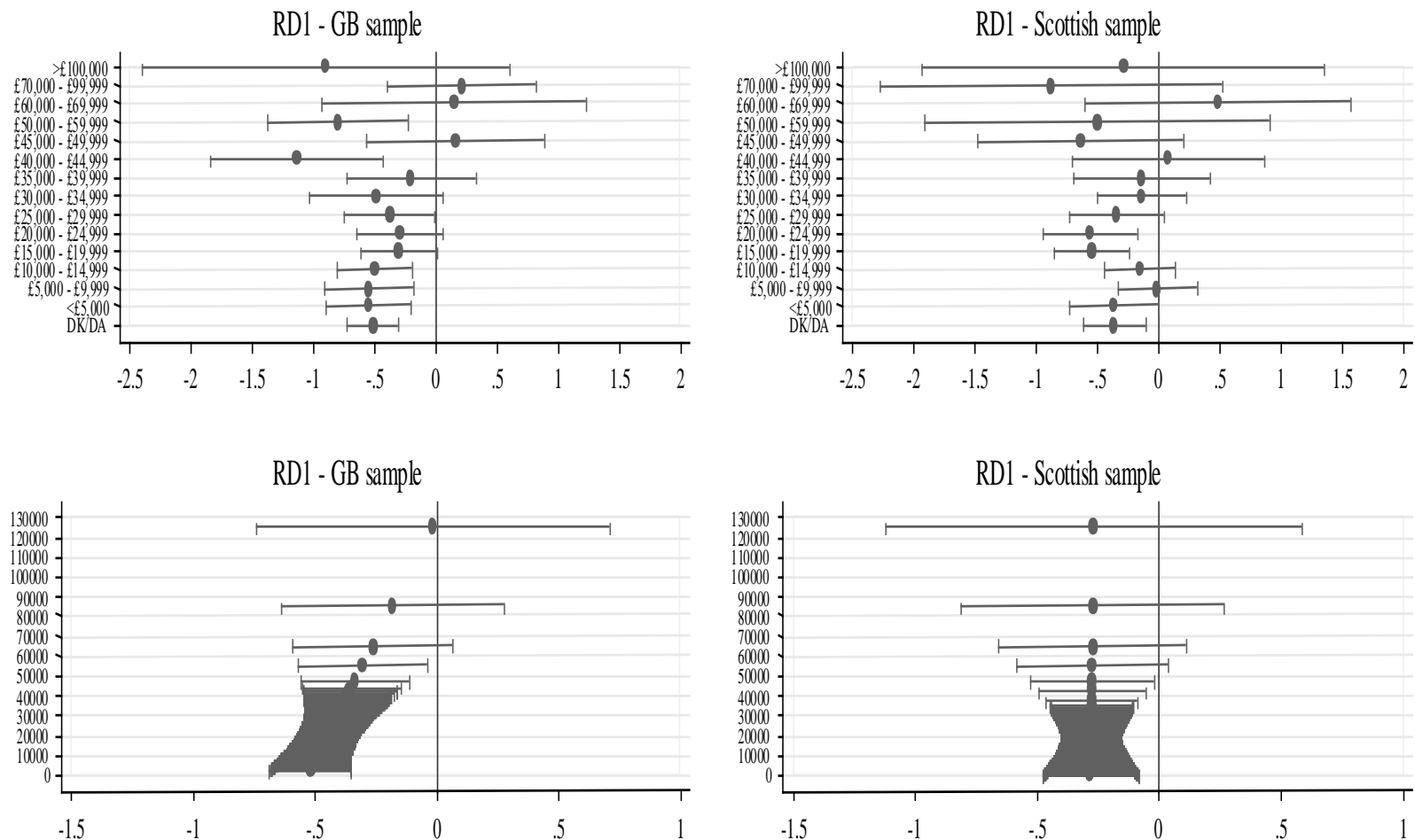

RD2 - GB sample
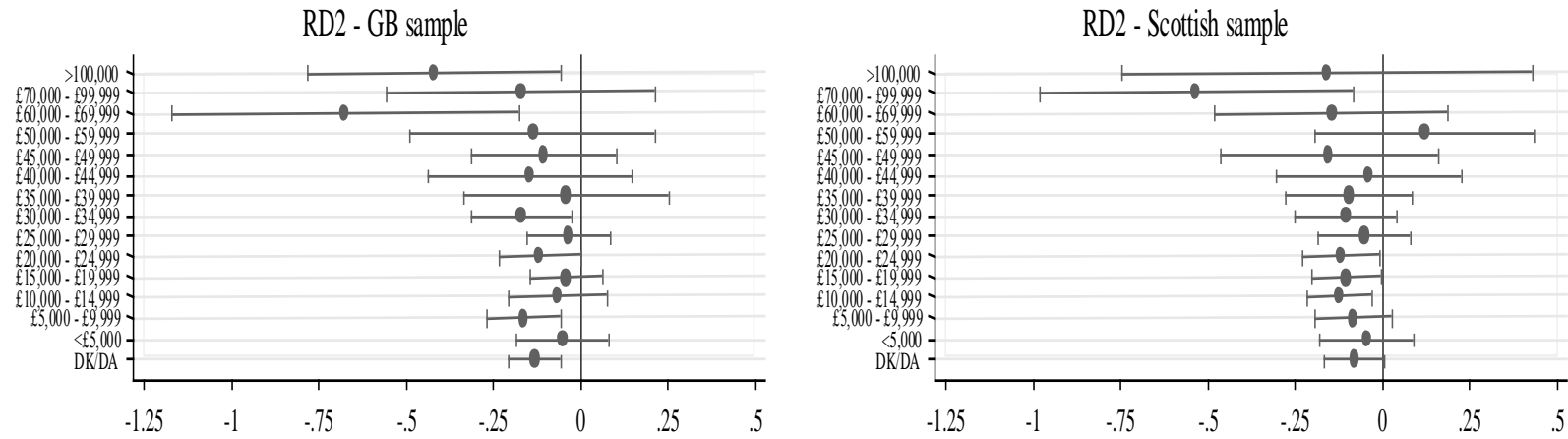

RD2 - GB sample
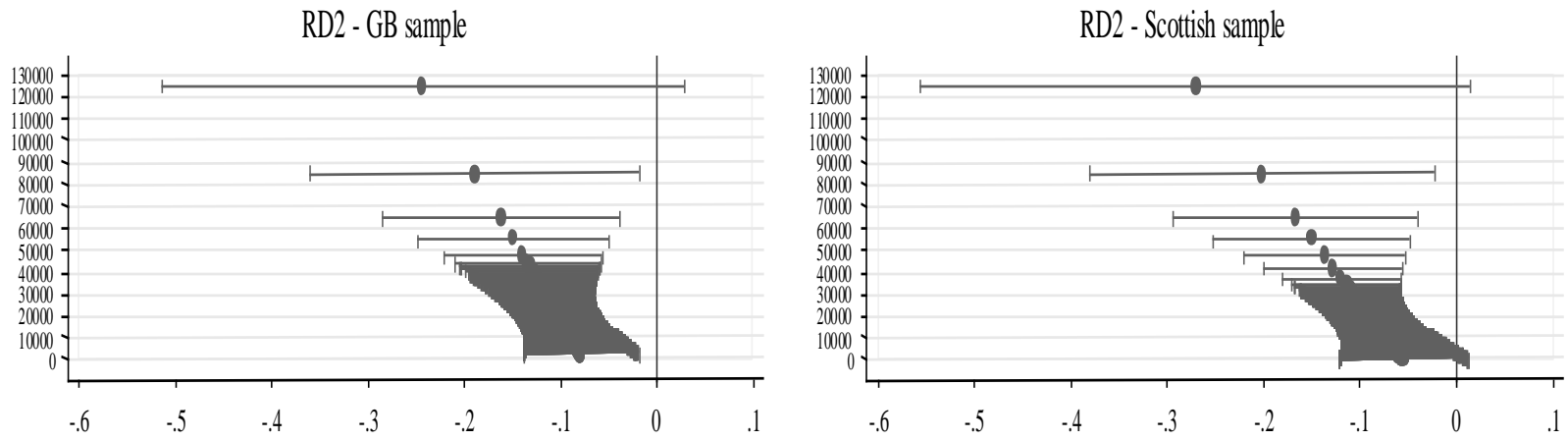

Notes: These plots show the impact of financial literacy as income varies when income is expressed in classes or as a continuous variable. $R D_{1}$ is the first measure (Government should try to make incomes more equal), while $R D_{2}$ is the second measure (Government should redistribute income from the better off to those worse off). 
Figure A3

Average marginal effects of financial literacy on attitudes towards redistribution by age
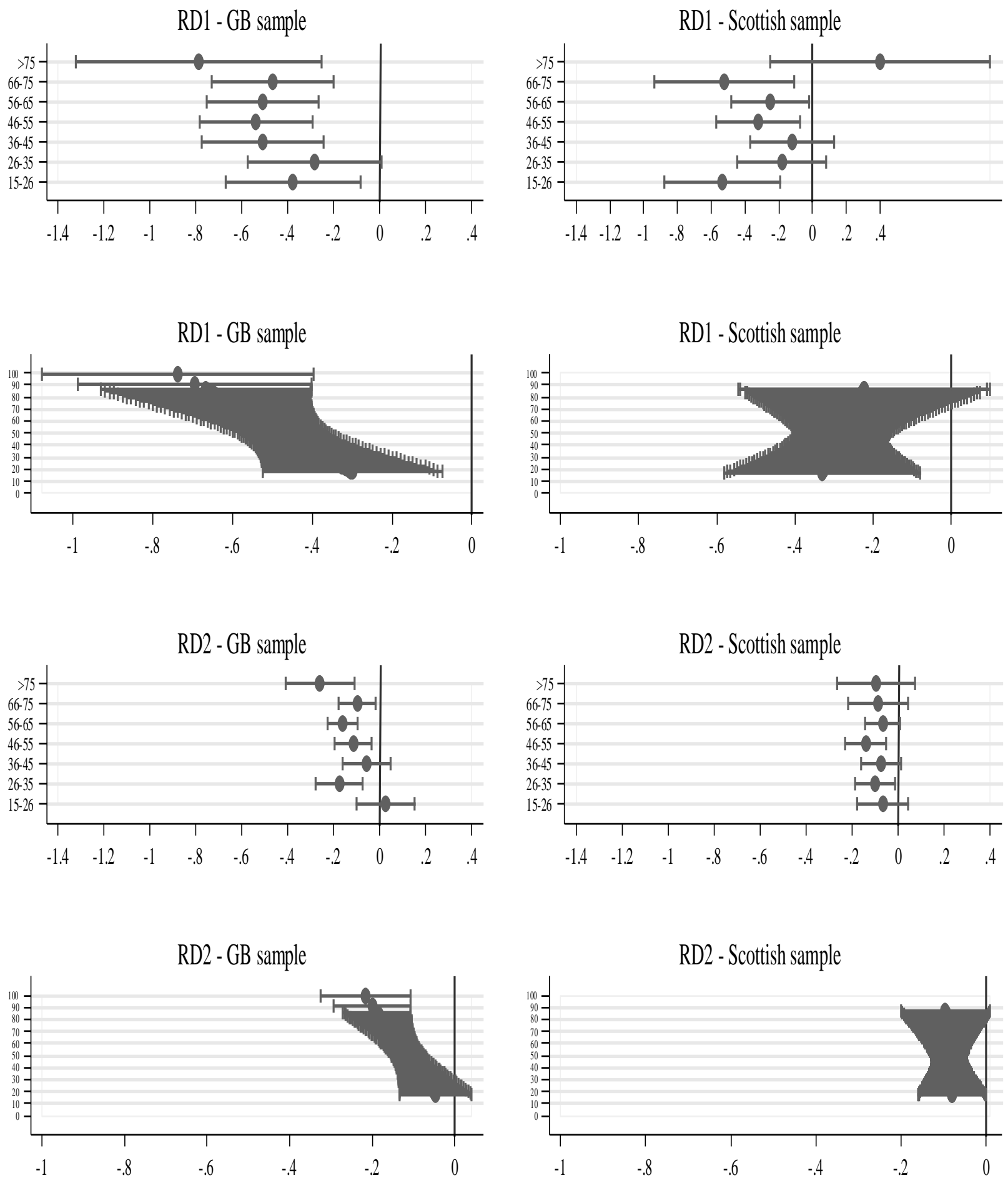

Notes: Each graph plots the impact of financial literacy on attitudes to redistribution, as age varies. The effects presented are from linear regressions that incorporate interaction terms between financial literacy and age variables. The specifications used are those of columns 2 and 3 of Table 4 . The first set of 4 plots uses a continuous variable for age, while the bottom set of 4 plots uses 7 age-group dummy variables. 
Figure A4

Average marginal effects of financial literacy on attitudes towards redistribution by political orientation and party voting
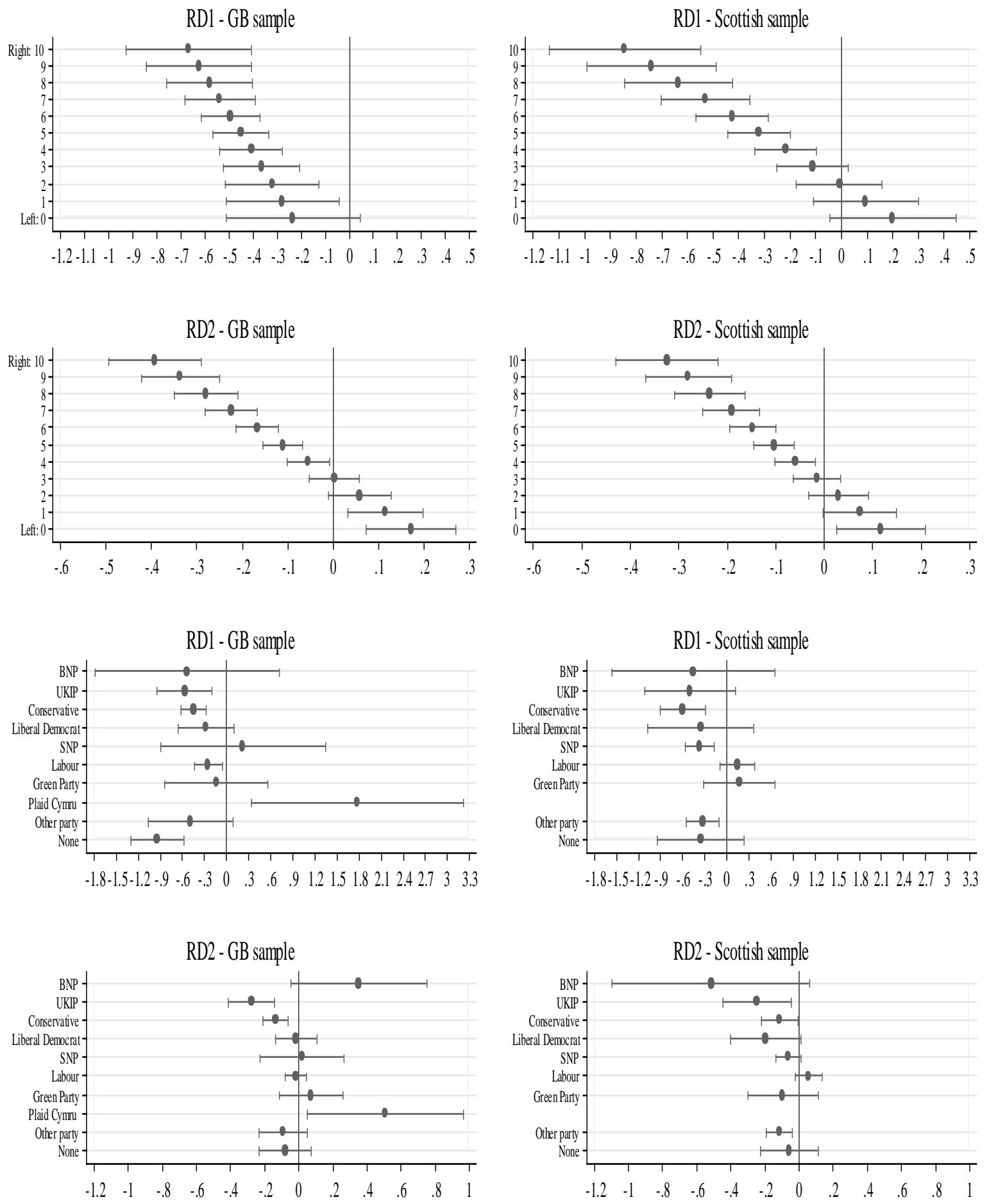

Notes: Each graph plots the impact of financial literacy on attitudes to redistribution, as political orientation varies. The effects presented are from linear regressions that incorporate interaction terms between financial literacy and political orientation. The specifications used are those of Columns 2 and 3 of Table 4. The first set of 4 plots uses a continuous variable for left-right orientation [0-10], while the bottom set of 4 plots uses 10 political-party dummy variables, with the first eight being ordered from left to right political orientation. 


\section{Figure A5}

Average marginal effects of financial literacy on attitudes towards redistribution from generalized ordered probit regressions (non-parallel line assumption for the effect of financial literacy)

(a)

Government should try to make incomes more equal (RD1) GB sample

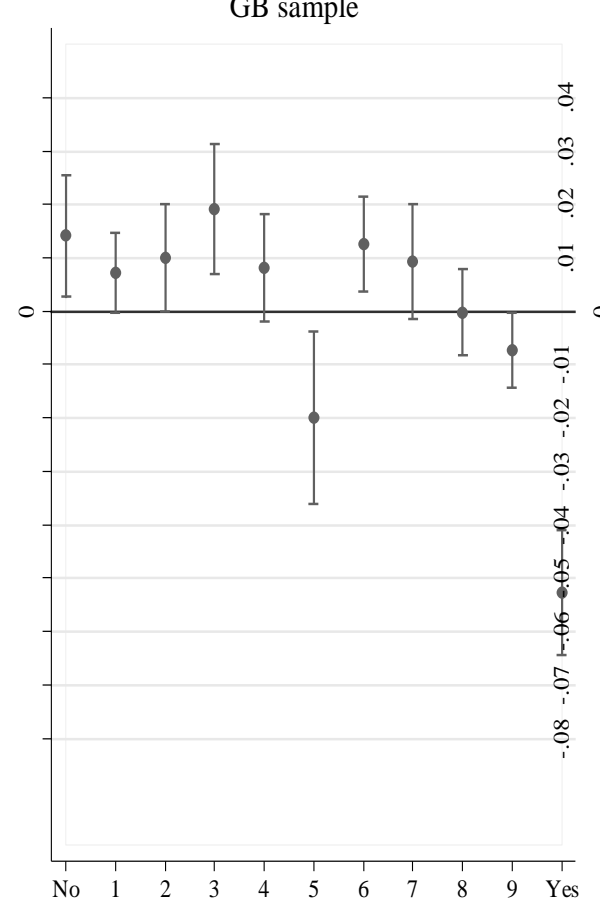

Scottish sample

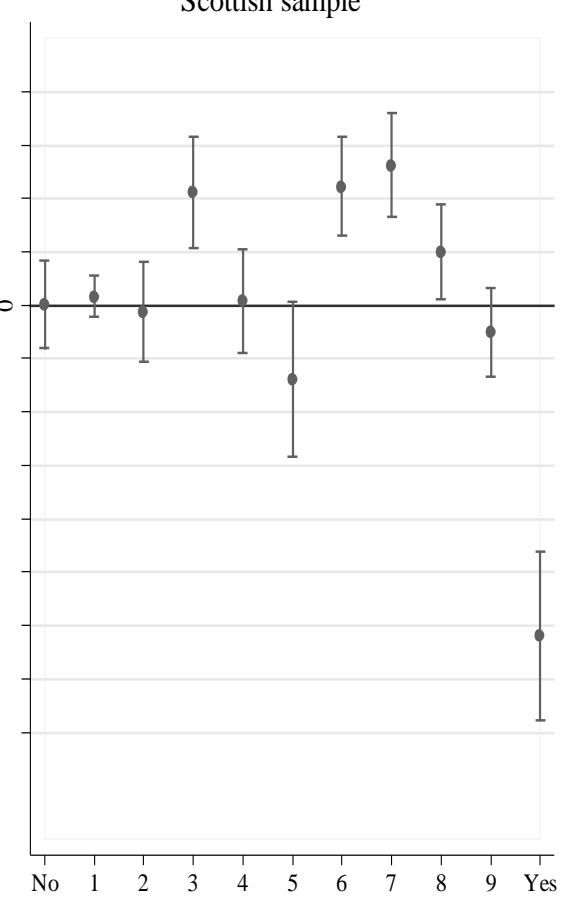

(b)

Government should redistribute income (RD2)

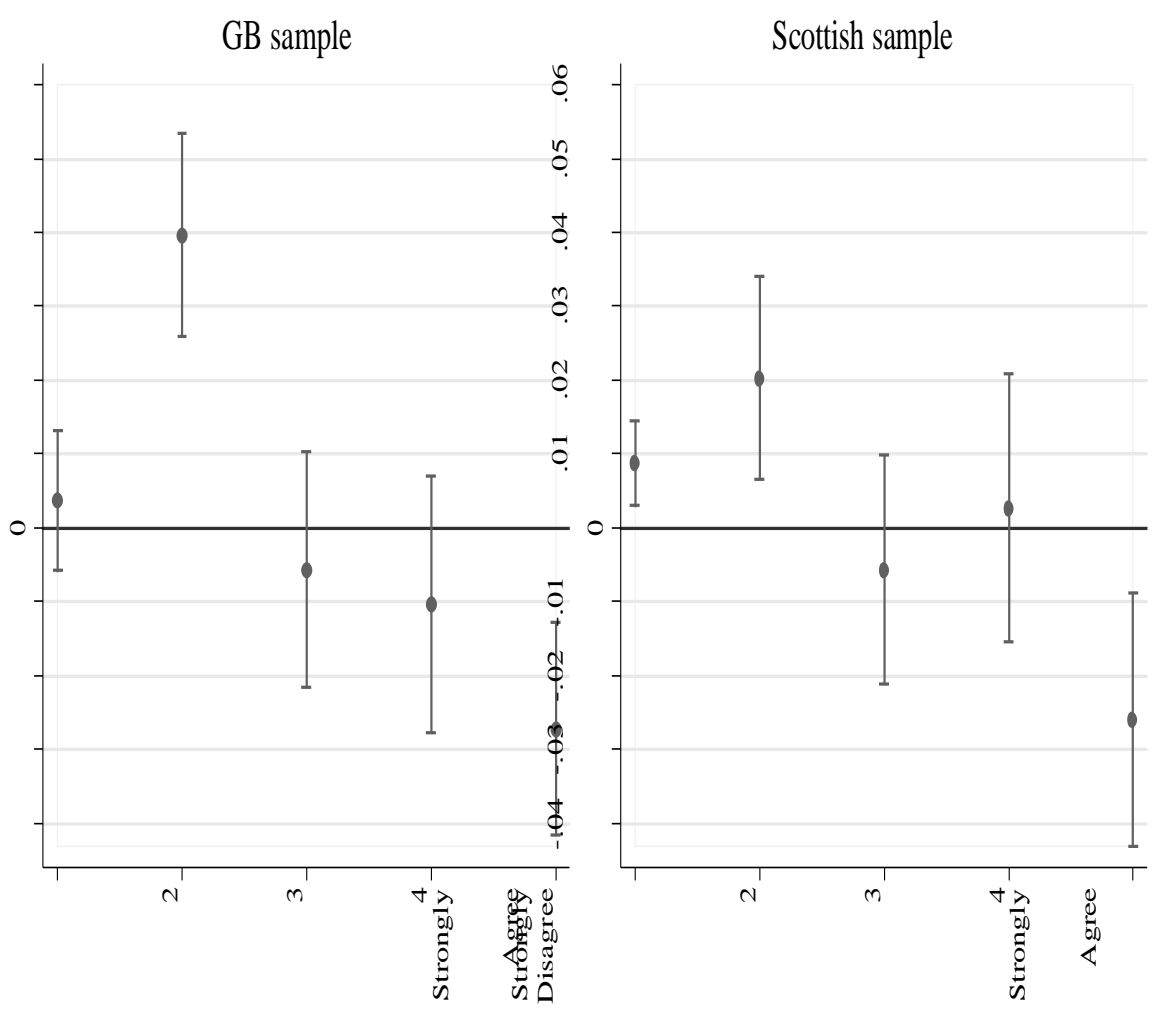

Notes: Each graph plots average marginal effects of financial literacy on attitudes to redistribution along with $95 \%$ confidence intervals. The estimates are from separate generalized ordered probit regressions of the redistribution variables, i.e. $R D_{1}$ and $R D_{2}$ respectively, on financial literacy and a rich set of control variables. The nonparallel-line assumption is imposed for the effect of financial literacy. They are weighted using population level weights and utilize robust standard errors. 
Table A1

Full sample and financial-literacy subsample comparisons

\begin{tabular}{|c|c|c|c|c|c|c|c|c|}
\hline \multirow[b]{2}{*}{ \#Observations } & \multicolumn{2}{|c|}{ Understanding Society } & \multicolumn{3}{|c|}{ BES Wave 2} & \multicolumn{3}{|c|}{ BES Wave 4} \\
\hline & Unweighted & Weighted & $\begin{array}{c}\text { Full } \\
\text { sample } \\
(\mathrm{GB}) \\
33,588\end{array}$ & $\begin{array}{c}\text { Fin. Lit. } \\
\text { sub-sample } \\
\text { (GB) } \\
5,552\end{array}$ & $\begin{array}{l}\text { Sig. } \\
\text { Diff. }\end{array}$ & $\begin{array}{c}\text { Full } \\
\text { sample } \\
(\mathrm{GB}) \\
39,719\end{array}$ & $\begin{array}{c}\text { Fin. Lit. } \\
\text { sub-sample } \\
\text { (Scotland) } \\
5,387\end{array}$ & $\begin{array}{l}\text { Sig. } \\
\text { Diff. }\end{array}$ \\
\hline$R D_{1}$ & - & - & 5.32 & 5.15 & $(0.000)$ & 5.53 & 6.23 & $(0.000)$ \\
\hline$R D_{2}$ & - & - & 3.45 & 3.43 & $(0.252)$ & 3.45 & 3.42 & $(0.000)$ \\
\hline Personal income & $21,569.3$ & $21,784.0$ & 20639.1 & 21078.3 & $(0.072)$ & 21117.2 & 16710.6 & $(0.000)$ \\
\hline Personal income: missing & $5.3 \%$ & $4.1 \%$ & $21.9 \%$ & $21.8 \%$ & $(0.921)$ & $22.1 \%$ & $21.1 \%$ & $(0.161)$ \\
\hline -"-: £0-£4,999 per year & $10.3 \%$ & $9.6 \%$ & $8.9 \%$ & $9.2 \%$ & $(0.473)$ & $9.1 \%$ & $9.4 \%$ & $(0.651)$ \\
\hline -"-: $£ 5,000-£ 9,999$ per year & $14.0 \%$ & $14.3 \%$ & $10.9 \%$ & $10.0 \%$ & $(0.051)$ & $11.1 \%$ & $12.8 \%$ & $(0.011)$ \\
\hline -"-: $£ 10,000-£ 14,999$ per year & $17.0 \%$ & $18.0 \%$ & $11.5 \%$ & $11.0 \%$ & $(0.328)$ & $11.7 \%$ & $12.5 \%$ & $(0.186)$ \\
\hline -"-: £15,000-£19,999 per year & $14.8 \%$ & $15.3 \%$ & $11.0 \%$ & $10.8 \%$ & $(0.610)$ & $11.0 \%$ & $11.6 \%$ & $(0.306)$ \\
\hline -"-: £20,000-£24,999 per year & $10.6 \%$ & $10.6 \%$ & $9.8 \%$ & $10.0 \%$ & $(0.578)$ & $9.7 \%$ & $9.1 \%$ & $(0.246)$ \\
\hline -"-: £25,000-£29,999 per year & $7.9 \%$ & $7.8 \%$ & $8.0 \%$ & $8.6 \%$ & $(0.184)$ & $7.8 \%$ & $7.0 \%$ & $(0.098)$ \\
\hline -"-: $£ 30,000-£ 34,999$ per year & $5.5 \%$ & $5.5 \%$ & $5.6 \%$ & $6.0 \%$ & $(0.367)$ & $5.5 \%$ & $5.8 \%$ & $(0.388)$ \\
\hline -"-: $£ 35,000-£ 39,999$ per year & $4.0 \%$ & $4.1 \%$ & $3.7 \%$ & $3.4 \%$ & $(0.290)$ & $3.9 \%$ & $3.6 \%$ & $(0.461)$ \\
\hline -"-: $£ 40,000-£ 44,999$ per year & $2.9 \%$ & $2.8 \%$ & $2.5 \%$ & $2.3 \%$ & $(0.271)$ & $2.5 \%$ & $2.3 \%$ & $(0.433)$ \\
\hline -"-: $£ 45,000-£ 49,999$ per year & $1.7 \%$ & $1.8 \%$ & $1.7 \%$ & $2.2 \%$ & $(0.051)$ & $1.6 \%$ & $1.2 \%$ & $(0.029)$ \\
\hline -"-: $£ 50,000-£ 59,999$ per year & $2.1 \%$ & $2.0 \%$ & $1.9 \%$ & $1.9 \%$ & $(0.936)$ & $1.8 \%$ & $1.7 \%$ & $(0.697)$ \\
\hline -"-: $£ 60,000-£ 69,999$ per year & $1.3 \%$ & $1.4 \%$ & $1.0 \%$ & $1.2 \%$ & $(0.104)$ & $0.9 \%$ & $0.9 \%$ & $(0.972)$ \\
\hline -"-: £70,000-£99,999 per year & $1.5 \%$ & $1.6 \%$ & $1.1 \%$ & $1.3 \%$ & $(0.289)$ & $1.0 \%$ & $0.8 \%$ & $(0.018)$ \\
\hline -"-: >£100,000 per year & $1.0 \%$ & $1.1 \%$ & $0.6 \%$ & $0.5 \%$ & $(0.093)$ & $0.6 \%$ & $0.4 \%$ & $(0.008)$ \\
\hline Years of education & 11.30 & 11.23 & 12.73 & 12.66 & $(0.273)$ & 12.65 & 12.66 & $(0.942)$ \\
\hline Education: $\mathrm{N}$ & $12.6 \%$ & $15.7 \%$ & - & - & - & - & - & - \\
\hline -"-: No education & $17.5 \%$ & $1.0 \%$ & $10.8 \%$ & $11.2 \%$ & $(0.377)$ & $10.3 \%$ & $10.8 \%$ & $(0.410)$ \\
\hline -"-: Level 1 & $1.8 \%$ & $2.2 \%$ & $4.5 \%$ & $4.4 \%$ & $(0.773)$ & $4.5 \%$ & $7.9 \%$ & $(0.000)$ \\
\hline -"-: Level 2 & $27.1 \%$ & $31.6 \%$ & $36.2 \%$ & $35.6 \%$ & $(0.383)$ & $36.8 \%$ & $31.1 \%$ & $(0.000)$ \\
\hline -"-: Apprenticeship & $1.2 \%$ & $1.4 \%$ & $1.5 \%$ & $1.4 \%$ & $(0.552)$ & $1.5 \%$ & $2.1 \%$ & $(0.026)$ \\
\hline -"-: Level 3 & $3.9 \%$ & $4.9 \%$ & $2.3 \%$ & $2.4 \%$ & $(0.753)$ & $2.5 \%$ & $1.7 \%$ & $(0.002)$ \\
\hline -"-: Level 4 & $11.7 \%$ & $14.3 \%$ & $14.7 \%$ & $15.0 \%$ & $(0.557)$ & $14.4 \%$ & $14.6 \%$ & $(0.681)$ \\
\hline -"-: University & $15.6 \%$ & $18.7 \%$ & $23.1 \%$ & $23.7 \%$ & $(0.426)$ & $22.7 \%$ & $23.8 \%$ & $(0.163)$ \\
\hline -"-: Graduate & $7.4 \%$ & $8.6 \%$ & $6.7 \%$ & $6.3 \%$ & $(0.275)$ & $6.5 \%$ & $7.1 \%$ & $(0.084)$ \\
\hline Age & 47.63 & 48.81 & 46.32 & 47.45 & $(0.000)$ & 45.74 & 46.61 & $(0.005)$ \\
\hline Age: $15-25$ & $15.3 \%$ & $13.5 \%$ & $15.0 \%$ & $13.3 \%$ & $(0.009)$ & $16.2 \%$ & $13.7 \%$ & $(0.001)$ \\
\hline -"-: 26-35 & $14.2 \%$ & $15.0 \%$ & $17.7 \%$ & $16.7 \%$ & $(0.133)$ & $17.6 \%$ & $15.4 \%$ & $(0.001)$ \\
\hline -"-: 36-45 & $17.3 \%$ & $16.5 \%$ & $15.1 \%$ & $15.2 \%$ & $(0.954)$ & $15.2 \%$ & $17.1 \%$ & $(0.005)$ \\
\hline -"-: 46-55 & $18.0 \%$ & $17.8 \%$ & $16.4 \%$ & $16.9 \%$ & $(0.382)$ & $16.6 \%$ & $18.9 \%$ & $(0.001)$ \\
\hline -"-: 56-65 & $15.0 \%$ & $15.3 \%$ & $20.5 \%$ & $21.8 \%$ & $(0.023)$ & $19.6 \%$ & $20.7 \%$ & $(0.087)$ \\
\hline -"-: 66-75 & $12.3 \%$ & $12.5 \%$ & $13.1 \%$ & $13.8 \%$ & $(0.091)$ & $12.7 \%$ & $12.5 \%$ & $(0.703)$ \\
\hline -"-: >76 & $7.8 \%$ & $9.5 \%$ & $2.2 \%$ & $2.4 \%$ & $(0.393)$ & $2.1 \%$ & $1.7 \%$ & $(0.083)$ \\
\hline Male & $46.5 \%$ & $47.6 \%$ & $48.5 \%$ & $49.4 \%$ & $(0.275)$ & $48.1 \%$ & $47.7 \%$ & $(0.634)$ \\
\hline Marital status: Single & $27.1 \%$ & $32.6 \%$ & $55.3 \%$ & $58.5 \%$ & $(0.000)$ & $61.0 \%$ & $60.8 \%$ & $(0.857)$ \\
\hline -"-: Married/Cohabiting/Civil part. & $38.2 \%$ & $46.6 \%$ & $23.1 \%$ & $22.6 \%$ & $(0.481)$ & $27.9 \%$ & $27.8 \%$ & $(0.913)$ \\
\hline -"-: Widowed/Divorced/Separated & $12.6 \%$ & $16.4 \%$ & $10.8 \%$ & $10.5 \%$ & $(0.534)$ & $11.2 \%$ & $11.4 \%$ & $(0.654)$ \\
\hline Household size & 2.96 & 2.80 & 2.59 & 2.56 & $(0.102)$ & 2.63 & 2.48 & $(0.000)$ \\
\hline Children at preschool and school age & - & - & $20.7 \%$ & $21.4 \%$ & $(0.351)$ & $21.8 \%$ & $20.5 \%$ & $(0.117)$ \\
\hline Occ. status: Self-employed & $7.8 \%$ & $7.8 \%$ & $6.8 \%$ & $7.0 \%$ & $(0.533)$ & $6.8 \%$ & $4.8 \%$ & $(0.000)$ \\
\hline -"-: Full-time employed & $32.3 \%$ & $32.7 \%$ & $38.2 \%$ & $37.8 \%$ & $(0.589)$ & $37.3 \%$ & $35.6 \%$ & $(0.043)$ \\
\hline -"-: Part-time employed & $10.3 \%$ & $10.2 \%$ & $11.6 \%$ & $11.5 \%$ & $(0.834)$ & $11.7 \%$ & $11.3 \%$ & $(0.495)$ \\
\hline -"-: Unemployed & $4.6 \%$ & $4.4 \%$ & $3.8 \%$ & $3.5 \%$ & $(0.278)$ & $3.8 \%$ & $4.3 \%$ & $(0.201)$ \\
\hline -"-: Student & $0.8 \%$ & $0.4 \%$ & $6.5 \%$ & $5.9 \%$ & $(0.212)$ & $6.7 \%$ & $7.9 \%$ & $(0.031)$ \\
\hline
\end{tabular}

Table Al continued in next page 
Table Al continued from last page

\begin{tabular}{|c|c|c|c|c|c|c|c|c|}
\hline & Unweighted & Weighted & $\begin{array}{c}\text { Full } \\
\text { sample } \\
(\mathrm{GB})\end{array}$ & $\begin{array}{l}\text { Fin. Lit. } \\
\text { sub-sample } \\
\text { (GB) }\end{array}$ & $\begin{array}{l}\text { Sig. } \\
\text { Diff. }\end{array}$ & $\begin{array}{c}\text { Full } \\
\text { sample } \\
(\mathrm{GB})\end{array}$ & $\begin{array}{c}\text { Fin. Lit. } \\
\text { sub-sample } \\
\text { (Scotland) }\end{array}$ & $\begin{array}{l}\text { Sig. } \\
\text { Diff. }\end{array}$ \\
\hline -"-: Retired & $23.2 \%$ & $25.2 \%$ & $21.4 \%$ & $22.8 \%$ & $(0.013)$ & $21.1 \%$ & $20.9 \%$ & $(0.783)$ \\
\hline -"-: Inactive & $21.1 \%$ & $19.3 \%$ & $11.7 \%$ & $11.5 \%$ & $(0.699)$ & $12.3 \%$ & $14.8 \%$ & $(0.000)$ \\
\hline Trade union member & $5.6 \%$ & $6.5 \%$ & $14.3 \%$ & $15.4 \%$ & $(0.045)$ & $2.5 \%$ & $2.9 \%$ & $(0.358)$ \\
\hline Ethnicity: White & $79.9 \%$ & $87.5 \%$ & $91.0 \%$ & $91.0 \%$ & $(0.992)$ & $91.3 \%$ & $96.5 \%$ & $(0.000)$ \\
\hline -"-: Black & $1.7 \%$ & $1.1 \%$ & $2.0 \%$ & $2.0 \%$ & $(0.901)$ & $1.9 \%$ & $0.1 \%$ & $(0.000)$ \\
\hline -"-: Mixed & $8.8 \%$ & $4.3 \%$ & $1.3 \%$ & $1.2 \%$ & $(0.757)$ & $1.3 \%$ & $0.6 \%$ & $(0.000)$ \\
\hline -"-: Asian & $2.1 \%$ & $1.2 \%$ & $3.6 \%$ & $3.8 \%$ & $(0.643)$ & $3.6 \%$ & $0.8 \%$ & $(0.000)$ \\
\hline -"-: Other & $0.4 \%$ & $0.2 \%$ & $2.2 \%$ & $2.0 \%$ & $(0.437)$ & $1.8 \%$ & $2.0 \%$ & $(0.474)$ \\
\hline Country of birth: England & - & - & $79.1 \%$ & $88.0 \%$ & $(0.000)$ & $63.4 \%$ & $13.4 \%$ & $(0.000)$ \\
\hline -"-: Scotland & - & - & $8.8 \%$ & $3.1 \%$ & $(0.000)$ & $26.2 \%$ & $81.8 \%$ & $(0.000)$ \\
\hline -"-: Wales & - & - & $4.5 \%$ & $1.7 \%$ & $(0.000)$ & $4.2 \%$ & $0.5 \%$ & $(0.000)$ \\
\hline -"-: Northern Ireland & - & - & $0.5 \%$ & $0.5 \%$ & $(0.760)$ & $0.4 \%$ & $0.5 \%$ & $(0.457)$ \\
\hline -"-: Republic of Ireland & - & - & $0.5 \%$ & $0.5 \%$ & $(0.837)$ & $0.5 \%$ & $0.2 \%$ & $(0.000)$ \\
\hline -"-: Commonwealth & - & - & $1.8 \%$ & $1.7 \%$ & $(0.641)$ & $1.6 \%$ & $1.2 \%$ & $(0.064)$ \\
\hline -"-: European Union & - & - & $1.8 \%$ & $1.8 \%$ & $(0.920)$ & $1.4 \%$ & $1.4 \%$ & $(0.745)$ \\
\hline -"-: Rest of World & - & - & $3.0 \%$ & $2.6 \%$ & $(0.240)$ & $2.4 \%$ & $1.2 \%$ & $(0.000)$ \\
\hline Home owner: outright & $32.0 \%$ & $32.8 \%$ & $28.2 \%$ & $30.7 \%$ & $(0.000)$ & $29.4 \%$ & $27.6 \%$ & $(0.018)$ \\
\hline Mortgage: leasehold/freehold & $38.4 \%$ & $35.8 \%$ & $28.0 \%$ & $28.5 \%$ & $(0.442)$ & $29.1 \%$ & $29.4 \%$ & $(0.776)$ \\
\hline Experienced income shock last year & - & - & $15.6 \%$ & $14.8 \%$ & $(0.152)$ & $7.3 \%$ & $9.9 \%$ & $(0.000)$ \\
\hline Father entrepreneur & - & - & $5.9 \%$ & $5.8 \%$ & $(0.774)$ & $4.7 \%$ & $4.7 \%$ & $(0.956)$ \\
\hline Attended private school & - & - & $17.9 \%$ & $18.4 \%$ & $(0.488)$ & $17.7 \%$ & $11.6 \%$ & $(0.000)$ \\
\hline Risk-taker: 1 (Low) - 4 (High) & - & - & 2.56 & 2.54 & $(0.282)$ & 2.57 & 2.60 & $(0.030)$ \\
\hline Political orient.n: 0 (left) - 10 (Right) & - & - & 5.06 & 5.14 & $(0.010)$ & 5.07 & 4.65 & $(0.000)$ \\
\hline Social desirab.: 0 (Low) - 4 (High) & - & - & 1.94 & 1.94 & $(0.668)$ & 1.95 & 1.89 & $(0.005)$ \\
\hline Religiousness & - & - & $53.8 \%$ & $55.2 \%$ & $(0.092)$ & $58.0 \%$ & $51.4 \%$ & $(0.000)$ \\
\hline BIG5: Agreeableness & 5.62 & 5.62 & 6.06 & 6.06 & $(0.928)$ & 6.07 & 6.12 & $(0.198)$ \\
\hline -"-: Conscientiousness & 5.47 & 5.46 & 6.65 & 6.75 & $(0.001)$ & 6.68 & 6.62 & $(0.109)$ \\
\hline -"-: Extraversion & 4.60 & 4.59 & 4.24 & 4.16 & $(0.016)$ & 4.24 & 4.07 & $(0.000)$ \\
\hline -"-: Neuroticism & 3.56 & 3.57 & 3.79 & 3.76 & $(0.398)$ & 3.76 & 3.73 & $(0.494)$ \\
\hline -"-: Openn & 4.56 & 4.56 & 5.54 & 5.50 & $(0.072)$ & 5.55 & 5.58 & $(0.293)$ \\
\hline Urban region & $77.3 \%$ & $77.7 \%$ & $56.5 \%$ & $60.2 \%$ & $(0.000)$ & $56.4 \%$ & $35.4 \%$ & $(0.000)$ \\
\hline Region: Northeast & $3.9 \%$ & $4.5 \%$ & $4.5 \%$ & $5.3 \%$ & $(0.025)$ & - & - & - \\
\hline -"-: Northwest & $10.3 \%$ & $11.2 \%$ & $11.1 \%$ & $12.4 \%$ & $(0.010)$ & - & - & - \\
\hline -"-: Yorkshire \& Humber & $8.7 \%$ & $9.0 \%$ & $9.0 \%$ & $9.7 \%$ & $(0.113)$ & - & - & - \\
\hline -"-: East Midlands & $8.2 \%$ & $7.7 \%$ & $7.8 \%$ & $9.0 \%$ & $(0.013)$ & - & - & - \\
\hline -"-: West Midlands & $8.5 \%$ & $8.8 \%$ & $8.7 \%$ & $10.5 \%$ & $(0.000)$ & - & - & - \\
\hline -"-: East England & $9.1 \%$ & $10.2 \%$ & $9.4 \%$ & $10.5 \%$ & $(0.024)$ & - & - & - \\
\hline -"-: Greater London & $12.8 \%$ & $11.7 \%$ & $13.0 \%$ & $14.7 \%$ & $(0.004)$ & - & - & - \\
\hline -"-: South East & $12.7 \%$ & $14.1 \%$ & $14.1 \%$ & $16.3 \%$ & $(0.000)$ & - & - & - \\
\hline -"-: South West & $8.4 \%$ & $9.3 \%$ & $8.2 \%$ & $9.7 \%$ & $(0.001)$ & - & - & - \\
\hline -"-: Wales & $7.9 \%$ & $5.0 \%$ & $5.4 \%$ & $0.8 \%$ & $(0.000)$ & - & - & - \\
\hline -"-: Scotland & $9.3 \%$ & $8.4 \%$ & $8.9 \%$ & $1.2 \%$ & $(0.000)$ & - & - & - \\
\hline Region: Borders & - & - & - & - & - & $1.6 \%$ & $2.2 \%$ & $(0.000)$ \\
\hline -"-: Central & - & - & - & - & - & $6.6 \%$ & $8.7 \%$ & $(0.000)$ \\
\hline -"-: Dumfries and Galloway & - & - & - & - & - & $1.5 \%$ & $2.2 \%$ & $(0.000)$ \\
\hline -"-: Fife & - & - & - & - & - & $6.4 \%$ & $8.8 \%$ & $(0.000)$ \\
\hline -"-: Grampian & - & - & - & - & - & $6.0 \%$ & $8.7 \%$ & $(0.000)$ \\
\hline -"-: Highland & - & - & - & - & - & $3.3 \%$ & $4.8 \%$ & $(0.000)$ \\
\hline -"-: Lothian & - & - & - & - & - & $10.9 \%$ & $14.6 \%$ & $(0.000)$ \\
\hline -"-: Orkney & - & - & - & - & - & $0.4 \%$ & $0.6 \%$ & $(0.002)$ \\
\hline
\end{tabular}


Table Al continued from last page

\begin{tabular}{|c|c|c|c|c|c|c|c|c|}
\hline & Unweighted & Weighted & $\begin{array}{c}\text { Full } \\
\text { sample } \\
(\mathrm{GB})\end{array}$ & $\begin{array}{l}\text { Fin. Lit. } \\
\text { sub-sample } \\
(\mathrm{GB})\end{array}$ & $\begin{array}{l}\text { Sig. } \\
\text { Diff. }\end{array}$ & $\begin{array}{c}\text { Full } \\
\text { sample } \\
(\mathrm{GB})\end{array}$ & $\begin{array}{c}\text { Fin. Lit. } \\
\text { sub-sample } \\
\text { (Scotland) }\end{array}$ & $\begin{array}{l}\text { Sig. } \\
\text { Diff. }\end{array}$ \\
\hline -"-: Strathclyde & - & - & - & - & - & $30.3 \%$ & $41.9 \%$ & $(0.000)$ \\
\hline -"-: Tayside & - & - & - & - & - & $4.8 \%$ & $6.6 \%$ & $(0.000)$ \\
\hline -"-: Western Isles & - & - & - & - & - & $0.3 \%$ & $0.4 \%$ & $(0.126)$ \\
\hline -"-: Rest of GB & - & - & - & - & - & $27.9 \%$ & $0.5 \%$ & $(0.000)$ \\
\hline
\end{tabular}

Notes: Averages from waves 2 and 4 the British Election Study and from wave 5 of Understanding Society (2013-2014). It is worth noting that the full sample from wave 4 is for the whole of Great Britain, with only the boosted financial-literacy subsample comprising of Scottish individuals. 
Table A2

Correlation matrix

\begin{tabular}{|c|c|c|c|c|c|c|c|c|c|c|c|c|c|c|c|c|c|c|c|c|c|c|}
\hline & $\overline{\hat{\alpha}}$ & $\hat{~}$ & 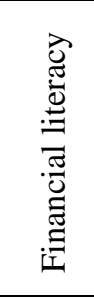 & $\sum_{\Sigma}^{\frac{0}{\pi}}$ & $\underset{8}{\infty}$ & 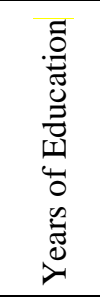 & 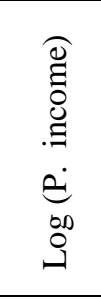 & 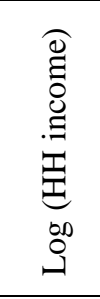 & $\begin{array}{l}\frac{0}{\infty 0} \\
\stackrel{\Xi}{=}\end{array}$ & 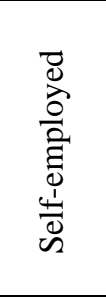 & 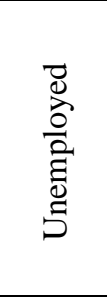 & 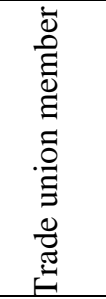 & 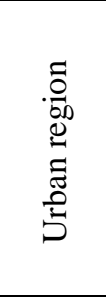 & 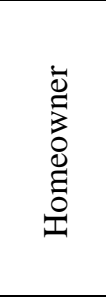 & 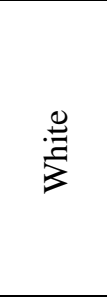 & 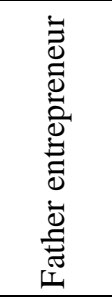 & 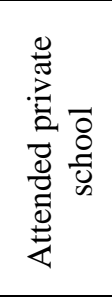 & 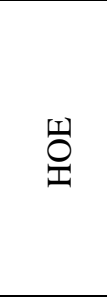 & $\sum_{2}^{1}$ & $\frac{w}{\sqrt{n}}$ & $\stackrel{2}{2}$ & $\stackrel{8}{3}$ \\
\hline $\mathrm{RD}_{1}$ & 1.00 & $0.54 *$ & $-0.15 *$ & -0.02 & -0.02 & $-0.10^{*}$ & $-0.08 *$ & $-0.20 *$ & $0.05^{*}$ & $-0.04 *$ & $0.11 *$ & 0.01 & $0.04 *$ & $-0.10 *$ & $-0.03 *$ & $-0.04 *$ & $-0.09 *$ & $-0.08 *$ & $*-0.32 *$ & $*-0.11 *$ & $-0.10^{*}$ & * $0.08 *$ \\
\hline $\mathrm{RD}_{2}$ & $0.43^{*}$ & 1.00 & $-0.09 *$ & $0.04 *$ & 0.01 & $-0.06^{*}$ & $-0.03 *$ & $-0.15^{*}$ & 0.02 & $-0.03^{*}$ & $0.07 *$ & 0.01 & $0.06 *$ & $-0.07 *$ & $-0.04 *$ & -0.01 & $-0.09 *$ & $-0.03 *$ & $*-0.32 *$ & $*-0.12 *$ & $-0.11 *$ & * $0.09 *$ \\
\hline Financial literacy & $-0.17 *$ & $-0.13^{*}$ & 1.00 & $0.20 *$ & $0.09 *$ & $0.22 *$ & $0.20 *$ & $0.24 *$ & $-0.04 *$ & $0.05^{*}$ & $-0.05^{*}$ & -0.01 & 0.00 & $0.12 *$ & 0.01 & $0.03 *$ & 0.00 & $0.20^{*}$ & $* \quad 0.02$ & $-0.02 *$ & 0.00 & $0.03 *$ \\
\hline Male & $-0.04 *$ & $0.02 *$ & $0.17 *$ & 1.00 & $-0.02 *$ & 0.01 & $0.18^{*}$ & $0.16^{*}$ & $0.05^{*}$ & 0.02 & $0.06^{*}$ & 0.00 & $0.03 *$ & 0.00 & $-0.03 *$ & 0.00 & 0.02 & $0.17 *$ & ${ }^{*}-0.03^{*}$ & $*_{-}-0.03 *$ & 0.00 & $0.05 *$ \\
\hline Age & $-0.03 *$ & 0.01 & $0.17 *$ & -0.02 & 1.00 & $-0.33^{*}$ & 0.00 & $-0.07 *$ & $-0.46^{*}$ & $0.05^{*}$ & $-0.07 *$ & $-0.09 *$ & $-0.16^{*}$ & $0.50 *$ & $0.08 *$ & $0.05^{*}$ & $0.04 *$ & 0.00 & $-0.14^{*}$ & $*-0.01$ & 0.00 & 0.01 \\
\hline Years of Education & $-0.06^{*}$ & $-0.06 *$ & $0.17 *$ & $-0.02 *$ & $-0.36^{*}$ & 1.00 & $0.17 *$ & $0.27 *$ & $0.16^{*}$ & $0.06^{*}$ & -0.01 & 0.00 & $0.09 *$ & $-0.11 *$ & $-0.05^{*}$ & 0.02 & $0.05 *$ & $0.17 *$ & $* \quad 0.01$ & 0.01 & $0.06^{*}$ & $0.04 *$ \\
\hline Log(Pers. income $)$ & $-0.13 *$ & $-0.12 *$ & $0.20 *$ & $0.22 *$ & $0.08 *$ & $0.17 *$ & 1.00 & $0.48^{*}$ & $-0.11 *$ & $0.04 *$ & $-0.13^{*}$ & $0.08 *$ & $0.06^{*}$ & $-0.09 *$ & $0.12 *$ & 0.00 & -0.02 & $0.99 *$ & $* 0.05 *$ & * $-0.03 *$ & 0.00 & $0.06^{*}$ \\
\hline Log(Hous. income $)$ & $-0.16^{*}$ & $-0.17 *$ & $0.25^{*}$ & $0.10^{*}$ & $-0.08 *$ & $0.27 *$ & $0.62 *$ & 1.00 & $-0.23 *$ & $0.08 *$ & $-0.19^{*}$ & $0.07 *$ & $0.03 *$ & 0.00 & $0.06^{*}$ & 0.00 & 0.00 & $0.48 *$ & $* 0.12 *$ & $* 0.00$ & $0.03 *$ & $0.02 *$ \\
\hline Single & $0.06^{*}$ & $0.04 *$ & $-0.08 *$ & $0.09 *$ & $-0.42 *$ & $0.17 *$ & $-0.17 *$ & $-0.20 *$ & 1.00 & $-0.05^{*}$ & $0.11 *$ & 0.01 & $0.13 *$ & $-0.22 *$ & $-0.04 *$ & $-0.03 *$ & 0.00 & $-0.11 *$ & $* 0.00$ & -0.01 & -0.01 & 0.00 \\
\hline Self-employed & $-0.04 *$ & $-0.05 *$ & $0.07 *$ & $0.04 *$ & $0.03 *$ & 0.02 & $0.04 *$ & $0.03 *$ & -0.01 & 1.00 & $-0.04 *$ & -0.02 & $-0.04 *$ & 0.02 & 0.00 & $0.05^{*}$ & $0.03 *$ & $0.04 *$ & 0.01 & $-0.02 *$ & -0.01 & $0.03 *$ \\
\hline Trade union member & $0.06^{*}$ & $0.06^{*}$ & $-0.05^{*}$ & $0.03 *$ & $-0.09 *$ & 0.01 & $-0.21 *$ & $-0.15^{*}$ & $0.12 *$ & $-0.05^{*}$ & 1.00 & $-0.03 *$ & 0.00 & $-0.07 *$ & $-0.05 *$ & 0.01 & $-0.02 *$ & $-0.12 *$ & $*-0.05 *$ & $*-0.01$ & -0.01 & 0.01 \\
\hline Unemployed & $0.07 *$ & $0.09 *$ & $0.07 *$ & $0.03 *$ & $0.02 *$ & $0.04 *$ & $0.19 *$ & $0.15^{*}$ & $-0.04 *$ & $-0.07 *$ & $-0.05^{*}$ & 1.00 & 0.00 & $-0.04 *$ & 0.01 & $-0.03 *$ & 0.00 & $0.09 *$ & $* 0.02 *$ & $* 0.00$ & 0.00 & 0.00 \\
\hline Urban region & $0.03^{*}$ & $0.04 *$ & $-0.06^{*}$ & 0.00 & $-0.14 *$ & 0.02 & -0.01 & -0.01 & $0.10 *$ & $-0.04 *$ & 0.01 & $0.03^{*}$ & 1.00 & $-0.13^{*}$ & $-0.04 *$ & $-0.02 *$ & 0.01 & $0.05 *$ & $* 0.00$ & 0.00 & 0.02 & 0.00 \\
\hline Homeowner & $-0.08 *$ & $-0.06 *$ & $0.13 *$ & -0.02 & $0.44 *$ & $-0.09 *$ & 0.00 & 0.00 & $-0.10 *$ & 0.00 & $-0.05^{*}$ & $-0.02 *$ & $-0.08 *$ & 1.00 & 0.02 & $0.05^{*}$ & $0.06^{*}$ & $-0.09 *$ & $*-0.06 *$ & $* 0.00$ & 0.01 & 0.00 \\
\hline White & -0.02 & $-0.03 *$ & $0.10 *$ & $-0.04 *$ & $0.19 *$ & $-0.08 *$ & 0.02 & $0.04 *$ & $-0.09 *$ & -0.01 & $-0.06 *$ & $0.02 *$ & $-0.15^{*}$ & $0.08 *$ & 1.00 & $-0.05 *$ & $-0.03 *$ & $0.11 *$ & * 0.01 & 0.00 & -0.01 & 0.00 \\
\hline Father entrepreneur & $-0.06 *$ & $-0.07 *$ & $0.04 *$ & $-0.04 *$ & 0.02 & 0.02 & $0.03 *$ & 0.02 & -0.02 & $0.03 *$ & $-0.03 *$ & $-0.03 *$ & 0.00 & $0.03 *$ & 0.00 & 1.00 & $0.06^{*}$ & 0.00 & 0.00 & -0.01 & 0.00 & 0.02 \\
\hline Attended private schoo & ]- $-0.06 *$ & -0.02 & $-0.07 *$ & $0.03 *$ & -0.02 & 0.00 & 0.00 & $-0.03 *$ & 0.00 & 0.00 & 0.00 & $-0.04 *$ & $0.03 *$ & 0.00 & $-0.14 *$ & $0.06 *$ & 1.00 & $-0.02 *$ & $* 0.00$ & 0.00 & 0.01 & 0.02 \\
\hline $\mathrm{HOE}$ & $-0.13 *$ & $-0.12 *$ & $0.19 *$ & $0.21 *$ & $0.08 *$ & $0.16^{*}$ & $0.98^{*}$ & $0.61 *$ & $-0.17 *$ & $0.04 *$ & $-0.20 *$ & $0.18^{*}$ & -0.01 & 0.00 & $0.03 *$ & $0.02 *$ & 0.01 & 1.00 & $0.05 *$ & * $-0.03 *$ & 0.01 & $0.06^{*}$ \\
\hline PVE & $-0.25^{*}$ & $-0.32 *$ & $0.06^{*}$ & -0.01 & $-0.12 *$ & $0.05^{*}$ & $0.10^{*}$ & $0.15^{*}$ & 0.00 & 0.00 & -0.01 & $-0.07 *$ & 0.00 & $-0.04 *$ & 0.00 & $0.05^{*}$ & $-0.03 *$ & $0.09 *$ & * 1.00 & $0.06^{*}$ & $0.04 *$ & $-0.05^{*}$ \\
\hline SRE & $-0.14 *$ & $-0.22 *$ & $0.02 *$ & 0.00 & $-0.02 *$ & $0.05^{*}$ & $0.05^{*}$ & $0.06^{*}$ & 0.02 & $0.06^{*}$ & 0.00 & $-0.03 *$ & 0.01 & 0.01 & 0.00 & 0.01 & $0.02 *$ & $0.05^{*}$ & $* 0.10 *$ & * 1.00 & $0.83^{*}$ & $-0.83 *$ \\
\hline DVD & $-0.12 *$ & $-0.20 *$ & $0.03 *$ & 0.00 & -0.01 & $0.06^{*}$ & $0.10^{*}$ & $0.08 *$ & 0.01 & $0.07 *$ & -0.01 & $-0.03^{*}$ & 0.00 & 0.00 & 0.02 & 0.01 & 0.00 & $0.11 *$ & $* 0.09 *$ & * $0.83 *$ & 1.00 & $-0.39 *$ \\
\hline UVD & $0.12 *$ & $0.17 *$ & 0.00 & 0.00 & $0.02 *$ & $-0.02 *$ & 0.02 & -0.01 & -0.02 & $-0.04 *$ & 0.00 & $0.03^{*}$ & $-0.03 *$ & -0.01 & 0.00 & -0.01 & $-0.03 *$ & 0.02 & $-0.08^{*}$ & $*_{-}-0.84 *$ & $-0.40^{*}$ & ${ }^{*} 1.00$ \\
\hline
\end{tabular}

Notes: Weighted correlation matrix. Cells below the diagonal are for Great Britain. Cells above the diagonal are for Scotland. 
Table A3

Financial literacy and attitudes to redistribution in 2014 Great Britain and Scotland - Ordered probit regressions

\begin{tabular}{|c|c|c|c|c|c|c|c|c|}
\hline & \multicolumn{2}{|c|}{$R D_{1}^{G B}$} & \multicolumn{2}{|c|}{$R D_{2}^{G B}$} & \multicolumn{2}{|c|}{$R D_{1}^{\text {Scotland }}$} & \multicolumn{2}{|c|}{$R D_{2}^{\text {Scotland }}$} \\
\hline Financial literacy: \#Correct responses & $-0.172 * * *$ & {$[0.023]$} & $-0.117 * * *$ & {$[0.024]$} & $-0.118 * * *$ & {$[0.024]$} & $-0.095 * * *$ & {$[0.023]$} \\
\hline Personal income: missing & $-0.245 * * *$ & {$[0.084]$} & $-0.196 * *$ & {$[0.091]$} & -0.094 & {$[0.097]$} & -0.036 & {$[0.096]$} \\
\hline -"-: $£ 0-£ 4,999$ per year & \multicolumn{2}{|c|}{ Ref. } & \multicolumn{2}{|c|}{ Ref. } & \multicolumn{2}{|c|}{ Ref. } & \multicolumn{2}{|c|}{ Ref. } \\
\hline -"-: £5,000-£9,999 per year & -0.029 & {$[0.103]$} & -0.008 & [0.097] & 0.001 & {$[0.104]$} & 0.143 & [0.103] \\
\hline -"-: £10,000-£14,999 per year & 0.069 & {$[0.095]$} & 0.074 & {$[0.103]$} & 0.066 & {$[0.103]$} & 0.062 & [0.101] \\
\hline -"-: £15,000-£19,999 per year & -0.111 & {$[0.099]$} & -0.007 & {$[0.102]$} & -0.024 & {$[0.106]$} & 0.081 & [0.104] \\
\hline -"-: £20,000-£24,999 per year & $-0.230 * *$ & {$[0.102]$} & -0.099 & [0.106] & -0.129 & {$[0.112]$} & 0.012 & [0.109] \\
\hline -"-: £25,000-£29,999 per year & $-0.181 *$ & [0.102] & -0.074 & [0.107] & -0.168 & {$[0.114]$} & 0.043 & [0.116] \\
\hline -"-: £30,000-£34,999 per year & $-0.322 * * *$ & {$[0.118]$} & -0.154 & {$[0.114]$} & -0.148 & {$[0.117]$} & -0.004 & [0.117] \\
\hline -"-: £35,000-£39,999 per year & $-0.293 * *$ & {$[0.125]$} & $-0.310 * *$ & [0.129] & $-0.247 * *$ & {$[0.123]$} & -0.122 & [0.141] \\
\hline -"-: $£ 40,000-£ 44,999$ per year & $-0.371 * *$ & [0.149] & -0.161 & {$[0.151]$} & $-0.394 * * *$ & [0.139] & -0.128 & [0.145] \\
\hline -"-: £45,000-£49,999 per year & $-0.270 *$ & {$[0.146]$} & -0.095 & {$[0.151]$} & -0.122 & {$[0.160]$} & 0.205 & [0.171] \\
\hline -"-: £50,000-£59,999 per year & $-0.505 * * *$ & [0.129] & 0.052 & {$[0.172]$} & $-0.474 * * *$ & {$[0.171]$} & -0.190 & [0.149] \\
\hline -"-: £60,000-£69,999 per year & $-0.412 * *$ & {$[0.163]$} & -0.174 & {$[0.262]$} & $-0.436 * *$ & {$[0.179]$} & -0.215 & [0.189] \\
\hline -"-: £70,000-£99,999 per year & $-0.685 * * *$ & {$[0.151]$} & $-0.408 *$ & [0.209] & $-0.552 * * *$ & {$[0.182]$} & $-0.449 * *$ & {$[0.210]$} \\
\hline -"-: >£100,000 per year & -0.200 & {$[0.266]$} & $-0.700 * * *$ & {$[0.193]$} & $-0.868 * * *$ & {$[0.218]$} & $-0.435^{*}$ & [0.239] \\
\hline Education: None & \multicolumn{2}{|c|}{ Ref. } & \multicolumn{2}{|c|}{ Ref. } & \multicolumn{2}{|c|}{$\operatorname{Ref}}$. & \multicolumn{2}{|c|}{ Ref. } \\
\hline -"-: Level 1 & 0.067 & {$[0.118]$} & -0.179 & {$[0.166]$} & 0.091 & {$[0.113]$} & -0.021 & [0.111] \\
\hline -"-: Level 2 & -0.011 & {$[0.079]$} & $-0.159 * *$ & {$[0.074]$} & $-0.222 * *$ & {$[0.089]$} & -0.093 & [0.084] \\
\hline -"-: Apprenticeship & 0.168 & [0.142] & $0.316^{*}$ & {$[0.168]$} & -0.261 & {$[0.215]$} & $-0.283^{*}$ & {$[0.172]$} \\
\hline -"-: Level 3 & $0.276 * *$ & {$[0.140]$} & -0.022 & {$[0.127]$} & 0.149 & {$[0.184]$} & 0.039 & [0.168] \\
\hline -"-: Level 4 & -0.060 & {$[0.090]$} & $-0.236 * * *$ & {$[0.081]$} & $-0.299 * * *$ & {$[0.095]$} & $-0.206^{* *}$ & {$[0.086]$} \\
\hline -"-: University & 0.004 & {$[0.084]$} & -0.129 & {$[0.081]$} & $-0.269 * * *$ & {$[0.090]$} & $-0.141 *$ & {$[0.085]$} \\
\hline -"-: Graduate & -0.110 & {$[0.101]$} & -0.023 & {$[0.103]$} & $-0.207 * *$ & [0.099] & -0.068 & {$[0.098]$} \\
\hline Age: $15-25$ & \multicolumn{2}{|c|}{ Ref. } & \multicolumn{2}{|c|}{ Ref. } & \multicolumn{2}{|c|}{ Ref. } & \multicolumn{2}{|c|}{ Ref. } \\
\hline -"-: 26-35 & 0.109 & {$[0.108]$} & $0.192 *$ & {$[0.106]$} & -0.121 & {$[0.108]$} & -0.001 & {$[0.112]$} \\
\hline -"-: 36-45 & $0.255^{* *}$ & {$[0.107]$} & $0.316 * * *$ & [0.109] & -0.080 & [0.113] & 0.122 & [0.116] \\
\hline -"-: 46-55 & $0.186^{*}$ & {$[0.108]$} & $0.341 * * *$ & {$[0.104]$} & 0.013 & {$[0.113]$} & $0.282 * *$ & {$[0.116]$} \\
\hline -"-: 56-65 & $0.229 * *$ & [0.112] & $0.499 * * *$ & {$[0.107]$} & -0.069 & {$[0.118]$} & $0.334 * * *$ & {$[0.123]$} \\
\hline -"-: 66-75 & 0.099 & {$[0.124]$} & $0.426^{* * *}$ & {$[0.121]$} & 0.140 & {$[0.136]$} & $0.299 * *$ & {$[0.140]$} \\
\hline -"-: >76 & $0.308 *$ & {$[0.163]$} & $0.470 * * *$ & {$[0.151]$} & 0.050 & {$[0.190]$} & 0.226 & {$[0.173]$} \\
\hline Male & 0.048 & {$[0.041]$} & $0.228 * * *$ & {$[0.048]$} & $0.118 * * *$ & {$[0.045]$} & $0.285 * * *$ & {$[0.045]$} \\
\hline Marital status: Single & \multicolumn{2}{|c|}{ Ref. } & \multicolumn{2}{|c|}{ Ref. } & \multicolumn{2}{|c|}{ Ref. } & \multicolumn{2}{|c|}{ Ref. } \\
\hline -"-: Married/Cohabiting/Civil partnership & -0.047 & [0.059] & -0.106 & {$[0.065]$} & -0.016 & {$[0.060]$} & 0.013 & {$[0.064]$} \\
\hline -"-: Widowed/Divorced/Separated & -0.012 & {$[0.077]$} & 0.016 & {$[0.084]$} & 0.023 & {$[0.080]$} & -0.008 & {$[0.076]$} \\
\hline $\log ($ Household size $)$ & -0.008 & [0.049] & 0.092 & {$[0.056]$} & 0.034 & {$[0.059]$} & -0.048 & {$[0.054]$} \\
\hline
\end{tabular}


Table A3 continued from last page

\begin{tabular}{|c|c|c|c|c|c|c|c|c|}
\hline \multirow[b]{2}{*}{ Children at preschool and school age } & \multicolumn{2}{|c|}{$R D_{1}^{G B}$} & \multicolumn{2}{|c|}{$R D_{2}^{G B}$} & \multicolumn{2}{|c|}{$R D_{1}^{\text {Scotland }}$} & \multicolumn{2}{|c|}{$R D_{2}^{\text {Scotland }}$} \\
\hline & -0.043 & {$[0.058]$} & -0.004 & {$[0.061]$} & -0.065 & {$[0.063]$} & 0.094 & {$[0.061]$} \\
\hline Occ. status: Self-employed & $-0.190 * *$ & {$[0.075]$} & -0.115 & {$[0.083]$} & -0.048 & {$[0.080]$} & -0.098 & {$[0.083]$} \\
\hline -"-: Full-time employed & \multicolumn{2}{|c|}{ Ref. } & \multicolumn{2}{|c|}{ Ref. } & \multicolumn{2}{|c|}{ Ref. } & \multicolumn{2}{|c|}{ Ref. } \\
\hline -"-: Part-time employed & -0.001 & {$[0.069]$} & 0.106 & {$[0.100]$} & -0.019 & {$[0.073]$} & -0.065 & {$[0.072]$} \\
\hline -"-: Unemployed & -0.050 & {$[0.145]$} & 0.144 & [0.139] & $0.384 * * *$ & {$[0.134]$} & $0.250 *$ & {$[0.129]$} \\
\hline -"-: Student & $-0.313 * *$ & {$[0.131]$} & -0.091 & {$[0.142]$} & $-0.231 * *$ & {$[0.114]$} & 0.011 & {$[0.123]$} \\
\hline -"-: Retired & $-0.154 * *$ & {$[0.076]$} & -0.035 & {$[0.076]$} & $-0.164 * *$ & {$[0.077]$} & -0.092 & {$[0.083]$} \\
\hline -"-: Inactive & -0.096 & {$[0.080]$} & $0.166 * *$ & {$[0.081]$} & -0.016 & [0.082] & $0.195 * *$ & {$[0.079]$} \\
\hline Trade union member (current or past) & 0.088 & {$[0.056]$} & $0.162 * *$ & {$[0.065]$} & $0.237 *$ & {$[0.143]$} & 0.166 & {$[0.141]$} \\
\hline Ethnicity: White & \multicolumn{2}{|c|}{ Ref. } & \multicolumn{2}{|c|}{ Ref. } & \multicolumn{2}{|c|}{ Ref. } & \multicolumn{2}{|c|}{ Ref. } \\
\hline -"-: Black & -0.162 & {$[0.165]$} & 0.123 & [0.239] & 0.502 & {$[0.761]$} & 0.665 & {$[0.405]$} \\
\hline -"-: Mixed & 0.111 & {$[0.205]$} & 0.241 & {$[0.217]$} & -0.177 & {$[0.266]$} & -0.052 & {$[0.321]$} \\
\hline -"-: Asian & 0.121 & {$[0.140]$} & 0.063 & [0.169] & $0.422 *$ & {$[0.241]$} & $0.457 *$ & {$[0.260]$} \\
\hline -"-: Other & -0.110 & {$[0.170]$} & 0.008 & {$[0.132]$} & -0.043 & {$[0.120]$} & 0.015 & {$[0.136]$} \\
\hline Country of birth: England & \multicolumn{2}{|c|}{ Ref. } & \multicolumn{2}{|c|}{ Ref. } & \multicolumn{2}{|c|}{ Ref. } & \multicolumn{2}{|c|}{ Ref. } \\
\hline -"-: Scotland & -0.148 & {$[0.100]$} & -0.047 & {$[0.098]$} & $0.133 * *$ & {$[0.060]$} & $0.098 *$ & {$[0.057]$} \\
\hline -"-: Wales & -0.123 & [0.107] & $0.293 *$ & [0.169] & 0.029 & {$[0.162]$} & -0.247 & {$[0.170]$} \\
\hline -"-: Northern Ireland & 0.145 & {$[0.181]$} & -0.039 & {$[0.268]$} & $-0.384 * *$ & [0.194] & $-0.687 * * *$ & {$[0.242]$} \\
\hline -"-: Republic of Ireland & 0.031 & {$[0.200]$} & 0.039 & {$[0.170]$} & -0.137 & {$[0.279]$} & -0.237 & {$[0.497]$} \\
\hline -"-: Commonwealth & 0.218 & {$[0.186]$} & 0.007 & {$[0.175]$} & -0.029 & {$[0.147]$} & -0.198 & {$[0.203]$} \\
\hline -"-: European Union & 0.105 & {$[0.136]$} & 0.017 & {$[0.125]$} & -0.033 & {$[0.148]$} & $-0.411 * *$ & {$[0.189]$} \\
\hline -"-: Rest of World & -0.109 & {$[0.183]$} & $-0.297 *$ & {$[0.159]$} & -0.021 & {$[0.129]$} & 0.010 & {$[0.160]$} \\
\hline Home owner: Own the leasehold/freehold outright & -0.061 & {$[0.053]$} & $-0.160 * * *$ & {$[0.054]$} & $-0.125 * *$ & {$[0.063]$} & $-0.108 *$ & {$[0.062]$} \\
\hline Mortgage: Buying leasehold/freehold on a mortgage & -0.050 & {$[0.052]$} & $-0.218 * * *$ & {$[0.061]$} & -0.092 & {$[0.058]$} & -0.093 & {$[0.057]$} \\
\hline Has experienced income shock in last year & $0.180 * * *$ & {$[0.062]$} & $0.405 * * *$ & {$[0.073]$} & $0.533 * * *$ & {$[0.081]$} & $0.562 * * *$ & {$[0.082]$} \\
\hline Father entrepreneur & $-0.143 * *$ & {$[0.072]$} & $-0.200 * *$ & {$[0.080]$} & -0.090 & {$[0.075]$} & -0.002 & {$[0.086]$} \\
\hline Attended private school & -0.073 & [0.047] & 0.056 & {$[0.056]$} & $-0.116^{*}$ & {$[0.061]$} & $-0.115^{*}$ & {$[0.061]$} \\
\hline Risk-taker: 1 (Low) - 4 (High) & -0.032 & {$[0.033]$} & -0.014 & {$[0.036]$} & -0.045 & {$[0.036]$} & -0.054 & {$[0.036]$} \\
\hline Political orientation: 0 (left) - 10 (Right) & $-0.188 * * *$ & {$[0.011]$} & $-0.197 * * *$ & {$[0.011]$} & $-0.214 * * *$ & {$[0.012]$} & $-0.233 * * *$ & {$[0.012]$} \\
\hline Social desirability: 0 (Low) - 4 (High) & 0.003 & {$[0.018]$} & -0.008 & [0.019] & $0.061 * * *$ & [0.019] & $0.039 * *$ & {$[0.018]$} \\
\hline Religiousness & -0.027 & {$[0.041]$} & 0.023 & [0.043] & 0.000 & {$[0.042]$} & 0.047 & {$[0.043]$} \\
\hline BIG5: Agreeableness & $0.035 * * *$ & {$[0.012]$} & 0.015 & [0.013] & $0.025 *$ & {$[0.014]$} & 0.021 & {$[0.014]$} \\
\hline -"-: Conscientiousness & -0.009 & {$[0.012]$} & -0.008 & [0.013] & $-0.023 *$ & [0.012] & -0.013 & {$[0.013]$} \\
\hline -"-: Extraversion & $-0.020 * *$ & {$[0.010]$} & 0.004 & [0.009] & 0.011 & {$[0.010]$} & -0.002 & {$[0.010]$} \\
\hline -"-: Neuroticism & 0.005 & {$[0.010]$} & $0.022 * *$ & {$[0.010]$} & $0.019 *$ & {$[0.011]$} & $0.032 * * *$ & {$[0.011]$} \\
\hline -"-: Openness & 0.001 & {$[0.013]$} & 0.006 & {$[0.013]$} & $0.043 * * *$ & {$[0.014]$} & $0.036 * * *$ & {$[0.014]$} \\
\hline Urban region & -0.048 & {$[0.043]$} & -0.003 & [0.048] & 0.061 & {$[0.048]$} & $0.128 * * *$ & {$[0.048]$} \\
\hline Region: Northeast & -0.022 & {$[0.095]$} & 0.025 & {$[0.112]$} & 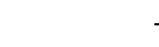 & - & - & \\
\hline -"-: Northwest & 0.027 & {$[0.075]$} & 0.019 & {$[0.077]$} & - & - & - & \\
\hline
\end{tabular}


Table A3 continued from last page

\begin{tabular}{|c|c|c|c|c|c|c|c|c|}
\hline & \multicolumn{2}{|c|}{$R D_{1}^{G B}$} & \multicolumn{2}{|c|}{$R D_{2}^{G B}$} & \multicolumn{2}{|c|}{$R D_{1}^{\text {Scotland }}$} & \multicolumn{2}{|c|}{$R D_{2}^{\text {Scotland }}$} \\
\hline -"-: Yorkshire \& Humber & $0.175 * *$ & {$[0.082]$} & 0.033 & {$[0.085]$} & - & & - & \\
\hline -"-: East Midlands & -0.084 & [0.089] & 0.027 & {$[0.090]$} & - & & - & \\
\hline -"-: West Midlands & -0.024 & {$[0.081]$} & -0.121 & {$[0.086]$} & - & & - & \\
\hline -"-: East England & -0.038 & {$[0.080]$} & $-0.163 * *$ & {$[0.083]$} & - & & - & \\
\hline -"-: Greater London & \multicolumn{2}{|c|}{ Ref. } & \multicolumn{2}{|c|}{ Ref. } & \multicolumn{2}{|c|}{-} & \multicolumn{2}{|c|}{-} \\
\hline -"-: South East & -0.036 & {$[0.075]$} & -0.032 & {$[0.075]$} & \multicolumn{2}{|c|}{-} & \multicolumn{2}{|c|}{-} \\
\hline -"-: South West & 0.103 & {$[0.084]$} & -0.097 & {$[0.103]$} & \multicolumn{2}{|c|}{-} & \multicolumn{2}{|c|}{-} \\
\hline -"-: Wales & $-0.537 * * *$ & {$[0.160]$} & -0.154 & {$[0.132]$} & \multicolumn{2}{|c|}{-} & \multicolumn{2}{|c|}{-} \\
\hline -"-: Scotland & $-0.293^{*}$ & {$[0.150]$} & -0.120 & {$[0.131]$} & \multicolumn{2}{|c|}{-} & \multicolumn{2}{|c|}{-} \\
\hline Region: Borders & \multicolumn{2}{|l|}{-} & \multicolumn{2}{|l|}{-} & 0.253 & {$[0.285]$} & 0.341 & [0.338] \\
\hline -"-: Central & \multicolumn{2}{|l|}{-} & \multicolumn{2}{|l|}{-} & 0.291 & {$[0.267]$} & 0.147 & [0.324] \\
\hline -"-: Dumfries and Galloway & \multicolumn{2}{|l|}{-} & \multicolumn{2}{|l|}{-} & 0.343 & [0.292] & 0.260 & [0.341] \\
\hline -"-: Fife & \multicolumn{2}{|l|}{-} & \multicolumn{2}{|l|}{-} & 0.297 & {$[0.268]$} & 0.251 & [0.324] \\
\hline -"-: Grampian & \multicolumn{2}{|l|}{-} & \multicolumn{2}{|l|}{-} & 0.161 & {$[0.265]$} & 0.055 & [0.323] \\
\hline -"-: Highland & \multicolumn{2}{|l|}{-} & - & & 0.341 & {$[0.270]$} & 0.329 & [0.326] \\
\hline -"-: Lothian & - & & - & & 0.291 & {$[0.259]$} & 0.275 & [0.318] \\
\hline -"-: Orkney & - & & - & & 0.283 & [0.402] & 0.383 & [0.344] \\
\hline -"-: Strathclyde & - & & - & & 0.411 & {$[0.259]$} & 0.302 & [0.317] \\
\hline -"-: Tayside & - & & - & & 0.289 & {$[0.270]$} & 0.273 & [0.324] \\
\hline -"-: Western Isles & - & & - & & 0.664 & {$[0.422]$} & -0.068 & [0.430] \\
\hline -"-: Rest of Great Britain & - & & - & & $\{$ Ref. & & $\{$ Ref. & \\
\hline Cut-off point 1 & $-2.918 * * *$ & {$[0.234]$} & $-2.839 * * *$ & {$[0.255]$} & $-2.507 * * *$ & {$[0.339]$} & $-2.474 * * *$ & [0.414] \\
\hline -"-: 2 & $-2.716 * * *$ & {$[0.235]$} & $-1.793 * * *$ & {$[0.252]$} & $-2.361 * * *$ & {$[0.338]$} & $-1.514 * * *$ & [0.414] \\
\hline -"-: 3 & $-2.422 * * *$ & {$[0.235]$} & $-1.013 * * *$ & {$[0.251]$} & $-2.036 * * *$ & {$[0.340]$} & $-0.768^{*}$ & [0.413] \\
\hline -"-: 4 & $-2.012 * * *$ & {$[0.234]$} & 0.075 & {$[0.251]$} & $-1.633 * * *$ & {$[0.338]$} & 0.263 & [0.412] \\
\hline -"-: 5 & $-1.778 * * *$ & {$[0.234]$} & - & & $-1.399 * * *$ & [0.339] & - & \\
\hline -"-: 6 & $-1.266 * * *$ & {$[0.233]$} & - & & $-0.960 * * *$ & [0.339] & - & \\
\hline -"-: 7 & $-1.027 * * *$ & {$[0.232]$} & - & & $-0.708 * *$ & [0.339] & - & \\
\hline -"-: 8 & $-0.687 * * *$ & {$[0.232]$} & - & & -0.371 & [0.339] & - & \\
\hline -"-: 9 & $-0.422 *$ & {$[0.232]$} & - & & -0.100 & [0.339] & - & \\
\hline -"-: 10 & -0.218 & {$[0.233]$} & - & & 0.100 & [0.339] & - & \\
\hline No. of Observations & 4,895 & & 5,101 & & 4,989 & & 4,986 & \\
\hline Pseudo $\mathrm{R}^{2}$ & 0.056 & & 0.094 & & 0.066 & & 0.096 & \\
\hline Log-likelihood & $-12,448.4$ & & $-7,989.1$ & & $-5,148.3$ & & $-3,002.2$ & \\
\hline LR $\chi 2$ & $690.43 * * *$ & & $820.64 * * *$ & & $876.31 * * *$ & & $851.95 * * *$ & \\
\hline
\end{tabular}

